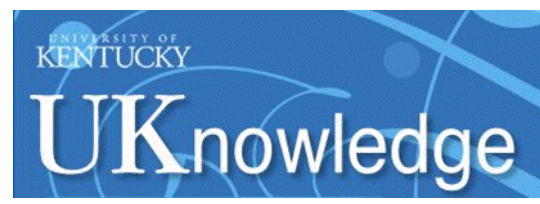

University of Kentucky

UKnowledge

2016

\title{
Effects of Dietary Amino Acid Supplementation on Measures of Whole-Body and Muscle Protein Metabolism in Aged Horses
}

Christine M. Latham

University of Kentucky, christine.m.latham@gmail.com

Digital Object Identifier: http://dx.doi.org/10.13023/ETD.2016.142

Right click to open a feedback form in a new tab to let us know how this document benefits you.

\section{Recommended Citation}

Latham, Christine M., "Effects of Dietary Amino Acid Supplementation on Measures of Whole-Body and Muscle Protein Metabolism in Aged Horses" (2016). Theses and Dissertations--Animal and Food Sciences. 63.

https://uknowledge.uky.edu/animalsci_etds/63

This Master's Thesis is brought to you for free and open access by the Animal and Food Sciences at UKnowledge. It has been accepted for inclusion in Theses and Dissertations--Animal and Food Sciences by an authorized administrator of UKnowledge. For more information, please contact UKnowledge@lsv.uky.edu. 


\section{STUDENT AGREEMENT:}

I represent that my thesis or dissertation and abstract are my original work. Proper attribution has been given to all outside sources. I understand that I am solely responsible for obtaining any needed copyright permissions. I have obtained needed written permission statement(s) from the owner(s) of each third-party copyrighted matter to be included in my work, allowing electronic distribution (if such use is not permitted by the fair use doctrine) which will be submitted to UKnowledge as Additional File.

I hereby grant to The University of Kentucky and its agents the irrevocable, non-exclusive, and royalty-free license to archive and make accessible my work in whole or in part in all forms of media, now or hereafter known. I agree that the document mentioned above may be made available immediately for worldwide access unless an embargo applies.

I retain all other ownership rights to the copyright of my work. I also retain the right to use in future works (such as articles or books) all or part of my work. I understand that I am free to register the copyright to my work.

\section{REVIEW, APPROVAL AND ACCEPTANCE}

The document mentioned above has been reviewed and accepted by the student's advisor, on behalf of the advisory committee, and by the Director of Graduate Studies (DGS), on behalf of the program; we verify that this is the final, approved version of the student's thesis including all changes required by the advisory committee. The undersigned agree to abide by the statements above.

Christine M. Latham, Student

Dr. Kristine Urschel, Major Professor

Dr. David L. Harmon, Director of Graduate Studies 


\title{
EFFECTS OF DIETARY AMINO ACID SUPPLEMENTATION ON MEASURES OF WHOLE-BODY AND MUSCLE PROTEIN METABOLISM IN AGED HORSES
}

THESIS

\author{
A thesis is submitted in partial fulfillment of the \\ requirements for the degree of Master of Science \\ in the College of Agriculture, Food and Environment \\ at the University of Kentucky
}

\begin{abstract}
By
Christine Latham

Lexington, $\mathrm{KY}$

Director: Dr. Kristine Urschel, Associate Professor of Animal Sciences Lexington, KY
\end{abstract}

2016

Copyright (C) Christine Latham 2016 


\section{ABSTRACT OF THESIS}

\section{EFFECTS OF DIETARY AMINO ACID SUPPLEMENTATION ON MEASURES OF WHOLE-BODY AND MUSCLE PROTEIN METABOLISM IN AGED HORSES}

Sarcopenia is a condition that is most common in aged animals, and is characterized by the loss of skeletal muscle mass and integrity, and can lead to physical disability and poor quality of life. Since skeletal muscle protein synthesis can be limited by the availability of amino acids, supplementation of limiting amino acids to ameliorate the progression of sarcopenia has become a topic of interest in companion animal research. The objective of this study was to examine the effect of amino acid supplementation in aged horses on markers of whole body and muscle protein metabolism. In a cross-over design, six old horses were studied while receiving each of three treatments in a replicated Latin square design. For all three treatments, horses received $1.8 \% \mathrm{BW} / \mathrm{d}$ of timothy hay cubes and $0.5 \%$ $\mathrm{BW} / \mathrm{d}$ of experimental concentrate. The three treatments included a control (CON) treatment concentrate that was designed to meet all requirements of mature horses when fed in combination with the timothy hay cubes, and two supplemented concentrates, LYS/THR with additional lysine and threonine $(40 \mathrm{mg} / \mathrm{kg} \mathrm{BW} / \mathrm{d}$ and $31 \mathrm{mg} / \mathrm{kg} \mathrm{BW} / \mathrm{d}$, respectively), and LYS/THR/MET with additional lysine, threonine, and methionine (40 $\mathrm{mg} / \mathrm{kg} \mathrm{BW} / \mathrm{d}, 31 \mathrm{mg} / \mathrm{kg} \mathrm{BW} / \mathrm{d}$ and $11 \mathrm{mg} / \mathrm{kg} \mathrm{BW} / \mathrm{d}$ respectively). In each $15 \mathrm{~d}$ period, following a 9-day adaptation, horses were fitted with a collection harness, and total urine and feces were collected for 72 hours for assessment of nitrogen balance and creatinine output. Blood samples were taken directly before feeding and 30, 60, 90, 120, 150, 180, 210, and 240 minutes post-feeding for analysis of plasma urea nitrogen (PUN), glucose, insulin, and plasma amino acid concentrations. Muscle biopsy samples were taken for analysis of proteins in the mTOR pathway. Additionally, horses underwent stable isotope infusion procedures, and comparisons of phenylalanine kinetics were used to determine whole-body rates of protein synthesis and degradation. There was no significant effect of treatment on creatinine output $(\mathrm{P}=0.58)$, relative abundance of proteins in the mTOR pathway $(\mathrm{P}>0.05)$, nitrogen retention $(\mathrm{P}=0.70)$, or phenylalanine kinetics $(\mathrm{P}>0.05)$. $\mathrm{PUN}$ concentrations were significantly $(\mathrm{P}=0.0058)$ higher for LYS/THR and LYS/THR/MET than for CON. Atrogin-1 activation was significantly higher for the pre-feeding CON sample compared to the post-feeding CON sample. Lack of significant difference in creatinine output suggests that there were not significant differences in muscle mass between treatments. Lack of significant differences in mTOR protein activation suggests that amino acid supplementation did not result in improvements in protein synthesis. Lack of significant differences in nitrogen retention and phenylalanine kinetics suggests that whole-body protein metabolism was not improved. Additionally, higher PUN concentrations in the supplemented diets suggests that the supplemented amino acids being provided were catabolized. However, increased activation of Atrogin-1 in the pre-feeding CON samples, but not the pre-feeding samples of supplemented treatments, suggests amino acid supplementation may have reduced protein degradation in the post-absorptive state. Data from the present study suggests that amino acid availability may not have been limiting protein synthesis in the sedentary aged horses in the present study.

Keywords: Equine, aged, supplementation, lysine, threonine, methionine

Christine Latham

April $20^{\text {th }}, 2016$ 


\section{EFFECTS OF DIETARY AMINO ACID SUPPLEMENTATION ON MEASURES OF WHOLE-BODY AND MUSCLE PROTIEN METABOLISM IN AGED HORSES}

By

Christine Latham

Dr. Kristine Urschel

Director of Thesis

Dr. David L. Harmon

Director of Graduate Studies

April 20 ${ }^{\text {th }}, 2016$ 


\section{ACKNOWLEDGEMENTS}

First and foremost, I would like to thank Dr. Kristine Urschel for her unwavering support and dedication to providing an excellent learning environment. She goes above and beyond her responsibilities as an advisor to ensure that her students have the best learning opportunities possible.

I would like to thank Dr. Lori Warren and Leigh Anne Skurupey for helping me gain experience in equine nutrition research as an undergraduate, and for supporting and inspiring me during my graduate studies.

I would also like to thank our laboratory manager, Tammy Barnes. This study would not have been possible without her wealth of technical knowledge and willingness to teach. Additionally, I would like to thank my fellow graduate and undergraduate students, ChanHee Mok, Kelsey Smith, Caroline Loos, Sarah Sivinski and Sophie Dorsch, who worked tirelessly to make sure that this study was a success. And most importantly, I would like to thank the horses; Linus, Easy, Kelo, Classy, Pie and Amarillo.

I would like to thank the members of my committee, Dr. Laurie Lawrence, Dr. Amanda Adams, and Dr. Eric Vanzant, for their time and guidance. Additionally, I would like to thank Dr. Kyle Mcleod, Dr. David Harmon and Dr. James Matthews for their time and support as educators.

Finally, I would like to thank my mother and father for their guidance and support. 


\section{Table of Contents}

Acknowledgements.................................................... ii

List of Tables........................................................ viii

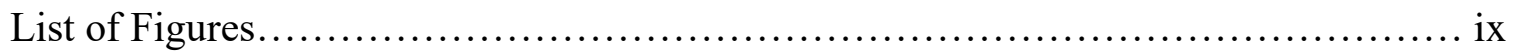

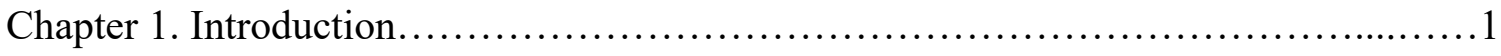

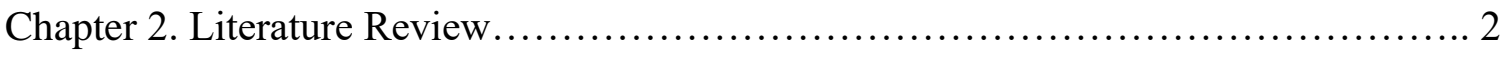

Protein Digestion and Absorption in Horses............................... 3

Essential and Limiting Amino Acids in the Equine Diet..................... 6

Protein Requirements in Horses...................................... 7

NRC Method of Determination.................................... 8

Methods of Evaluating Amino Acid Requirements........................ 11

Whole-body Protein Metabolism................................. 11

Plasma Metabolites.......................................... 17

Effect of Age on Protein Requirement................................. 22

Amino Acid Supplementation and Protein Synthesis and Degradation Signaling ....................................................... 24

Function of Signaling Pathways.............................. 25

Tissue Distribution and Cellular Localization....................... 25

Regulation................................................ 26

Equine Research on Protein Synthesis and Degradation Signaling....... 29

Conclusion........................................................ 31

Chapter 3. Rationale and Objectives...................................... 32

Rationale........................................................ 32

Objectives......................................................... 33

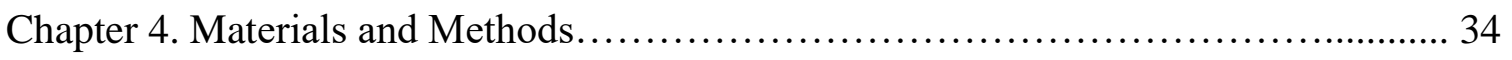

Animals, Housing and Feeding ..................................... 34

Experimental Treatments and Diets.................................... 35

Experimental Design............................................. 42

Sample Collection................................................ 42 
Urine and Feces Collection....................................... 42

Pre- and Post-Feeding Blood Samples............................... 43

Muscle Biopsies.................................................. 43

Stable Isotope Infusion Procedures.................................. 44

Laboratory Analysis and Calculations....................................... 48

Feed Amino Acids.................................................. 48

Urine and Feces Samples......................................... 48

Pre- and Post-Feeding Blood Samples............................... 51

Muscle Samples.................................................. 51

Stable Isotope Infusion............................................. 54

Statistical Analysis......................................................... 57

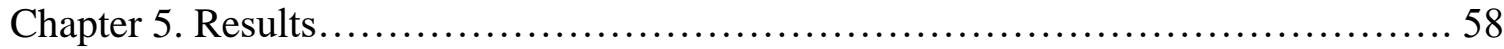

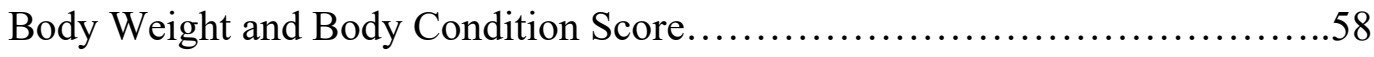

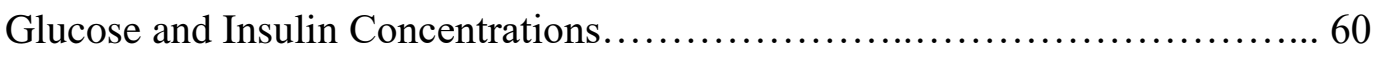

Plasma Urea Nitrogen Concentrations.................................... 62

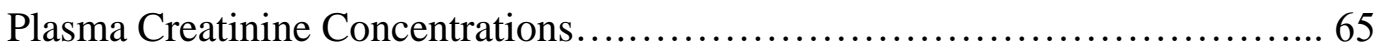

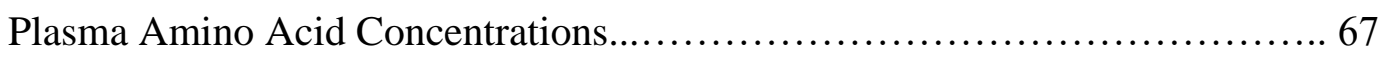

Nitrogen Retention................................................... 75

Urinary Creatinine Output............................................. 80

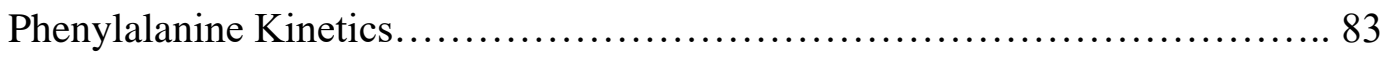

Muscle Protein Synthesis and Degradation Signaling......................... 85

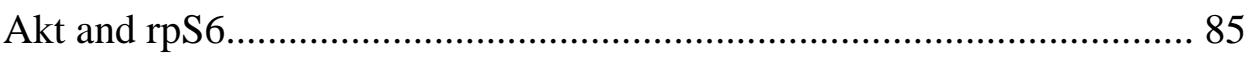

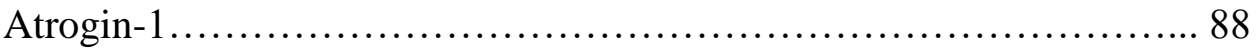

AMPK ............................................................. 90

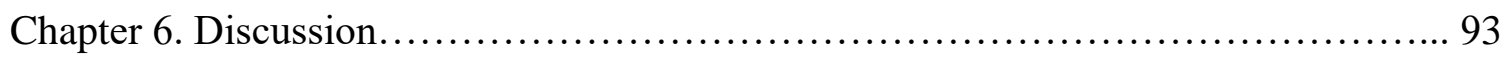

Crude Protein Intake.................................................... 93

Body Weight ......................................................... 93

Plasma Glucose, Insulin and Urea Nitrogen Concentrations..................... 94 
Plasma Amino Acid Concentrations.................................... 98

Nitrogen Metabolism and Urinary Creatinine Output..................... 101

Phenylalanine Kinetics............................................ 103

Muscle Protein Synthesis and Degradation Signaling..................... 106

Comparison of the Present Study to Previous Equine Research.............. 109

Limitations and Avenues of Further Research........................... 112

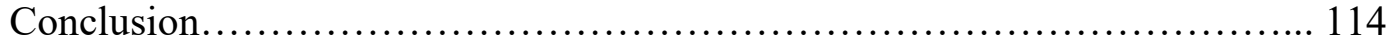

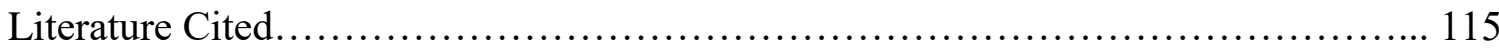

Curriculum Vitae........................................................ 123 
List of Tables

Table 2.1 Summary of data used to form NRC crude protein recommendations.......... 9

Table 4.1 As-fed nutrient composition of feeds................................. 36

Table 4.2 As-fed amino acid composition of feeds............................. 38

Table 4.3 Composition of experimental concentrates............................... 39

Table 4.4 Nutrient intakes for each of the experimental treatment groups.............. 40

Table 4.5 Calculation of nitrogen balance parameters.............................. 50

Table 4.6 Primary antibody procedures for Western Blotting....................... 53

Table 4.7 Calculation of Phenylalanine kinetics parameters...................... 56

Table 5.1 Pre-feeding and post-feeding plasma amino acid concentrations in aged horses receiving concentrates with no amino acid supplementation, lysine and threonine supplementation or lysine, threonine and methionine supplementation............... 69

Table 5.2 Nitrogen consumption, urinary excretion, fecal excretion and nitrogen retention in aged horses over a three-day collection period by treatment...................... 76

Table 5.3 Nitrogen consumption, urinary excretion, fecal excretion and nitrogen retention in aged horses by day of collection........................................... 78

Table 5.4 Phenylalanine kinetics............................................ 84 


\section{List of Figures}

Figure 2.1 Select amino acid transport systems.............................. 5

Figure 2.2 Major fates of endogenous and dietary amino acids .................... 13

Figure 2.3 Patterns of PUN concentration change in response to amino acid

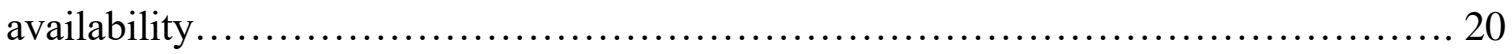

Figure 2.4 Schematic representation of proteins of interest in the mTOR pathway...... 28

Figure 4.1 Sampling timeline for collection of pre/post fed blood samples, muscle biopsies, and stable isotope infusion samples......................................... 47

Figure 5.1 Changes in weight over the $15 \mathrm{~d}$ experimental periods in aged horses........ 59

Figure 5.2 Pre-feeding and post-feeding plasma glucose and insulin concentrations in aged horses.................................................................... 61

Figure 5.3 Pre-feeding and post-feeding PUN concentrations in aged horses........... 63

Figure 5.4 Plasma creatinine concentrations in aged horses......................... 66

Figure 5.5 Nitrogen intake and absorption in aged horses......................... 79

Figure 5.6 Creatinine output in aged horses................................... 81

Figure 5.7 Before the morning meal and after the morning meal activation of Akt in aged horses................................................................... 86

Figure 5.8 Before the morning meal and after the morning meal activation of rpS6S in aged horses.

Figure 5.9 Before the morning meal and after the morning meal relative abundance of Atrogin-1 in aged horses.................................................... 89

Figure 5.10 Before the morning meal and after the morning meal activation of AMPK in aged

horses. 


\section{Chapter 1. Introduction}

Sarcopenia is a condition characterized by loss of muscle mass and function, and it is most commonly observed in aged animals (Santilli et al., 2014). Loss of skeletal muscle integrity associated with sarcopenia can lead to physical disability and poor quality of life. Sarcopenia is becoming a pressing issue for many pet owners because companion animal lifespans are increasing. The condition results from an imbalance in muscle protein synthesis and degradation rates, which ultimately causes a net loss of muscle mass.

Skeletal muscle protein synthetic processes can be limited by the availability of amino acids, and can be stimulated by the presence of amino acids. The limiting amino acid in an animal's diet is the essential amino acid that is present in the diet the furthest below the animal's requirement. It is called the limiting amino acid because its deficiency limits the amount of protein synthesis that can occur. If the amount of the limiting amino acid is increased, the level of protein synthesis can be increased proportionally until the amino acid of interest is no longer limiting. Therefore, if this is a primary contributing factor, supplementation of suspected limiting amino acids could ameliorate the progression of sarcopenia by increasing the availability of limiting amino acids and therefore increasing protein synthesis. The topic of amino acid supplementation is of particular interest in horses, as relatively little is known about the protein and amino acid requirements of horses of any age, and very little is known about the requirements of aged horses. Although there is some data to support the idea that amino acid supplementation improves maintenance of muscle mass in aged horses (Graham-Thiers and Kronfeld, 2005), the cellular mechanisms of that improvement have yet to be 
elucidated. Therefore, the objective of this research was to examine the effect of amino acid supplementation in aged horses on markers of whole body and muscle protein metabolism.

\section{Chapter 2. Literature Review}

Horses older than 20 years of age comprise about $7 \%$ of the equine population in the United States (Wineland, 1998; APHIS, 2005). However, relatively little is known about protein requirements of aged horses. The NRC provides recommendations for mature horses in various levels of activity and production (NRC, 2007), but there is no adjustment made for the possibility of altered requirements associated with aging. It has been postulated in other species that aging may increase the protein requirement, and that not meeting that increased requirement could contribute to sarcopenia (Rafii et al., 2015). In order to better understand how requirements could be increased in aged animals, this literature review will first address basic nutritional principles such as how protein digestion and absorption occur and how recommendations for protein intake were determined. Additionally, it will review methodological considerations such as the benefits and drawbacks of the current methods used to assess protein status and new methods and indicators that can be employed. Finally, it will address the signaling pathways responsible for muscle anabolism, and how they are affected by age and amino acid supplementation. 


\section{Protein Digestion and Absorption in Horses}

Before proteins can be absorbed and used by the horse, they must be broken down to individual amino acids and small peptides. Total tract dietary nitrogen digestibility differs between the forage (approximately 60\%) and the grain (approximately 95\%) components of the diet (Gibbs et al., 1988; Farley et al., 1995). Many of the proteins in grain products are effectively digested and the resulting amino acids are absorbed in the small intestine. However, some proteins present in forage sources are associated with or bound by fiber fractions, making them less available for digestion in the small intestine. Proteins that are not available for digestion in the small intestine will pass to the cecum and large intestine, where microbial fermentation occurs. Data suggests that there is not a physiologically significant amount of amino acid absorption from the hindgut (McMeniman et al., 1987). However, ammonia form microbial metabolism can be absorbed in the hindgut (Bochroder et al., 1994) and can be used for amino acid synthesis.

In horses, the foregut is the main site of protein digestion. Digestion begins in the stomach, where proteins are linearized by hydrochloric acid ( $\mathrm{HCl})$. Additionally, $\mathrm{HCl}$ converts the enzyme pepsinogen to its active form, pepsin. Active pepsin cleaves proteins into smaller peptides, and cleaved peptides and proteins then travel to the small intestine. In the small intestine, proteins are broken down into smaller peptides by pancreatic enzymes and brush border enzymes. Pancreatic peptidases are secreted as an inactive zymogen and include trypsinogen, chymotrypsinogen and procarboxypeptidase.

Trypsinogen is activated by duodenal enteropeptidase, and active trypsin in turn activates chymotrypsinogen to chymotrypsin, and procarboxypeptidase to carboxypeptidase. The 
activated zymogens work to break peptides into smaller chains. Pancreatic enzyme digestion of proteins and peptides in the small intestine yields oligopeptides, di- and tripeptides and free amino acids. These shortened amino acid chains are further broken down by aminopeptidases and endopeptidases at the brush border membrane of the jejunum and ileum, and brush border enzymes yield di- and tri-peptides, and free amino acids for absorption in the small intestine. Amino acids and small peptides are absorbed via a number of transporter systems in the small intestine, and di- and tri-peptides are absorbed via the transporter PepT-1 (Figure 2.1). To date there is very little research in horses on specific amino acid transporter systems in horses, although one study (Woodward et al., 2010) examined cationic and neutral amino acid transporter transcript abundance in the small and large intestine of the horse, and found that cationic and neutral amino acid transporters are present at differing levels in the small and large intestine, and that while some increase in abundance from cranial to caudal portions of the intestine, others decrease, and some remain relatively constant (Woodward et al., 2010). 
Figure 2.1 Select amino acid transport systems

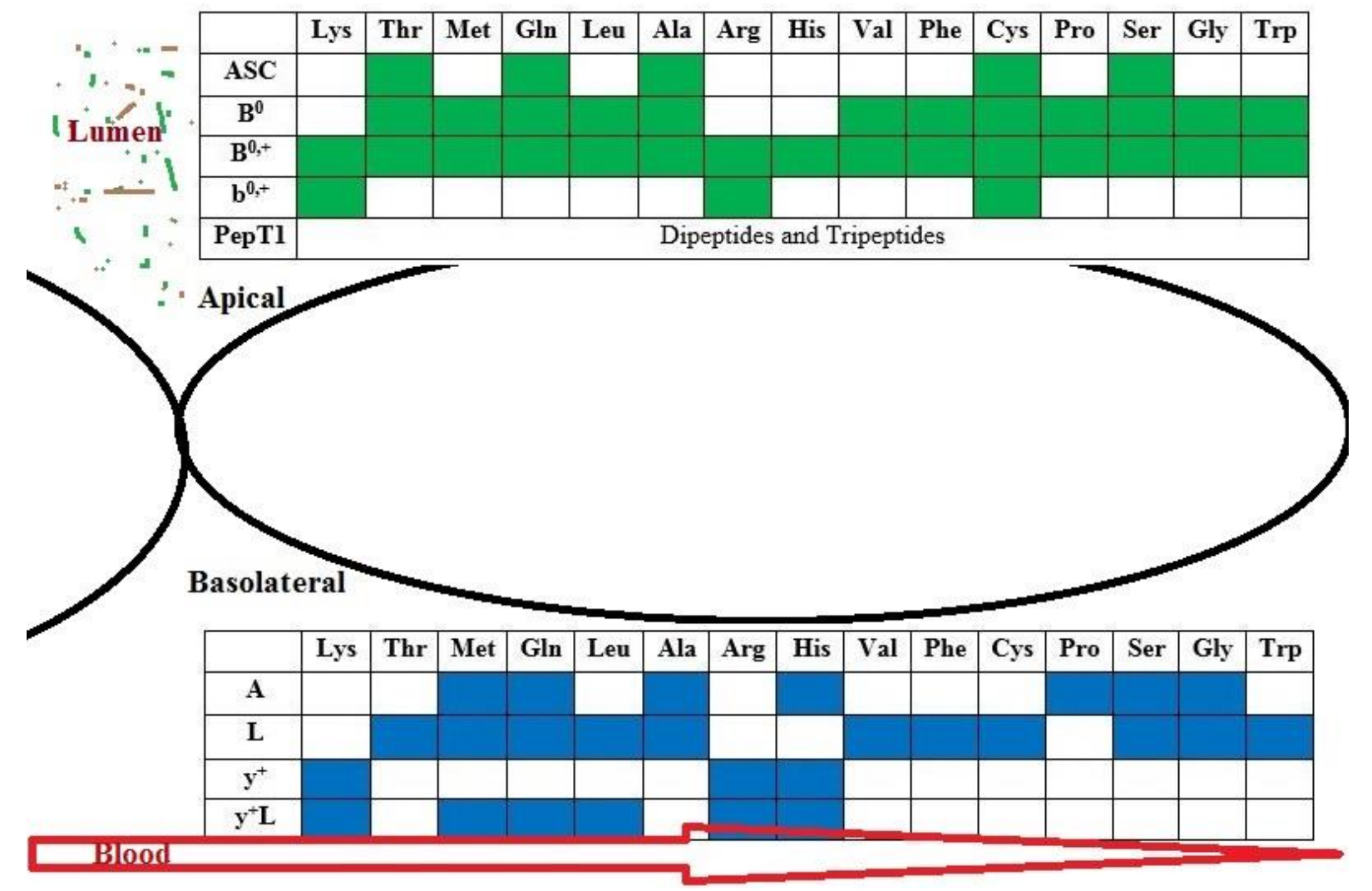

Amino acids are absorbed from the lumen across the apical membrane of the intestine via a number of transporter systems, including ASC, $\mathrm{B}^{0}, \mathrm{~B}^{0,+}$ and $\mathrm{b}^{0,+}$. Transporter systems are specific to certain combinations of amino acids. In the figure above, each system that can transport a specific amino acid across the apical membrane is highlighted in green. Di- and tri-peptides are absorbed from the lumen across the apical membrane of the intestine via the transporter PepT-1. Amino acids are transported across the basolateral membrane into circulation via a number of transporter systems that are specific to certain combinations of amino acids, including $\mathrm{A}, \mathrm{L}, \mathrm{y}^{+}$and $\mathrm{y}^{+} \mathrm{L}$. In the figure above, each system that can transport a specific amino acid across the basolateral membrane is highlighted in blue.

Figure adapted from Equine Applied and Clinical Nutrition (Urschel and Lawrence, 2013) 
Proteins associated with feed fractions that are not effectively digested and absorbed in the small intestine will pass to the large intestine, where microbial fermentation occurs. Here, microbes break down fiber and other nutrients that bypassed the small intestine, such as protein and starch. As a by-product, microbes produce a number of products including volatile fatty acids, which are absorbed in the large intestine. Additionally, some microbes primarily consume proteins and amino acids, and in addition to producing volatile fatty acids, also produce ammonia, which can be absorbed in the large intestine, and circulate to the liver, where it can be used to produce amino acids (Russell, 2002).

Microbial bodies are a potential source of protein for the horse, as they contain amino acids. However, there is currently no literature indicating that absorption of amino acids and proteins in the large intestine, either microbial or residual from the small intestine, make a significant contribution to meeting protein requirements in horses (Reitnour and Salsbury, 1972; McMeniman et al., 1987; Bergen, 2015).

\section{Essential and Limiting Amino Acids in the Equine Diet}

Essential amino acids are amino acids that must be provided in the diet because they are not synthesized by the body in sufficient amounts to meet the requirement. There are nine amino acids that are assumed to be essential in the equine diet; histidine, isoleucine, leucine, lysine, methionine, phenylalanine, threonine, tryptophan and valine (Urschel and Lawrence, 2013). Although arginine was classically considered to be essential for most animals, some species, such as swine, no longer considered arginine to 
be essential (NRC, 2012). And although arginine was also once considered an essential amino acid in horses (NRC, 2007), contemporary studies have shown that arginine is typically only essential in species such as fish, birds and carnivores, or at specific developmental stages, such as in neonates, where the demand for arginine for use in pathways such as nitrogen excretion are higher than its rate of endogenous synthesis (Ball et al., 2007). The limiting amino acid is the essential amino acid that is present in the diet the furthest below the animal's requirement. Because protein synthesis requires a specific ratio of amino acids, when an amino acid is not present in sufficient amounts, it limits protein synthesis. Therefore, all other amino acids will be in excess of the amount of protein synthesis that the limiting amino acid allows and will be catabolized. The first limiting amino acid in most common equine diets is lysine (Breuer et al., 1970; Hintz et al., 1971a; Potter and Huchton, 1975). The second limiting amino acid has been proposed to be threonine (Graham et al., 1994; Staniar et al., 2001). Finally, it has been proposed that methionine could potentially be a limiting amino acid in equine diets, although it has received comparatively little research (Breuer et al., 1970; Glade and Luba, 1990; Winsco et al., 2011). Therefore, supplementation of these individual amino acids has the potential to increase the capacity for protein synthesis by increasing the amounts of essential amino acids that may be limiting protein synthesis.

\section{Protein Requirements in Horses}

Recommendations for protein intakes for mature sedentary horses are published in Nutrient Requirements of Horses (NRC, 2007). The NRC recommends an average of $1.26 \mathrm{~g} \mathrm{CP} / \mathrm{kg} \mathrm{BW} / \mathrm{d}$ and $4.3 \%$ of $\mathrm{CP}$ intake as lysine, which equates to $54 \mathrm{mg} / \mathrm{kg} \mathrm{BW} / \mathrm{d}$. 
Currently, the only amino acid requirement that has been specified is lysine.

Requirements for other amino acids have not been extensively studied, but with the development of more sophisticated methods of amino acid requirement estimation in horses, such as stable isotope infusion, it is now possible to more closely examine those requirements.

\section{NRC Method of Determination}

The NRC recommended minimum crude protein intakes are based on data from twelve studies that assessed nitrogen balance in mature sedentary horses fed a variety of diets (Table 2.1.) Nitrogen balance data was fitted to a broken line model, giving an estimate of $1.26 \mathrm{~g} \mathrm{CP} / \mathrm{kg} \mathrm{BW} / \mathrm{d}$. Using the $95 \%$ confidence interval from that model gives a lower $95 \%$ confidence limit of $1.08 \mathrm{~g} \mathrm{CP} / \mathrm{kg} \mathrm{BW} / \mathrm{d}$, an average requirement of $1.26 \mathrm{~g}$ $\mathrm{CP} / \mathrm{kg} \mathrm{BW} / \mathrm{d}$, and an upper $95 \%$ confidence limit of $1.44 \mathrm{~g} \mathrm{CP} / \mathrm{kg} \mathrm{BW} / \mathrm{d}$, which correspond to the NRC's minimum, average and elevated maintenance $\mathrm{CP}$ requirements respectively. 
Table 2.1 Summary of data used to form NRC crude protein recommendations

\begin{tabular}{|c|c|c|c|c|c|c|c|}
\hline Author & $\mathbf{n}=$ & Age/Sex & $\begin{array}{l}\text { Avg. } \\
\text { Weight }\end{array}$ & N Intakes & $\begin{array}{l}\text { Major } \\
\text { Protein } \\
\text { Source }\end{array}$ & DM Intake & $\begin{array}{l}\text { Estimated } \\
\text { Requirement }\end{array}$ \\
\hline $\begin{array}{l}\text { (Slade et al., } \\
\text { 1970) }\end{array}$ & 7 & $\begin{array}{l}\text { Adult } \\
\text { Mares }\end{array}$ & $\begin{array}{l}\text { Horses, } \\
480 \pm \\
40.5 \mathrm{~kg}\end{array}$ & $\begin{array}{l}\text { Fish: } 72.5,104.9, \\
135.4,165.9 \mathrm{~g} / \mathrm{d} \\
\text { Corn gluten: } 74.1, \\
\text { 108.6, 141.6, } 176.7 \\
\mathrm{~g} / \mathrm{d}\end{array}$ & $\begin{array}{l}\text { Fish meal } \\
\text { Corn gluten } \\
\text { meal }\end{array}$ & $\sim 1.3 \% \mathrm{BW}^{1}$ & $\begin{array}{l}580 \mathrm{mg} \\
\mathrm{DP} / \mathrm{kg} \mathrm{BW} / \mathrm{d}\end{array}$ \\
\hline $\begin{array}{l}\text { (Hintz and } \\
\text { Schryver, } \\
\text { 1972) }\end{array}$ & 4 & $\begin{array}{l}\text { Mature/ } \\
\text { Geldings }\end{array}$ & $\begin{array}{l}\text { Ponies, } \\
\sim 160 \mathrm{~kg}^{2}\end{array}$ & $\begin{array}{l}123,186,165 \\
\mathrm{mg} / \mathrm{kg} \mathrm{BW} / \mathrm{d}\end{array}$ & $\begin{array}{l}\begin{array}{l}\text { Soybean } \\
\text { meal }\end{array} \\
\text { Linseed } \\
\text { meal }\end{array}$ & $1.3 \% \mathrm{BW}$ & $\begin{array}{l}631 \mathrm{mg} \\
\mathrm{DP} / \mathrm{kg} \mathrm{BW} / \mathrm{d}\end{array}$ \\
\hline $\begin{array}{l}3 \text { (Reitnour } \\
\text { and Salsbury, } \\
\text { 1972) }\end{array}$ & 4 & $\begin{array}{l}\text { Not } \\
\text { specified }\end{array}$ & $\begin{array}{l}\text { Ponies, } \\
\text { not } \\
\text { specified }\end{array}$ & $\begin{array}{l}24.8 \text { (basal), } 55.9 \\
\text { (fishmeal), } 56.6 \\
\text { (soybean meal), } \\
57.5 \text { (linseed meal) } \\
\text { g/d }\end{array}$ & $\begin{array}{l}\text { Fishmeal } \\
\begin{array}{l}\text { Soybean } \\
\text { meal }\end{array} \\
\begin{array}{l}\text { Linseed } \\
\text { meal }\end{array}\end{array}$ & $\begin{array}{l}1.1 \mathrm{x} \\
\text { maintenance } \\
\text { requirement }\end{array}$ & $\begin{array}{l}\text { Not } \\
\text { Specified }^{3}\end{array}$ \\
\hline $\begin{array}{l}\text { (Harper and } \\
\text { Vanderno.Gw, } \\
\text { 1974) }\end{array}$ & 4 & $\begin{array}{l}\text { Mature/ } \\
\text { Geldings }\end{array}$ & $\begin{array}{l}\text { Not } \\
\text { specified }\end{array}$ & $\begin{array}{l}81,86,94,119, \\
234,333 \mathrm{mg} \mathrm{N} / \mathrm{kg} \\
\mathrm{BW} / \mathrm{d}\end{array}$ & $\begin{array}{l}\text { Not } \\
\text { Specified }\end{array}$ & $\begin{array}{l}\text { Not } \\
\text { specified }\end{array}$ & $\begin{array}{l}440 \mathrm{mg} \\
\mathrm{DP} / \mathrm{kg} \mathrm{BW} / \mathrm{d}\end{array}$ \\
\hline $\begin{array}{l}\text { (Reitnour and } \\
\text { Salsbury, } \\
\text { 1976) }\end{array}$ & 4 & $\begin{array}{l}\text { Mature/ } \\
\text { Not } \\
\text { specified }\end{array}$ & $\begin{array}{l}\text { Ponies, } \\
180 \mathrm{~kg}\end{array}$ & $\begin{array}{l}22.1 \text { (basal), } 38.3 \\
\text { (corn gluten), } 39.5 \\
\text { (corn gluten }+ \text { Lys) } \\
\text { and } 42.5 \text { (casein) } \\
\text { g/d }\end{array}$ & $\begin{array}{l}\text { Corn gluten } \\
\text { Corn gluten } \\
+ \text { Lys } \\
\text { Casein }\end{array}$ & $\begin{array}{l}\text { Not } \\
\text { specified }\end{array}$ & $\begin{array}{l}\text { Not } \\
\text { specified }^{4}\end{array}$ \\
\hline (Meyer, 1983) & $145^{5}$ & Various $^{5}$ & Various $^{5}$ & Various $^{5}$ & Various $^{5}$ & Various $^{5}$ & $\begin{array}{l}3.4 \mathrm{~g} \mathrm{DCP} / \mathrm{kg} \\
\mathrm{BW}^{0.75}\end{array}$ \\
\hline $\begin{array}{l}\text { (Meyer et al., } \\
\text { 1985) }\end{array}$ & 3 & $\begin{array}{l}\text { Not } \\
\text { specified }\end{array}$ & $\begin{array}{l}\text { Ponies, } \\
\sim 200 \mathrm{~kg}\end{array}$ & $\begin{array}{l}51.9 \text { (control), } 7.1 \\
\text { (depletion) and } \\
47.9 \text { (repletion) }\end{array}$ & Casein & $\begin{array}{l}\text { Not } \\
\text { specified }\end{array}$ & $\begin{array}{l}500 \mathrm{mg} \\
\mathrm{DP} / \mathrm{kg} \mathrm{BW} / \mathrm{d}\end{array}$ \\
\hline
\end{tabular}


Table 2.1 Continued

\begin{tabular}{|c|c|c|c|c|c|c|c|}
\hline $\begin{array}{l}\text { (Freeman et } \\
\text { al., 1986) }\end{array}$ & 4 & $\begin{array}{l}\text { Mature/ } \\
\text { Geldings }\end{array}$ & $\begin{array}{l}\text { Not } \\
\text { Specified }\end{array}$ & $81.8 \mathrm{~g} / \mathrm{d}$ & $\begin{array}{l}\text { Not } \\
\text { Specified }\end{array}$ & $\begin{array}{l}\text { Not } \\
\text { Specified }\end{array}$ & $\begin{array}{l}\text { Not } \\
\text { Specified }^{7}\end{array}$ \\
\hline $\begin{array}{l}\text { (Freeman et } \\
\text { al., 1988) }\end{array}$ & 5 & $\begin{array}{l}\text { Mature/ } \\
\text { Geldings }\end{array}$ & $\sim 480 \mathrm{~kg}^{8}$ & $\begin{array}{l}\sim 237 \mathrm{mg} \mathrm{N} / \mathrm{kg} \\
\mathrm{BW} / \mathrm{d}\end{array}$ & Oat grain & $\begin{array}{l}\text { Not } \\
\text { specified }\end{array}$ & $\begin{array}{l}\text { Not } \\
\text { specified }^{9}\end{array}$ \\
\hline $\begin{array}{l}\text { (Gibbs et al., } \\
\text { 1988) }\end{array}$ & 3 & $\begin{array}{l}\text { Mature/ } \\
\text { Geldings }\end{array}$ & $\sim 135 \mathrm{~kg}$ & $\begin{array}{l}47.2 \text { (coastal } \\
\text { Bermuda), } 59.6 \\
\text { (low protein } \\
\text { alfalfa), } 71.4 \text { (high } \\
\text { protein alfalfa) }\end{array}$ & $\begin{array}{l}\text { Coastal } \\
\text { Bermuda } \\
\text { grass } \\
\text { Low protein } \\
\text { alfalfa } \\
\text { High protein } \\
\text { alfalfa }\end{array}$ & $2 \% \mathrm{BW}$ & $\begin{array}{l}\text { Not } \\
\text { specified }^{10}\end{array}$ \\
\hline $\begin{array}{l}\text { (Martin et al., } \\
\text { 1996) }\end{array}$ & 3 & $\begin{array}{l}\text { Adult/ } \\
\text { Geldings }\end{array}$ & $\sim 400 \mathrm{~kg}$ & $\begin{array}{l}28.2 \text { (low } \\
\text { nitrogen), } 95.1 \text { (low } \\
\text { nitrogen + urea), } \\
\text { and } 98.2 \text { (low } \\
\text { nitrogen + soybean } \\
\text { meal) g/d }\end{array}$ & $\begin{array}{l}\text { Urea } \\
\text { Soybean } \\
\text { Meal }\end{array}$ & $\begin{array}{l}\text { Not } \\
\text { specified }\end{array}$ & $\begin{array}{l}\text { Not } \\
\text { specified }^{11}\end{array}$ \\
\hline $\begin{array}{l}\text { (Olsman et al., } \\
\text { 2003) }\end{array}$ & $3^{12}$ & Various $^{12}$ & $\begin{array}{l}\text { Ponies, } \\
\text { Various }{ }^{12}\end{array}$ & Various $^{12}$ & Various $^{12}$ & Various $^{12}$ & $\begin{array}{l}545 \mathrm{mg} \\
\mathrm{DP} / \mathrm{kg} \mathrm{BW} /\end{array}$ \\
\hline
\end{tabular}

${ }^{1}$ Calculated by dividing fixed intake by average BW.

${ }^{2}$ Average weight of horses between the two trials conducted.

${ }^{3}$ This study examined protein digestibility and nitrogen retention when protein was infused directly into the cecum. Therefore, intakes reflect the sum of dietary and cecally infused protein, and protein requirement was not specified.

${ }^{4}$ This study examined responses in nitrogen balance to different sources of protein and given supplemental Lys. Therefore, protein requirement was not specified.

${ }^{5}$ This data is a meta-analysis of 145 digestion trials, and equations to estimate the requirement account for differences in DM intake ( $\mathrm{n}=136), \mathrm{N}$ intake $(\mathrm{n}=145)$ and crude fiber intake $(\mathrm{n}=124)$.

${ }^{6}$ The objective of this study was to measure endogenous and renal $\mathrm{N}$ losses in order to estimate the maintenance protein requirement for ponies.

${ }^{7}$ The objective of this study was to examine changes in nitrogen data in response to long term low intensity exercise. The data included in this chart represents period 1, an estimate of nitrogen balance at maintenance.

${ }^{8}$ Average BW for the 9 horses studied.

${ }^{9}$ This study examined differences in $\mathrm{N}$ retention in response to different levels of work. $\mathrm{N}$ intake differed by no more than $0.5 \%$ throughout the study.

${ }^{10}$ The objective of this study was to determine prececal, postileal and total tract digestion.

${ }^{11}$ The objective of this study was to examine urea utilization in the large intestine.

${ }^{12}$ This study measured nitrogen balance in three ponies, and also conducted a meta-analysis of existing data. Specifications in this chart reflect both the meta-analysis and the experimentation. 
The requirement for lysine is estimated as $4.3 \%$ of the crude protein requirement, with estimates being derived from linear regression of data that reported the lysine composition of the diet and nitrogen retention. Since the publication of the NRC in 2007, protein and amino acid requirements have been further studied and characterized. There has been an increase in research that focuses on determining which amino acids are limiting protein synthesis (Ohta et al., 2007; Winsco et al., 2011; Mastellar et al., 2016b), and what the requirements for those amino acids are in horses in different physiological states. At the time of publication of the 2007 NRC, there were no studies that had evaluated the lysine requirements of mature horses at maintenance. Therefore, recommendations for lysine intake were made not from studies specifically designed to estimate the lysine requirement, but by post hoc analysis of data that reported lysine intake and nitrogen retention. Since then, the focus of equine protein requirement research has shifted from studying protein requirements in general, to studying the requirements of individual amino acids, and there has been some innovation in the experimental methods used to assess whole-body protein metabolism in horses.

\section{Methods in Evaluating Amino Acid Adequacy}

\section{Whole Body Protein Metabolism}

Two ways to get a whole-animal estimate of use of dietary amino acids are nitrogen balance and stable isotope infusion. In order to understand how each of these methods works, it is important to understand the major fates of dietary and body amino acids. Figure 2.2 illustrates the major fates of amino acids in the body. These approaches each account for nitrogen utilization and excretion in different manners. While nitrogen 
balance has been the classically accepted method of determining protein requirements, it is no longer considered the "gold standard" method in other species (WHO, 2007). Stable isotope infusion is a relatively new technique, and has recently been implemented in horses to study amino acid metabolism, estimate requirements of amino acids, and evaluate dietary amino acid adequacy. 
Figure 2.2 Major fates of endogenous and dietary amino acids

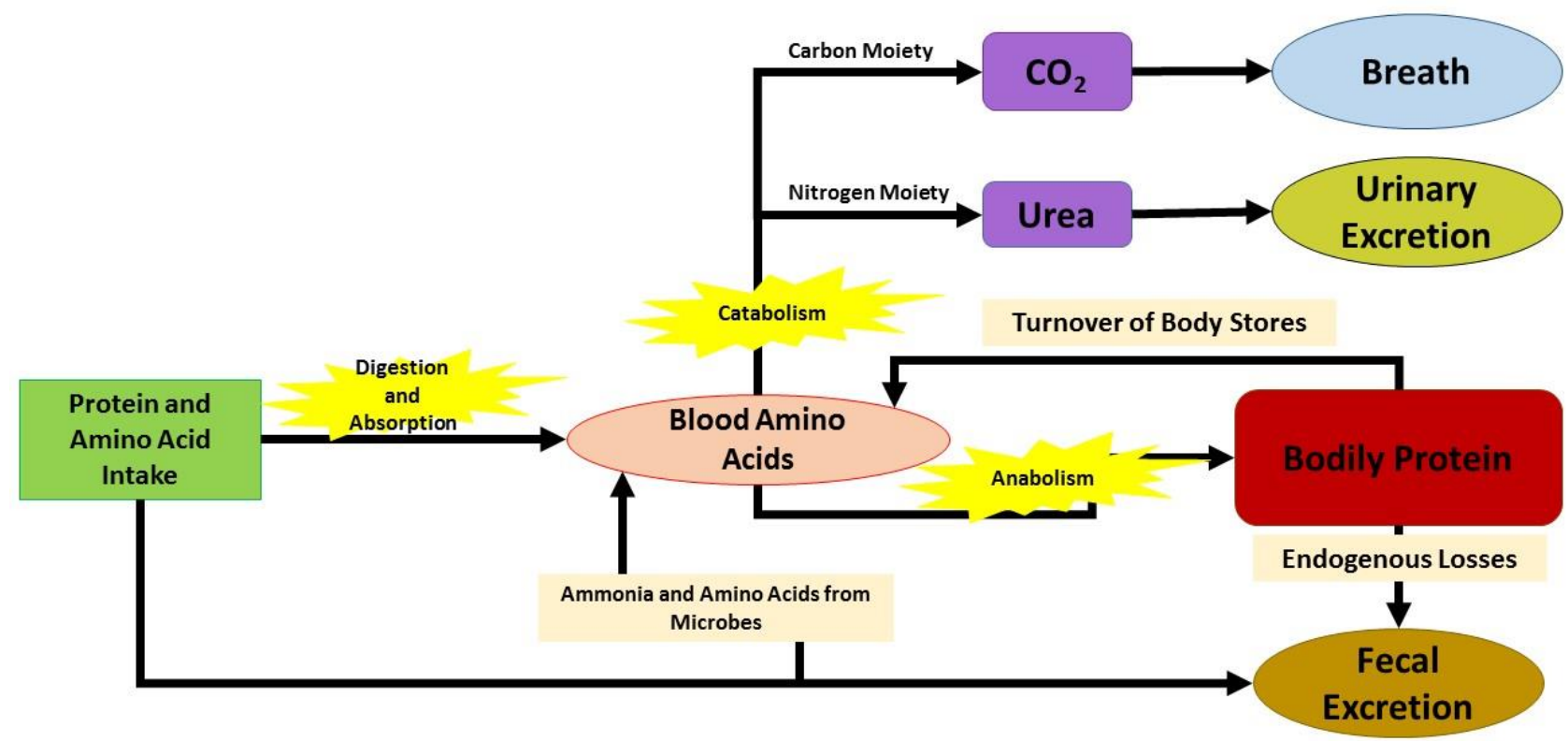

Amino acids consumed in the diet are either digested and absorbed, or excreted in the feces. Ammonia and amino acids from microbial activity and microbial bodies can also be absorbed from the hindgut, and the absorbed ammonia can be used to synthesize amino acids. Absorbed amino acids enter the blood amino acid pool where they are either used to synthesize protein, or are catabolized. Body protein can be broken down to its respective amino acids, and those amino acids can re-enter the blood amino acid pool, where they can be recycled into new body proteins, or catabolized. Conversely, body protein can remain intact and be sloughed off and lost (endogenous losses). Amino acids that are catabolized are broken into a carbon moiety, which can be completely oxidized to $\mathrm{CO}_{2}$, and expired in the breath (or recycled for use in synthesis of other body compounds), and a nitrogen moiety, which is converted to urea and excreted in the urine. 
Nitrogen balance is calculated by determining the difference between nitrogen intake and nitrogen excretion in urine and feces. Positive nitrogen balance suggests net retention of nitrogen, presumably for use in synthetic processes, such as anabolism of skeletal muscle. Negative nitrogen balance suggests breakdown and excretion of body nitrogen stores. Therefore, nitrogen balance can be used as a broad assessment of the net use of dietary and body nitrogen. Classically, nitrogen balance has been used to determine the requirement for protein in animals of various stages of exercise (Freeman et al., 1988) and development (Hintz et al., 1971b), and on different diets (Graham-Thiers and Bowen, 2011). The NRC (NRC, 2007) provides estimates of crude protein requirements for horses at maintenance, exercising, during pregnancy, during lactation and during growth. These estimates account for maintenance protein requirements, as well as the amount of protein required to produce their respective products. However, when examining excretion of nitrogen, it is important to consider where the nitrogen in each excretory product could be coming from. Nitrogen in urine results from absorption of proteins, amino acids or ammonia, and eventual catabolism of either body amino acids, or excess dietary amino acids. Catabolism of amino acids results in free ammonia, which is converted to urea, and is targeted for excretion in the urine. Fecal nitrogen values reflect proteins and amino acids that were not absorbed by the animal, as well as endogenous proteins and amino acids that were excreted into the digestive tract. Together these values reflect an estimate of catabolized body nitrogen, endogenous nitrogen losses and unabsorbed dietary nitrogen (Figure 2). It is not possible to distinguish between the excretion of catabolized dietary amino acids and catabolized body amino acids in the urine. Additionally, values given do not distinguish between 
excretion of endogenous and unabsorbed nitrogen in the feces. Thus, nitrogen balance is not a very specific measure of protein utilization, but more of an overall assessment of the balance between nitrogen intake and nitrogen excretion. Furthermore, while nitrogen balance can be used to compare nitrogen retention at different levels of crude protein, data suggests that it is not a sensitive enough measure to determine specific amino acid requirements in horses (Antilley et al., 2007; Malesky et al., 2013). In 2007, one study proposed that nitrogen retention may not be a suitable response criterion for assessing amino acid adequacy as compared to inadequacy (Antilley et al., 2007). For the purposes of that study, six yearling Quarter Horse fillies were used in a 3 x 3 Latin square design to evaluate nitrogen retention as a response criterion for amino acid studies. Treatments included an amino acid adequate control diet, a diet that was amino acid deficient and supplemented with urea, and an amino acid deficient diet fed in conjunction with oral dosing of essential amino acids. There were significant differences in the biological value of nitrogen (nitrogen retention as a percent of nitrogen absorbed) between amino acid sufficient and insufficient diets. However, there was not a significant difference in nitrogen retention between the amino acid sufficient treatments and the amino acid insufficient treatment. Therefore, nitrogen retention did not appear to be a sensitive enough criterion to distinguish between amino acid sufficient diets and amino acid insufficient diets. Thus, estimates of amino acid requirements are now often made using newer techniques.

A more contemporary assessment of amino acid utilization involves stable isotope infusion and measurement of isotope tracer kinetics. Much like nitrogen balance, stable isotope kinetics can address the effects of changing levels of limiting amino acids in the 
diet, and can be used to estimate amounts of amino acids used for protein synthesis across different levels of intake. This technique is based on the principle that dietary amino acids that cannot be used for protein synthesis cannot be stored in the body and must be oxidized and excreted. Therefore, if an essential amino acid is limiting in the diet, protein synthesis will be limited by the amount of this amino acid and therefore all other amino acids will be in excess of what is needed for protein synthesis and they must be metabolized and excreted. For the purposes of this technique, an isotope of a non-limiting essential amino acid, often phenylalanine, is administered to use as an indicator (the indicator amino acid), and then differing levels of the limiting amino acid (the test amino acid) are fed, and breath and blood samples are collected. Plasma isotope enrichment represents dilution of the isotope in the plasma, and allows for the calculation of flux. Flux is an estimate of the rate of amino acid entry and exit from the free amino acid pool. Amino acids enter the pool through dietary intake, de novo synthesis and protein breakdown, and exit the free amino acid pool through protein synthesis, oxidation and conversion to other metabolites. The concentration of isotopic carbon dioxide in the breath represents the amount of indicator amino acid that was catabolized, and because the rates of oxidation can be determined, the non-oxidative losses of the amino acid, which includes use for protein synthesis and conversion to other metabolites, can be calculated. By comparing the rates of indicator amino acid oxidation between diets, what is essentially being compared is the rate of protein synthesis that can be supported by the diet. Thus, isotope tracer kinetics provide more direct insight into to differences in protein utilization between diets. Stable isotope infusion methods are well established in several species such as humans (Elango et al., 2008) and pigs (Moehn et al., 2005), but 
more recently, methods have been validated for use in horses (Urschel et al., 2012).

While these methods are useful for getting more specific estimates of whole-body protein metabolism, they do not give a general indication of whether animals are in a positive or negative nitrogen balance. Therefore, isotope tracer kinetics may be able to elucidate an adequate or optimal intake of a specific amino acid in a specific diet, but they cannot be used alone to determine whether horses are in a positive nitrogen balance, or are losing body nitrogen stores.

Nitrogen balance and isotope tracer kinetics, alone or taken together, are often used to assess the use of dietary protein on the whole-animal level. In addition to these methods, there are several other supporting measurements of certain metabolites that address the use of both dietary and tissue amino acids. These metabolites are often studied in conjunction with measures of whole-animal nitrogen metabolism to get a comprehensive representation of the way that both dietary and tissue amino acids are being metabolized.

\section{Plasma Metabolites}

Several plasma metabolites are used to assess dietary protein utilization and overall animal protein status. In order to get a complete picture of amino acid status and metabolism in an animal, there are several metabolites that can be considered. The results of these metabolite analyses should be taken together to address changes in protein metabolism in response to meal feeding, the animal's use of dietary amino acids, 
catabolism of skeletal muscle, and relative overall gains in skeletal muscle in response to feeding and exercise.

Plasma amino acid concentration, in conjunction with other measures of dietary amino acid use, have been used as a method to determine limiting amino acid and amino acid requirements in species other than the horse (Mitchell et al., 1968; Ishibashi, 1985), but potential in horses at different levels of work and stages of development have yet to be fully explored (Graham-Thiers and Bowen, 2011). However, plasma amino acids are commonly compared across diets and used as an assessment of availability of amino acids following a meal. Additionally, plasma amino acids are often compared over time after feeding a meal to characterize changes in amino acid metabolism with meal feeding. Finally, plasma amino acids can be used to estimate the requirements of amino acids. Plasma lysine data has been used to estimate the lysine requirement in mature thoroughbreds (Ohta et al., 2007), where samples were taken three hours after feeding a meal, and plasma lysine levels remained relatively constant with increasing levels of dietary lysine intake until the requirement was met, and then a breakpoint occurred and lysine concentrations increased with increasing lysine intake. Some plasma amino acid data suggests that the requirement for lysine may be higher than current recommendations (Ohta et al., 2007; Malesky et al., 2013).

Plasma urea nitrogen (PUN) is often used as an indicator of dietary amino acid catabolism because there are two primary fates of dietary amino acids after absorption: protein synthesis or catabolism. Amino acid catabolism occurs either when protein synthesis is maximized and excess amino acids remain, or if the dietary supply of amino acids cannot support further protein synthesis due to one or more limiting amino acids. In 
the case of catabolism, the carbon backbone of the amino acid is oxidized to $\mathrm{CO}_{2}$ and the amino moiety is converted to ammonia and subsequently urea is produced for excretion. Therefore, post-feeding PUN is an indicator of amount of dietary amino acid catabolism. PUN is commonly used to study amino acid sufficiency, and has been shown to respond quadratically to increasing intakes of limiting amino acid (Winsco et al., 2011; Coma et al., 1995). PUN levels decrease with increasing intake of a limiting amino acid until the requirement of the limiting amino acid is achieved, at which point PUN concentration reaches a plateau (Figure 2.3). The decreasing concentration of PUN results from the fact that as the level of supplementation of limiting amino acid is increased, a larger proportion of the other dietary amino acids are used to make protein, and a smaller proportion undergoes metabolism to urea. To study the efficiency of amino acid utilization, plasma samples are commonly taken while animals are in a postprandial state, as measurements taken in this state offer an estimate of the amount of urea that is entering the bloodstream as a result of metabolism of dietary amino acids. Post-feeding comparisons of PUN can be used to address differences in relative levels of catabolism of dietary amino acids between treatments. PUN is therefore often used as an indicator of relative dietary protein quality and utilization (Graham-Thiers and Kronfeld, 2005). However, it is important to note that since ammonia is absorbed from the hindgut (Bochroder et al., 1994), circulating PUN values reflect not only catabolism of dietary amino acids, but also absorption of nitrogen from the hindgut that could be occurring. 
Figure 2.3 Patterns of PUN concentration change in response to amino acid availability

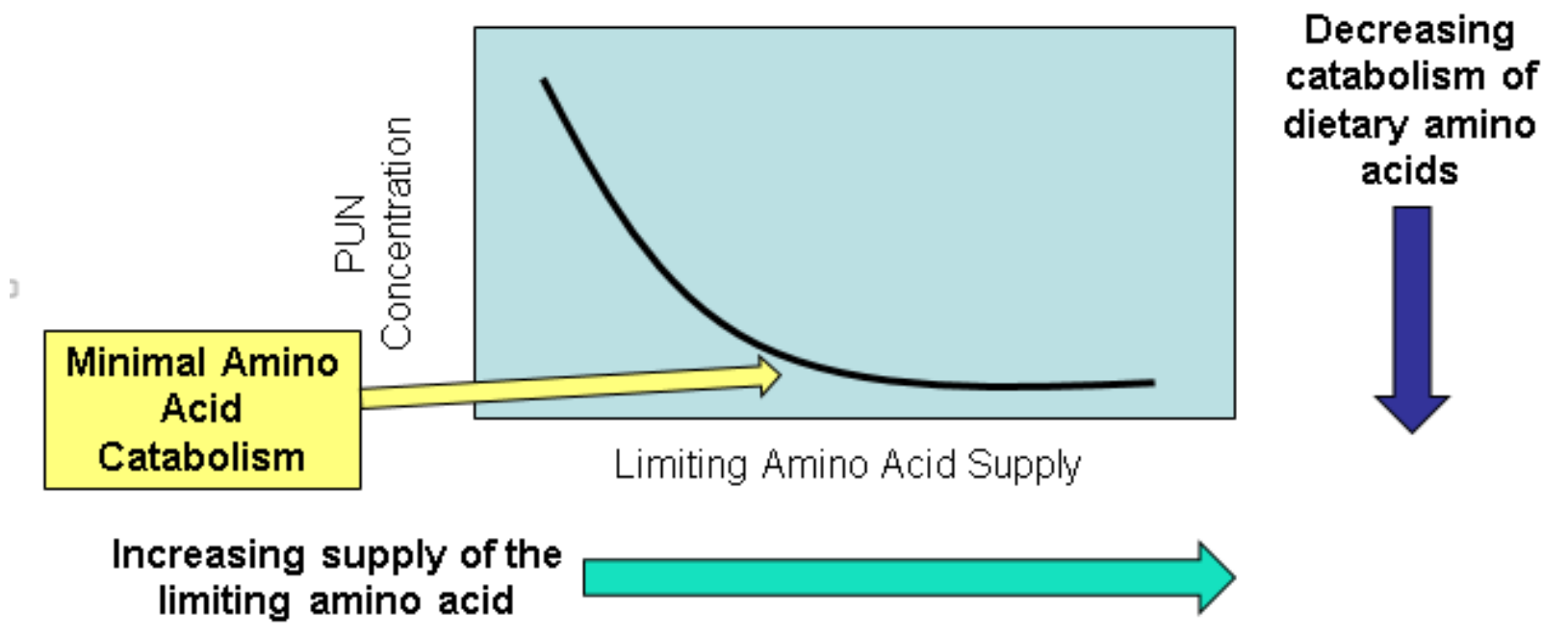


3-methyl histidine $(3 \mathrm{MH})$ is often used as a measure of skeletal muscle amino acid catabolism. $3 \mathrm{MH}$ is formed when the histidine in actin and myosin filaments is methylated during peptide bond formation (Young and Munro, 1978), and is part of the primary structure of actin and myosin (Johnson et al., 1967). Therefore, circulating 3MH is a by-product of the breakdown of actin and myosin fibers, and it is used as a marker of muscle catabolism (Gallagher et al., 1999). Comparing differences in 3MH across treatments can give an estimate of changes in muscle protein catabolism, which is of particular interest in aged animals, where rates of muscle protein catabolism exceeding rates of muscle protein anabolism leads to sarcopenia.

Additionally, plasma creatinine levels are often compared across treatments to address differences in muscle masses between animals. Creatinine is formed from the physiochemical dehydration of creatine in muscle, which occurs at a rate of approximately 1.1-2.4\% per day (Heymsfield et al., 1983a; Heymsfield et al., 1983b). Creatinine is used as a marker of muscle mass because creatine is only found in muscle, it is found at constant concentrations in muscle, and it is excreted at a uniform rate per mass of muscle (Heymsfield et al., 1983a). Therefore, animals can be adapted to a diet, and plasma or urinary creatinine can be used to estimate differences in muscle mass due to treatment.

These indicators of amino acid utilization in combination with the above mentioned whole body estimates of protein and amino acid utilization provide a comprehensive assessment of the way that dietary amino acids are being metabolized and incorporated into and/or liberated from skeletal muscle. Comparing these measures in horses fed different levels of protein or amino acids may give a more comprehensive 
view of the way that amino acids are being used to support anabolism and maintain skeletal muscle.

\section{Effect of Age on Protein Requirement}

There are a number of factors that could impact protein and amino acid requirements in aged horses, including poor dentition and decreased digestibility. In the late 1980 's, one study showed a decrease in digestibility of crude protein, along with phosphorus and calcium, in aged horses compared to mature horses (Ralston et al., 1989). A subsequent study conducted in 1996, however, did not show the same decreased digestibility of crude protein, despite similar diets to the previously conducted study (Christensen et al., 1996). Several causes of the difference in results have been proposed, including differences in body condition score and dentition of the experimental subjects, as well as the deworming program that the horses received throughout their life. It is therefore suggested that because horses in earlier studies were in low body condition, had poorer dentition, and had not been on a regular deworming program throughout their lives, that the decreased apparent digestibility and improvement with protein, calcium and phosphorus supplementation may be most beneficial to aged horses that are already in low body condition, have poor dentition, or have a history of parasite problems (Ralston et al., 2001). Additionally, sarcopenia - the loss of muscle mass and functionis a condition that is observed most commonly in aged individuals (Santilli et al., 2014). Sarcopenia is thought to result from an imbalance in muscle protein synthesis and degradation rates (Combaret et al., 2009; Koopman and van Loon, 2009; Marcell, 2003), such that protein is being degraded at a faster rate than it is being made. Skeletal muscle protein synthesis is limited by the availability of amino acids and signaling pathways that 
regulate protein synthesis are regulated in part by the presence of amino acids. Therefore, protein synthesis may be affected by advanced age, and increasing dietary protein intake or specific amino acid intake may stimulate muscle protein synthesis to ameliorate the age-related effects of sarcopenia.

Data on the protein requirement of aged versus young animals is often conflicting, and there is a sparsity of data in equids. Some nitrogen balance studies in humans (Campbell et al., 2008) and isotope studies in horses (Wagner et al., 2013) do not support the idea that the protein requirement of old animals is significantly different from that of young animals. Conversely, some studies in humans using isotope tracer kinetics suggest that the optimal protein intake may be higher in aged subjects than what is currently recommended (Rafii et al., 2015). Many researchers argue that this disagreement can only be resolved with more data from newer methods such as stable isotope infusion, because older methods of assessment of dietary protein and amino acid adequacy such as nitrogen balance are no longer the "gold standard."

Although there is still debate as to whether the protein requirement of aged animals is elevated, there is evidence that imbalances in muscle protein synthesis, due to alterations in the responsiveness of the mechanistic target of rapamycin (mTOR) signaling pathway, could play a role in the development of sarcopenia. The supplementation of certain amino acids is of particular interest in this area of research because muscle protein synthesis can be limited by the availability of essential amino acids, and the mTOR signaling pathway can be regulated partially by amino acid presence. It has therefore been suggested that ensuring adequate supply of amino acids could positively alter protein synthesis signaling in aged animals, and ultimately decrease 
the occurrence and severity of sarcopenia. Therefore, much recent research has focused on supplementation of specific amino acids that are either known or suspected to be limiting or to influence protein synthesis (Graham-Thiers and Kronfeld, 2005; Kim et al., 2014; Luiking et al., 2014; Ellis et al., 2016; Kalhan et al., 2016), rather than a general increase in protein intake. Supplementation with these specific amino acids has the potential to supply the substrates and stimulus needed to improve muscle protein synthesis.

Taken together, current data show promising evidence that targeted nutritional intervention such as specific amino acid supplementation has the potential to improve the negative effects of sarcopenia in aged animals. If these nutritional approaches are applied in the feed industry, they have the potential to positively impact quality of life for aged domestic animals.

\section{Amino Acid Supplementation and Protein Synthesis and Degradation Signaling}

The signaling molecule mTOR is a serine-threonine kinase that was first discovered in yeast, and is the crux of a highly conserved signaling pathway of eukaryotes that ultimately aids in regulation of cell growth. The functionality of mTOR is achieved by two different categories of protein complexes, mTORC1 and mTORC2, which have different structural and functional properties. mTORC1 is rapamycin sensitive, and is involved in ribosome biogenesis, transcription, translation, nutrient transport, and autophagy. This protein is the main focus of studies that examine effects of nutritional factors on protein synthesis. mTORC1 is composed of three protein sub-units; raptor, mLST8, and mTOR. mTORC2 is rapamycin insensitive and contributes to the regulation 
of the actin cytoskeleton, which ultimately determines spatial control of cell growth. mTORC2 is composed of five protein sub-units including mSIN1, PRR5, rictor, mLST8, and mTOR (Hall, 2008).

\section{Function of Signaling Pathways}

The mTOR pathway functions mainly to regulate of cell growth. This regulation is achieved in a number of ways. First, mTOR influences translation of mRNA by stimulating ribosomal recruitment. mTOR activates eukaryotic translation initiation factor 4E (eIF4E,) by phosphorylation of its repressor, eIF4E binding protein 1(4EBP1.) Additionally, mTOR phosphorylates S6 kinase proteins (S6K,) which activates ribosomal protein S6 (rpS6), which promotes translation of mRNA that encodes for many components of ribosomal translation machinery (Hay and Sonenberg, 2004). Ultimately, mTOR stimulates cell growth by increasing transcription, which leads to an increase in protein synthesis.

\section{Tissue distribution and Cellular Localization}

mTOR is ubiquitous across tissues, and has been extensively studied in many tissues including myoblasts, fibroblasts (Drenan et al., 2004), adipocytes (Pham et al., 2000) and many other cell types. mTOR is predominantly localized to the endoplasmic reticulum

and the golgi apparatus. However, mTOR has been shown to relocate to the cytoplasm or nuclear membrane in response to different inputs such as feedback of downstream 
effectors. This translocation may play a role in regulating availability of TOR complexes for ribosome biogenesis (Drenan et al., 2004).

\section{Regulation}

mTOR is a signaling cascade for cell growth that is stimulated by several metabolic substrates and growth factors.

Insulin and insulin-like growth factor (IGF) both effectively stimulate mTOR function through the same cascade. They bind at the membrane growth factor receptor, and induce intracellular recruitment and phosphorylation of insulin receptor substrate (IRS.) IRS then recruits phosphoinositidine-3-kinase (PI3K) to the plasma membrane, where PI3K produces the second messenger phosphatidylinositol-3,4,5-triphosphate (PIP3.) PIP3 recruits phosphoinositidine-dependent kinase-1 (PDK1) and Akt. PDK1 activates Akt, which, when activated, phosphorylates tuberous sclerosis 2 (TSC2) and proline rich Akt substrate 40 (PRAS40,) which, when dephosphorylated, inhibit mTORC1 (Hall, 2008). Additionally, decreased Akt phosphorylation stimulates Forkhead Box Protein O1 (FOXO), which stimulates Atrogin-1, ultimately increasing protein degradation.

Inadequate cellular energy status ultimately inhibits mTOR function. High AMP/ATP ratios activate adenosine monophosphate-activated protein kinase (AMPK,) which is responsible for restoring cellular energy levels by inhibiting costly synthetic pathways. In the case of mTOR, AMPK phosphorylates TSC2, which then inhibits Rheb, 
which has the net effect of inhibiting mTORC1. Additionally, AMPK directly phosphorylates and inactivates the raptor subunit of mTORC1(Hall, 2008).

Nutrients appear to be the most influential inputs for the TOR pathway, as amino acids can stimulate mTORC1 in the absence of other pathway stimulants, such as insulin, but the absence of amino acids prevents function of mTORC1. Therefore, amino acids play a sort of rate limiting role in the flow of the mTOR pathway. Although amino acid availability appears to be a crucial point of regulation, the mechanism it employs has not yet been well described (Hall, 2008). It is suggested that the pathway involves vascular protein-sorting-associated protein 34 (VPS34) interaction with Ras related GTP binding protein (Rag) which translocates to influence mTOR function (Laplante and Sabatini, 2009). 
Figure 2.4 Schematic representation of proteins of interest in the mTOR pathway

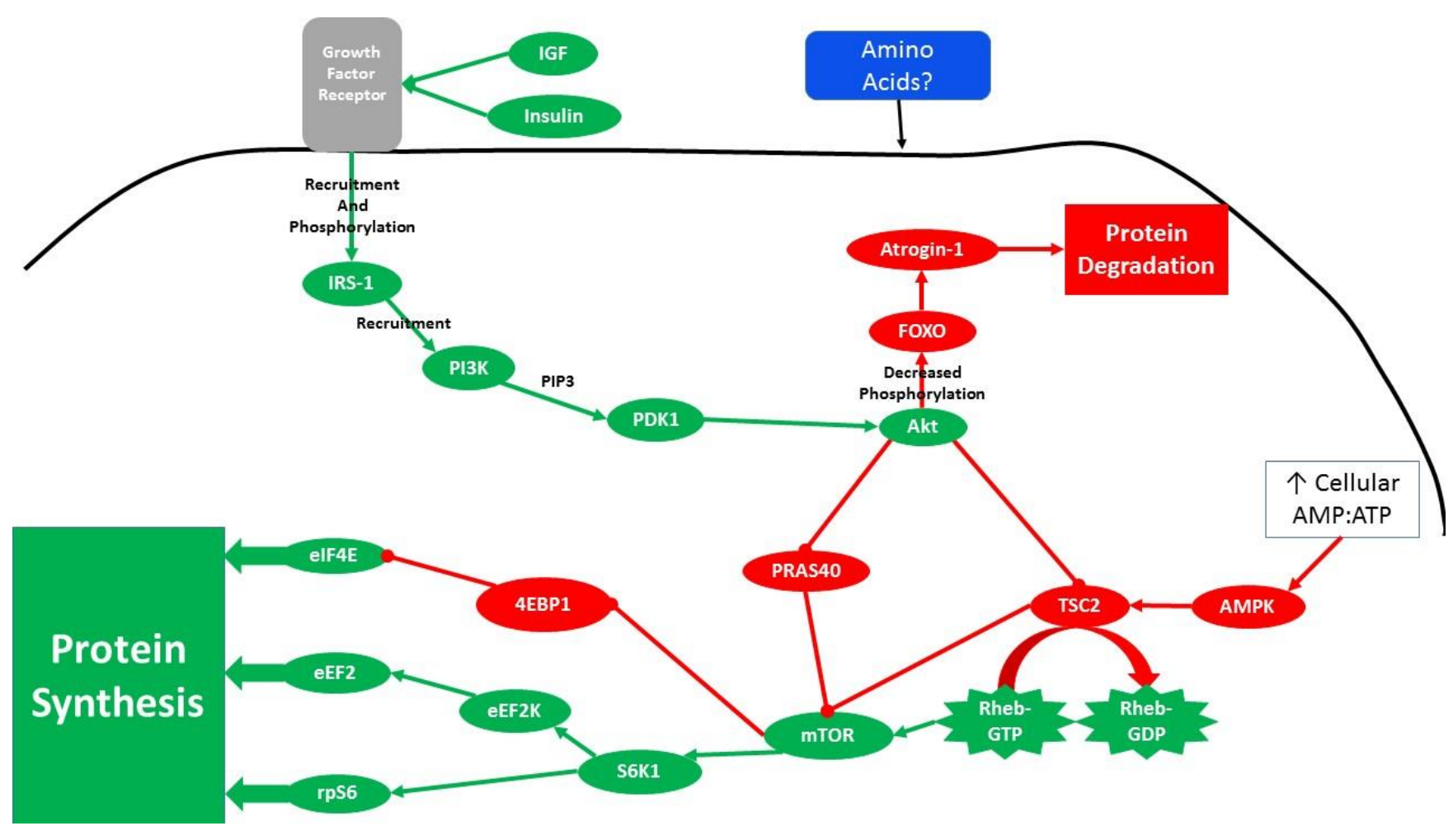




\section{Equine Research on Protein Synthesis and Degradation Signaling}

Although there has been extensive research on the mTOR pathway in food animals, the amount of research in horses is significantly smaller, and in much earlier stages than in other animals. With respect to stimulants of the mTOR pathway in horses, one study examined the effects of refeeding after an 18-hour feed withholding on the phosphorylation of proteins in the mTOR pathway. This study found a significant increase in phosphorylation of rpS6 and 4EBP1 after refeeding. Therefore, it was concluded that feeding resulted in stimulation of the mTOR pathway independent of Akt phosphorylation, and that dietary amino acids seemed to be the main stimulator of these effects (Urschel et al., 2011). Additionally, an insulin clamp study that included biopsies of the gluteus showed that insulin administration increased phosphorylation of Akt, 4EBP1, and rpS6 at all observed rates of infusion $(1.2 \mathrm{mU} / \mathrm{kg} / \mathrm{min}, 3 \mathrm{mU} / \mathrm{kg} / \mathrm{min}$, and 6 $\mathrm{mU} / \mathrm{kg} / \mathrm{min}$.) This data suggests anabolic effects of insulin on muscle in horses via mTOR signaling (Urschel et al., 2014).

There has also been some research on the effect of developmental stage on mTOR pathway proteins. One study examined the effect of stage of development on mTOR protein responsiveness. The study used six yearlings, six two-year-old horses and six mature horses, and examined the effect of refeeding on phosphorylation of Akt, S6K1, rpS6 and 4EBP1. The study found a significant increase in phosphorylation of all proteins after refeeding, but also found that yearlings had the most responsive phosphorylation of proteins, suggesting that the increased muscle protein synthesis observed during growth could be resultant from increased rates of muscle protein synthesis following consumption of a meal (Wagner and Urschel, 2012). Additionally, in a study that 
compared protein metabolism between mature (7-14 years) and aged horses (22-26 years,) no difference was found between the age groups in phosphorylation of Akt, rpS6, or 4EBP1. There was significantly lower phosphorylation of S6K in aged horses, but it could not be concluded that the observed decrease in phosphorylation of S6K resulted in a decrease in muscle protein synthesis, because there were not significant differences in whole-body protein kinetics between the two age groups (Wagner et al., 2013).

Finally, there is data that suggests an effect of exercise on expression of a number of proteins, including some of those that comprise the mTOR pathway. Data showed an increase in expression of four unspecified genes related to the mTOR signaling pathway during recovery from exercise in thoroughbreds. The effect of exercise on gene expression was found to be most prominent four hours after exercise as compared to immediately after exercise. This data suggests mTOR as one of a number of pathways that contribute to improved skeletal muscle integrity and hypertrophy in response to exercise in horses (McGivney et al., 2009).

Some data in humans suggests that muscle protein synthesis in response to anabolic stimulus may be delayed in older subjects (Drummond et al., 2008). However, the mechanism of this delay has yet to be elucidated, as regulation of protein synthesis is governed by many undefined factors both at the post-transcriptional level (Zacharewicz et al., 2014), as well as upstream of transcription. However, as previously mentioned supplementation with additional protein has not consistently been shown to improve measures of protein synthesis (Campbell et al., 2008; Rafii et al., 2015). 


\section{Conclusion}

Current recommendations for protein and lysine intakes are the result of data derived from nitrogen balance studies, and linear regression of data to estimate the lysine and crude protein requirements. However, as the focus of equine research has shifted from examination of protein requirements, to examining specific amino acid requirements, there are many questions left to be answered. New techniques have given us the ability to study the effect of feeding different levels of proposed limiting amino acids on whole-body protein metabolism, muscle mass, and regulation of muscle protein metabolism. With more sensitive methods, we can now explore the possible benefits of supplementing individual amino acids in aged animals, which are known to experience sarcopenia. 


\section{Chapter 3. Rationale and Objectives}

\section{Rationale}

Relatively little is known about the amino acid requirements of horses, and there is currently no data examining the amino acid requirements of aged horses specifically. Since aged horses (>20 years old) now comprise approximately $7 \%$ of the equine population in the United States (APHIS, 2005), there is an appreciable population of aged horses whose requirements have not been extensively explored. However, aged horses, like other aged animals, may exhibit muscle wasting as an effect of sarcopenia. The muscle mass and integrity loss associated with sarcopenia has the potential to be particularly detrimental to aged horses, who are often still athletically active, and may therefore be more at risk of injury.

The observed muscle mass loss associated with sarcopenia results from an imbalance in the rates of muscle protein synthesis and muscle protein degradation, which ultimately cause a net loss of muscle mass (Combaret et al., 2009; Koopman and van Loon, 2009; Marcell, 2003). The rates of muscle protein synthesis and degradation are influenced by several factors, including nutritional factors such as insulin levels and the presence of amino acids.

In a previous study examining the effects of amino acid supplementation in aged horses (Graham-Thiers and Kronfeld, 2005), animals were fed a grass forage at a rate of $1.8 \% \mathrm{BW} / \mathrm{d}$ and a commercial concentrate at a rate of $0.5 \% \mathrm{BW} / \mathrm{d}$ for a total of 14 weeks. Treatments included a control diet without the supplementation of amino acids, and an experimental diet with additional lysine $(20 \mathrm{~g} / \mathrm{d})$ and threonine $(15 \mathrm{~g} / \mathrm{d})$. Subjects were grouped by age, including a young group ( $\sim 10$ years) and an old group ( 20 years). 
Results showed that supplementation of amino acids improved visual muscle scores and decreased circulating PUN and 3MH concentrations in horses of both age groups. While this study addressed some indicators of dietary protein utilization such as PUN and $3 \mathrm{MH}$, it did not examine more robust measures of protein metabolism such as nitrogen balance, whole-body rates of protein synthesis and breakdown, or the signaling pathway associated with muscle protein synthesis. Therefore, it is unclear what improvements in protein metabolism caused improvements in the measured variables. Furthermore, the treatments used in the previous study were not isonitrogenous and therefore we cannot conclude that the improvements observed were not simply due to the intake of additional nitrogen.

\section{Objectives}

The aim of this study was to expand on the research done by Graham-Thiers and Kronfeld in 2005 by taking more robust measures of protein utilization and metabolism. Therefore, the current study used similar treatments, in addition to adding a diet that was supplemented with lysine, threonine and methionine, as methionine has been identified as the second or third limiting amino acid in other livestock species (Richardson and Hatfield, 1978; Boisen et al., 2000).

The objective of this study was to determine the effects of lysine and threonine (LYS/THR) or lysine, threonine and methionine (LYS/THR/MET) supplementation in aged horses by measuring indicators of whole-body protein utilization including plasma urea and amino acid concentrations, nitrogen balance, creatinine concentrations, whole- 
body phenylalanine kinetics and the activation of proteins associated with synthesis and degradation signaling.

\section{Chapter 4. Materials and Methods}

\section{Animals, Housing and Feeding}

Six aged horses were obtained from Maine Chance Farm at the University of Kentucky. At the beginning of the study, horses weighed an average of $560 \pm 40 \mathrm{~kg}$, and had an average body condition score of 5.75 (Henneke body condition scoring scale). Horses were aged ( $20 \pm 1.1$ years) and included three mares and three geldings. Breeds included four Thoroughbreds, one Quarter Horse, and one Standardbred. Before the start of adaptation, horses were kept in a pasture where they had ad libitum access to grass. Horses underwent an initial adaptation to stalls, paddocks and hay cubes for approximately 2 weeks before the initiation of the experimental treatments and sample collection protocols. During the day, horses were turned out into a paddock together wearing grazing muzzles to prevent grass consumption. Horses were individually fed and housed overnight and during collection procedures in $3.6 \mathrm{~m}$ x $3.6 \mathrm{~m}$ stalls. Weights were measured using an electronic scale (TI-500, Transcell Technology Inc., Buffalo Grove, IL) on days $0,4,9$ and 14 of each experimental period, and feed quantity offered was adjusted accordingly, as described below. The protocol was approved by a University of Kentucky Institutional Animal Care and Use Committee before the start of collection procedures. 


\section{Experimental Treatments and Diets}

The experimental treatments included a control (CON) treatment concentrate, a concentrate supplemented with lysine and threonine (LYS/THR) and a concentrate supplemented with lysine, threonine, and methionine (LYS/THR/MET). Horses received each of the experimental treatments in a replicated Latin square design. All three diets were designed to meet or slightly exceed nutrient requirements for mature horses at maintenance (NRC, 2007). Horses were fed half of the daily intake of both hay and concentrate at 7:30 am and the remainder was fed at 2:30 pm. Feed refusals from the previous day's meals were collected directly before offering the next morning's meal. For all three treatments, timothy hay cubes (Timothy Balance Cubes, Guelph, Canada; Table $4.1 \&$ Table 4.2 ) were offered at a rate of $1.8 \%$ body weight per day. The three experimental concentrates (Table 4.1, 4.2, 4.3) were designed to be isocaloric and isonitrogenous, and were kept isonitrogenous by altering the ratios of soybean hulls and wheat middlings (Table 4.3). Concentrates were offered at $0.5 \%$ of body weight per day. Experimental concentrates included a control diet (CON), LYS/THR which was designed to be nutritionally similar to CON but supplemented with lysine and threonine, and LYS/THR/MET which was designed to be nutritionally similar to CON but supplemented with lysine, threonine and methionine. The targeted levels of supplementation were $40 \mathrm{mg} / \mathrm{kg} \mathrm{BW} / \mathrm{d}$ of lysine, $30 \mathrm{mg} / \mathrm{kg} \mathrm{BW} / \mathrm{d}$ of threonine and 10 $\mathrm{mg} / \mathrm{kg} \mathrm{BW} / \mathrm{d}$ of methionine above CON intakes (Table 4.2). Feed samples were collected on d 15 of each sampling period and sent to DairyOne (Ithaca, NY, USA) for proximate analysis. Amino acid compositions of the feeds were analyzed using HPLC (see "Analysis" section for further description of methods). 
Table 4.1 As-fed nutrient composition of feeds ${ }^{1}$

\begin{tabular}{|c|c|c|c|c|}
\hline & $\begin{array}{l}\text { Timothy } \\
\text { hay cubes }\end{array}$ & $\mathrm{CON}$ & LYS/THR & $\begin{array}{l}\text { LYS/THR/ } \\
\text { MET }\end{array}$ \\
\hline Dry matter (\%) & $92.00 \pm 0.4$ & $90.50 \pm 0.2$ & $90.40 \pm 0.7$ & $90.30 \pm 0.1$ \\
\hline Digestible energy (Mcal/kg) & $1.78 \pm 0.04$ & $2.31 \pm 0.01$ & $2.24 \pm 0.02$ & $2.21 \pm 0.0$ \\
\hline Crude protein (\%) & $11.1 \pm 0.3$ & $12.1 \pm 0.2$ & $12.2 \pm 0.1$ & $12.3 \pm 0.2$ \\
\hline Acid detergent fiber (\%) & $38.5 \pm 1.1$ & $23.9 \pm 0.4$ & $27.8 \pm 1.0$ & $28.4 \pm 0.2$ \\
\hline Neutral detergent fiber $(\%)$ & $55.0 \pm 0.8$ & $40.7 \pm 1.0$ & $42.9 \pm 0.6$ & $43.1 \pm 0.5$ \\
\hline Water soluble carbohydrates (\%) & $5.2 \pm 0.5$ & $4.1 \pm 0.5$ & $3.3 \pm 0.3$ & $3.3 \pm 0.2$ \\
\hline Ether soluble carbohydrates (\%) & $3.9 \pm 0.9$ & $2.9 \pm 0.1$ & $2.7 \pm 0.6$ & $2.6 \pm 0.8$ \\
\hline Starch (\%) & $0.7 \pm 0.2$ & $13.8 \pm 0.9$ & $11.3 \pm 0.6$ & $10.9 \pm 0.6$ \\
\hline Crude Fat (\%) & $1.1 \pm 0.3$ & $3.2 \pm 0.1$ & $3.7 \pm 0.8$ & $3.0 \pm 0.1$ \\
\hline $\operatorname{Ash}(\%)$ & $9.2 \pm 0.1$ & $6.8 \pm 0.1$ & $7.0 \pm 0.2$ & $6.8 \pm 0.3$ \\
\hline Calcium (\%) & $0.74 \pm 0.01$ & $1.03 \pm 0.04$ & $0.98 \pm 0.05$ & $1.00 \pm 0.05$ \\
\hline Phosphorus (\%) & $0.21 \pm 0.02$ & $0.58 \pm 0.01$ & $0.52 \pm 0.01$ & $0.52 \pm 0.03$ \\
\hline Magnesium (\%) & $0.31 \pm 0.02$ & $0.35 \pm 0.01$ & $0.32 \pm 0.01$ & $0.33 \pm 0.01$ \\
\hline Potassium (\%) & $1.73 \pm 0.13$ & $0.96 \pm 0.01$ & $0.92 \pm 0.01$ & $0.93 \pm 0.00$ \\
\hline Sodium (\%) & $0.07 \pm 0.01$ & $0.18 \pm 0.02$ & $0.16 \pm 0.02$ & $0.15 \pm 0.02$ \\
\hline Chloride (\%) & $0.26 \pm 0.02$ & $0.41 \pm 0.05$ & $0.57 \pm 0.03$ & $0.58 \pm 0.06$ \\
\hline Sulfur (\%) & $0.19 \pm 0.01$ & $0.17 \pm 0.01$ & $0.17 \pm 0.01$ & $0.21 \pm 0.01$ \\
\hline Iron $(\mathrm{mg} / \mathrm{kg})$ & $291 \pm 13$ & $413 \pm 13$ & $475 \pm 5$ & $490 \pm 30$ \\
\hline
\end{tabular}

Table 4.1 Continued 


$\begin{array}{llllc}\text { Zinc (mg/kg) } & 110 \pm 21 & 165 \pm 7 & 151 \pm 5 & 170 \pm 8 \\ \text { Copper (mg/kg) } & 45 \pm 8 & 47 \pm 1 & 42 \pm 2 & 48 \pm 1 \\ \text { Manganese (mg/kg) } & 108 \pm 8 & 105 \pm 5 & 81 \pm 3 & 94 \pm 2 \\ \text { Molybdenum (mg/kg) } & 0.83 \pm 0.12 & 1.47 \pm 0.23 & 1.10 \pm 0 & 1.10 \pm 0.10 \\ \text { Cobalt (mg/kg) } & 0.51 \pm 0.17 & 1.93 \pm 0.17 & 1.66 \pm 0.04 & 1.92 \pm 0.11\end{array}$

${ }^{1}$ Values are mean \pm standard deviation of 3 samples measured in duplicate. 
Table 4.2 As-fed amino acid composition of feeds ${ }^{1}$

\begin{tabular}{|c|c|c|c|c|}
\hline & $\begin{array}{l}\text { Timothy } \\
\text { hay cubes }\end{array}$ & $\mathrm{CON}$ & LYS/THR & LYS/THR/MET \\
\hline Alanine (\%) & $0.49 \pm 0.08$ & $0.44 \pm 0.04$ & $0.42 \pm 0.03$ & $0.40 \pm 0.00$ \\
\hline Arginine (\%) & $0.50 \pm 0.04$ & $0.62 \pm 0.07$ & $0.57 \pm 0.05$ & $0.54 \pm 0.01$ \\
\hline Aspartate + & $0.73 \pm 0.15$ & $0.67 \pm 0.06$ & $0.65 \pm 0.06$ & $0.64 \pm 0.03$ \\
\hline Asparagine (\%) & & & & \\
\hline $\begin{array}{l}\text { Glutamate + } \\
\text { Glutamine (\%) }\end{array}$ & $1.04 \pm 0.20$ & $1.58 \pm 0.20$ & $1.43 \pm 0.11$ & $1.35 \pm 0.04$ \\
\hline Glycine (\%) & $0.43 \pm 0.06$ & $0.53 \pm 0.03$ & $0.54 \pm 0.02$ & $0.51 \pm 0.02$ \\
\hline Histidine (\%) & $0.21 \pm 0.04$ & $0.27 \pm 0.03$ & $0.25 \pm 0.03$ & $0.24 \pm 0.02$ \\
\hline Isoleucine (\%) & $0.41 \pm 0.05$ & $0.38 \pm 0.04$ & $0.34 \pm 0.06$ & $0.31 \pm 0.05$ \\
\hline Leucine (\%) & $0.69 \pm 0.09$ & $0.66 \pm 0.05$ & $0.63 \pm 0.05$ & $0.59 \pm 0.01$ \\
\hline Lysine (\%) & $0.43 \pm 0.03$ & $0.46 \pm 0.03$ & $1.14 \pm 0.06$ & $1.10 \pm 0.05$ \\
\hline Methionine (\%) & $0.22 \pm 0.02$ & $0.21 \pm 0.01$ & $0.24 \pm 0.02$ & $0.41 \pm 0.03$ \\
\hline Phenylalanine (\%) & $0.47 \pm 0.06$ & $0.44 \pm 0.06$ & $0.40 \pm 0.06$ & $0.38 \pm 0.03$ \\
\hline Proline (\%) & $0.62 \pm 0.19$ & $0.56 \pm 0.05$ & $0.53 \pm 0.05$ & $0.50 \pm 0.04$ \\
\hline Serine $(\%)$ & $0.40 \pm 0.02$ & $0.42 \pm 0.09$ & $0.46 \pm 0.06$ & $0.45 \pm 0.06$ \\
\hline Threonine (\%) & $0.38 \pm 0.03$ & $0.32 \pm 0.05$ & $0.83 \pm 0.09$ & $0.88 \pm 0.11$ \\
\hline Tyrosine (\%) & $0.29 \pm 0.02$ & $0.33 \pm 0.01$ & $0.33 \pm 0.02$ & $0.32 \pm 0.01$ \\
\hline Valine (\%) & $0.52 \pm 0.08$ & $0.49 \pm 0.05$ & $0.43 \pm 0.08$ & $0.40 \pm 0.05$ \\
\hline
\end{tabular}

${ }^{1}$ Values are mean \pm standard deviation of 3 samples. 
Table 4.3 As-fed composition of experimental concentrates 1 , \%

\begin{tabular}{|c|c|c|c|}
\hline Ingredient & CON & LYS/THR & LYS/THR/MET \\
\hline Wheat middlings & 34.7 & 19.0 & 16.3 \\
\hline Soybean hulls & 32.3 & 45.6 & 48.1 \\
\hline Ground oats & 25.0 & 25.0 & 25.0 \\
\hline Dehydrated alfalfa (17\%) & 3.75 & 3.75 & 3.75 \\
\hline Limestone & 1.70 & 1.35 & 1.25 \\
\hline Soybean oil & 1.00 & 1.30 & 1.30 \\
\hline Biofos $^{2}$ & 0.60 & 1.20 & 1.30 \\
\hline Salt & 0.50 & 0.50 & 0.50 \\
\hline Horse Vitamin Premix ${ }^{3}$ & 0.25 & 0.25 & 0.25 \\
\hline Magnesium oxide & 0.15 & 0.20 & 0.20 \\
\hline Horse Trace Mineral & 0.10 & 0.10 & 0.10 \\
\hline \multicolumn{4}{|l|}{ Premix ${ }^{4}$} \\
\hline Selenium & 0.03 & 0.03 & 0.03 \\
\hline L - Lysine - HCl (98\%) & 0.000 & 1.035 & 1.035 \\
\hline L - Threonine (98\%) & 0.000 & 0.675 & 0.680 \\
\hline DL - Methionine DL (99\%) & 0.000 & 0.013 & 0.245 \\
\hline
\end{tabular}

${ }^{1}$ Values are expressed as a percentage of the concentrate

${ }^{2}$ Monocalcium phosphate

${ }^{3}$ Contains vitamin $\mathrm{A}$, vitamin $\mathrm{E}$, vitamin $\mathrm{D}$, vitamin $\mathrm{K}$, choline, biotin, folic acid, riboflavin, pantothenic acid, niacin, vitamin $\mathrm{B}_{12}$, pyroxidine and thiamin

${ }^{4}$ Contains zinc, manganese, copper, iodine, and cobalt 
Table 4.4 Nutrient intakes for each of the experimental treatment groups ${ }^{1}$

\begin{tabular}{|c|c|c|c|}
\hline & $\mathrm{CON}$ & LYS/THR & LYS/THR/MET \\
\hline Dry Matter $\left(\mathrm{g} / \mathrm{kg} \mathrm{BW} \mathbf{H}^{*} \mathrm{~d}\right)$ & 21.1 & 21.1 & 21.1 \\
\hline Acid Detergent Fiber (g/kg BW*d) & 8.1 & 8.3 & 8.4 \\
\hline Neutral Detergent Fiber (g/kg BW * d) & 11.9 & 12.0 & 12.1 \\
\hline Digestible Energy (Mcal/kg BW*d) & 0.044 & 0.043 & 0.043 \\
\hline Crude Protein (g/kg BW*d) & 2.6 & 2.6 & 2.6 \\
\hline Calcium (mg/kg BW*d) & 184.7 & 182.2 & 183.2 \\
\hline Phosphorus (mg/kg BW*d) & 66.8 & 63.8 & 63.8 \\
\hline Lysine (mg/kg BW*d) & 100 & 134 & 132 \\
\hline Threonine (mg/kg BW*d) & 84 & 110 & 112 \\
\hline Methionine (mg/kg BW*d) & 51 & 52 & 62 \\
\hline Alanine (mg/kg BW*d) & 110 & 109 & 108 \\
\hline Arginine (mg/kg BW*d) & 120 & 118 & 116 \\
\hline Aspartate + Asparagine (mg/kg BW*d) & 164 & 163 & 163 \\
\hline Glutamate + Glutamine $(\mathrm{mg} / \mathrm{kg} \mathrm{BW} * \mathrm{~d})$ & 266 & 258 & 255 \\
\hline Glycine (mg/kg BW*d) & 104 & 105 & 103 \\
\hline Histidine (mg/kg BW*d) & 51 & 50 & 50 \\
\hline Isoleucine (mg/kg BW*d) & 92 & 90 & 89 \\
\hline Leucine (mg/kg BW*d) & 158 & 156 & 154 \\
\hline Phenylalanine (mg/kg BW*d) & 106 & 104 & 103 \\
\hline Proline (mg/kg BW*d) & 139 & 137 & 136 \\
\hline
\end{tabular}


Table 4.4 Continued

Serine $\left(\mathrm{mg} / \mathrm{kg} \mathrm{BW}{ }^{*} \mathrm{~d}\right)$

93

96

95

Tyrosine (mg/kg BW*d)

68

68

68

Valine (mg/kg BW*d)

119

116

114

${ }^{1}$ Daily intakes were calculated based on daily intakes of $1.8 \% \mathrm{BW} / \mathrm{d}$ of forage and $0.5 \% \mathrm{BW} / \mathrm{d}$ of the respective concentrate. 


\section{Experimental Design}

Horses were assigned to receive each of the experimental treatments in a replicated Latin square design, and were studied for a total of 15 days for each treatment. Each period included 9 days of adaptation (d 0-9) to the diet. Adaptation was followed by three days of total urine and feces collection for determination of nitrogen balance and urinary creatinine output (d 10-12). Pre- and post- feeding blood collection was conducted on d 12 for determination of plasma glucose, insulin, plasma urea nitrogen (PUN), creatinine, and amino acid concentrations. Muscle biopsy samples of the gluteus medius were taken before (d 13) and after (d 14) consuming a meal on d 14 for determination of the relative abundances of proteins associated with the mTOR pathway (Akt, rpS6 (ribosomal protein S6), AMPK (AMP-activated protein kinase) and Atrogin1). A primed, constant isotope infusion of $\left[1-{ }^{13} \mathrm{C}\right]$ phenylalalnine was conducted on $\mathrm{d} 15$ for estimation of whole body protein synthesis and degradation.

\section{Sample Collection}

\section{Urine and Feces Collection}

At 6:30 am on d 10, horses were fitted with total urine and feces collection harnesses (Equisan Nappy, South Melbourne, Australia) and urine and feces were collected every $4 \mathrm{~h}$ for $72 \mathrm{~h}$. Collection harnesses were modified to ensure complete collection of urine in females by creating funnels to ensure that urine output was channeled into the urine collection bag. Weight and volume of urine output, and weight of feces output was recorded at each $4 \mathrm{~h}$ collection. Urine was pooled over $24 \mathrm{~h}$ periods in air-tight containers stored at room temperature. After each $24 \mathrm{~h}$ period of collection, 
urine was homogenized by shaking and a $100 \mathrm{~mL}$ sub-sample of the $24 \mathrm{~h}$ pooled urine was collected. Urine sub-samples were stored in sterile, air-tight containers at $-20^{\circ} \mathrm{C}$ until further analysis. Feces were pooled over $24 \mathrm{~h}$ periods in 20 -gallon plastic bags stored at room temperature. After each $24 \mathrm{~h}$ period of collection, feces were homogenized by hand, and a $1 \mathrm{~kg}$ sub-sample of the $24 \mathrm{~h}$ pooled feces was collected. Fecal samples were stored in bags with round wire closure (Fisherbrand Bags with Round-Wire Closure, Fisher Scientific, Waltham, MA) at $-20^{\circ} \mathrm{C}$ until further analysis.

\section{Pre- and Post- Feeding Blood Samples}

On d 12 at 6:00, am horses were aseptically fitted with a jugular vein catheter (Hospira, Lake Forest, IL) and venous blood samples were taken 30 minutes (Figure 4.1) before the morning meal $(t=-30)$, directly before the morning meal $(t=0)$ and $30,60,90$, 120, 150, 180, 210 and 240 minutes after consuming the morning meal. Blood samples were collected into heparinized evacuated containers (BD, Franklin Lakes, NJ), and centrifuged at $1,500 \mathrm{x}$ g for 10 minutes at $4^{\circ} \mathrm{C}$. Plasma was collected and stored in microcentrifuge tubes at $-20^{\circ} \mathrm{C}$ until further analysis.

\section{Muscle Biopsies}

Muscle biopsies were collected on the mornings of d 13 and d 14 (Figure 4.1). On d 13 at 6:30am, after the final urine and feces collection, diapers were removed. Approximately ten minutes before the biopsy procedure was to be conducted, horses were sedated with a weight appropriate dose of xylazine $\mathrm{HCl}(1.1 \mathrm{mg} / \mathrm{kg} \mathrm{BW}$; AnaSed, 
Lloyd, Inc., Shenandoah, IA). Horses were placed in veterinary stocks and the biopsy area was desensitized subcutaneously with $3 \mathrm{~mL}$ of lidocaine, and intramuscularly to a depth of 1.5 inches with $10 \mathrm{~mL}$ of lidocaine (Lidoject, Butler Schein Animal Health, Dublin, $\mathrm{OH})$. The lidocaine was allowed to take effect for approximately 2 min and then a muscle sample was taken from the gluteus medius using a Bergstrom needle as previously described (Urschel et al., 2011). After the biopsy procedure was complete, the incision site was closed with a single stitch. Horses were given $2 \mathrm{~g}$ of phenylbutazone, allowed to recover from sedation, and were then fed their morning meals. On the morning of d 14 horses were fed their morning meal at 7:30 am. Horses consumed their morning concentrate within 30 minutes, and were offered their hay cubes after finishing their concentrate. Approximately 90 minutes after beginning the morning meal, biopsy procedures began. Biopsy procedures for $\mathrm{d} 14$ were identical to those of $\mathrm{d} 13$, except that samples were taken from the opposite side of the horse. Muscle samples were homogenized in $7 \mu \mathrm{L}$ of homogenization buffer (20mM HEPES, 2mM EGTA, 50mM sodium fluoride, $100 \mathrm{mM}$ potassium chloride, $0.2 \mathrm{mM}$ EDTA, and $50 \mathrm{mM} \beta$ -

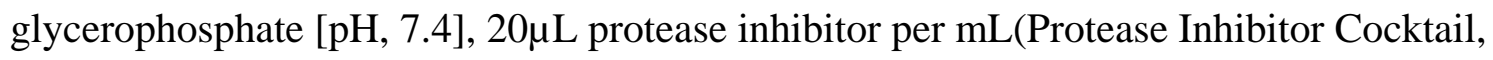
Sigma Aldrich, St. Louis, MO)), per mg of wet tissue as previously described (Wagner and Urschel, 2012) and stored in microcentrifuge tubes at $-80^{\circ} \mathrm{C}$ until further analysis.

\section{Stable Isotope Infusion Procedures}

During stable isotope infusion procedures, isotopic sodium bicarbonate was infused at a constant rate, and isotopic $\mathrm{CO}_{2}$ was measured in breath samples to estimate total $\mathrm{CO}_{2}$ production (Urschel et al., 2009). Then, isotopic phenylalanine was 
administered orally, and isotopic $\mathrm{CO}_{2}$ production from phenylalanine, in conjunction with total $\mathrm{CO}_{2}$ production data was used to calculate the amount of phenylalanine oxidation occurring, which then enabled the estimation of phenylalanine use for protein synthesis.

At 6:00am on d 15, a catheter was placed in the jugular vein and stable isotope infusion procedures were conducted (Figure 4.1) as previously described (Tanner et al., 2014). Horses were kept in a steady metabolic state for the entirety of the isotope infusion procedures by feeding small portions of the daily meal every 30 minutes (Urschel et al., 2012). At approximately 7:00 am horses were fed $3 / 48$ of their daily meal ( $t=-90 \mathrm{BC})$, and 30 minutes later horses were fed $1 / 48$ of their daily meal ( $\mathrm{t}=-60 \mathrm{BC}$ ) to begin maintenance of the metabolic steady state. Thirty minutes $(\mathrm{t}=-30 \mathrm{BC})$ before beginning $\left[{ }^{13} \mathrm{C}\right]$ sodium bicarbonate infusion a baseline blood and breath sample were taken, and horses were then fed $1 / 48^{\text {th }}$ their daily meal. Breath samples were collected into gas impermeable bags, and blood samples were collected into evacuated heparinized containers. Fifteen minutes before $(\mathrm{t}=-15 \mathrm{BC})\left[{ }^{13} \mathrm{C}\right]$ sodium bicarbonate infusion, additional baseline breath and blood samples were taken. $\left[{ }^{13} \mathrm{C}\right]$ sodium bicarbonate isotope was infused directly into the jugular vein catheter. Bicarbonate was administered as a $5.3 \mu \mathrm{mol} / \mathrm{kg}$ prime dose given immediately before beginning constant infusion, and then infused at a rate of $4.4 \mu \mathrm{mol} / \mathrm{kg} / \mathrm{h}$ using cordless infusion pumps. Breath samples were collected 30 and 15 minutes before the beginning of $\left[{ }^{13} \mathrm{C}\right]$ sodium bicarbonate infusion, and at 30, 60, 75, 90, 105 and 120 minutes of $\left[{ }^{13} \mathrm{C}\right]$ sodium bicarbonate infusion. $1 / 48^{\text {th }}$ of the meal was given every 30 minutes during $\left[{ }^{13} \mathrm{C}\right]$ sodium bicarbonate infusion. 
After two hours of $\left[{ }^{13} \mathrm{C}\right]$ sodium bicarbonate infusion, infusion pumps were removed and $\left[1-{ }^{13} \mathrm{C}\right]$ phenylalanine administration began.

Prime and constant doses of $\left[1-{ }^{13} \mathrm{C}\right]$ phenylalanine administration were previously validated (Mastellar et al., 2016a). [1- $\left.{ }^{13} \mathrm{C}\right]$ phenylalanine isotope was given as a 10.3 $\mu \mathrm{mol} / \mathrm{kg}$ prime dose and at a rate of $3.6 \mu \mathrm{mol} / \mathrm{kg}$ each half hour for constant infusion. The prime dose of $\left[1-{ }^{13} \mathrm{C}\right]$ phenylalanine was included with the first constant dose at the beginning of $\left[1-{ }^{13} \mathrm{C}\right]$ phenylalanine infusion. $\left[1-{ }^{13} \mathrm{C}\right]$ phenylalanine constant infusion was achieved by top-dressing half the hourly dose of $\left[1-{ }^{13} \mathrm{C}\right]$ phenylalanine on $1 / 48^{\text {th }}$ of the daily meal. Meals were administered every 30 minutes directly following collection of a breath and a blood sample. Horses generally readily consumed meals, and any feed refusals were weighed and re-fed with the following meal. $\left[1-{ }^{13} \mathrm{C}\right]$ phenylalanine was administered and samples were collected for four hours.

Breath samples were analyzed on the day they were collected for the ratio of ${ }^{13} \mathrm{CO}_{2}:{ }^{12} \mathrm{CO}_{2}$ using a non-dispersive infrared isotope analyzer (IRIS-3, Wagner Analysen Technik Vetriebs GmbH, Bremen, Germany). Blood samples were centrifuged at 1,500 x g for 10 minutes at $4^{\circ} \mathrm{C}$, and then plasma was collected and stored at $-20{ }^{\circ} \mathrm{C}$ until further analysis. 
Figure 4.1 Sampling timeline for collection of pre/post fed blood samples, muscle biopsies, and stable isotope infusion samples.

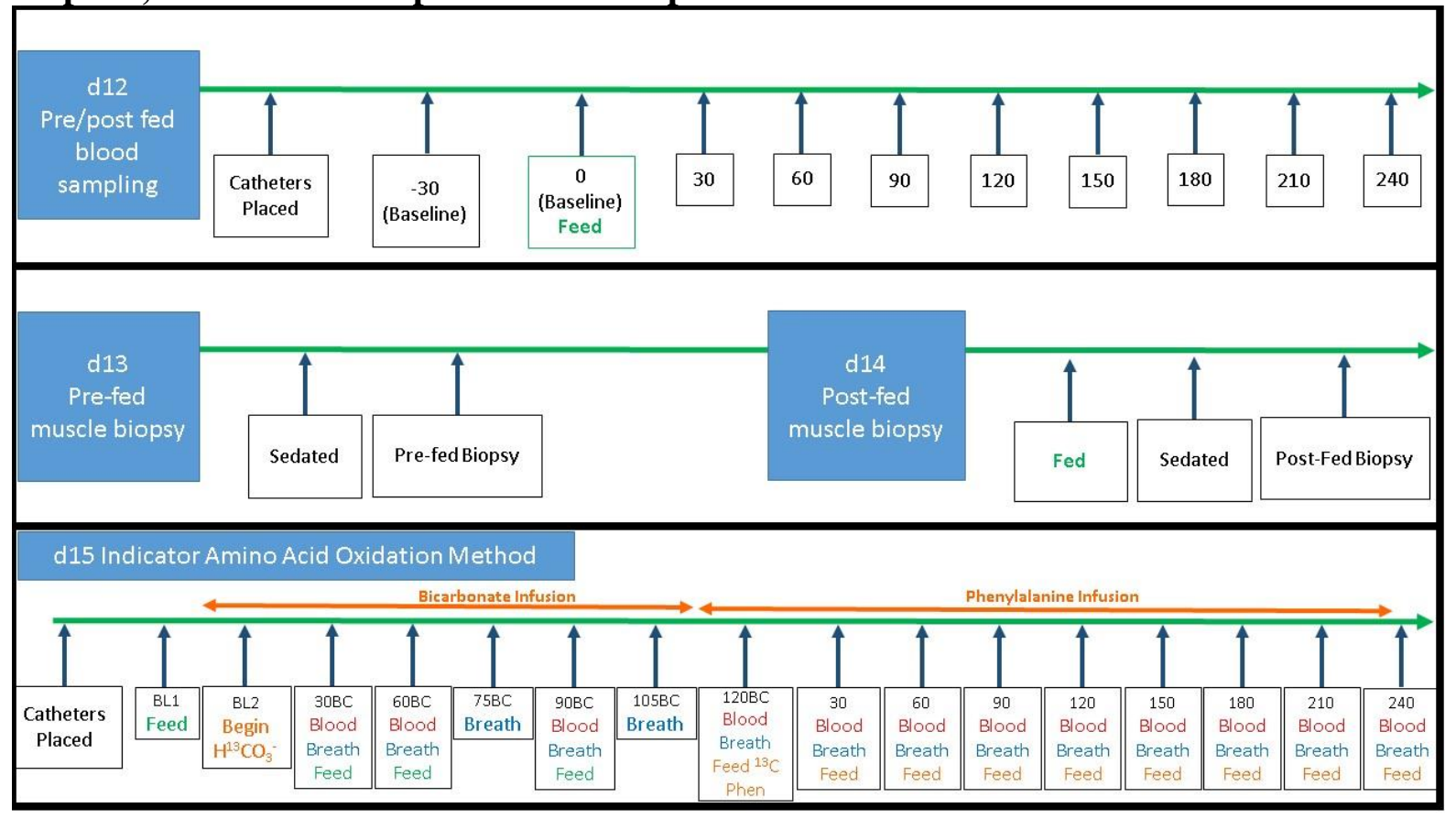




\section{Laboratory Analysis and Calculations}

\section{Feed Amino Acids}

Feed samples were ground to particles smaller than $1 \mathrm{~mm}$, and subjected to acid hydrolysis in $6 \mathrm{M} \mathrm{HCl}$ (AOAC method 994). Briefly, $300 \mu \mathrm{L}$ of $100 \mathrm{mM}$ norleucine was added to $0.2 \mathrm{~g}$ of feed sample as an internal standard. $12 \mathrm{~mL}$ of $6 \mathrm{M} \mathrm{HCl}$ was added to the tube, the tubes were purged with $\mathrm{N}_{2}$ gas, and were heated for 24 hours at $110^{\circ} \mathrm{C}$. For the determination of feed methionine levels, feed samples first underwent performic acid oxidation procedures prior to acid hydrolysis procedures (AOAC method 994).

Phenylisothiocyanate derivatives of the samples were prepared as previously described (Urschel et al., 2011) and were analyzed by reverse phase HPLC $(3.9 \times 300 \mathrm{~mm}$ PICOTAG reverse phase column, Waters, Milford, MA). Briefly, samples were filtered through $\mu \mathrm{m}$ syringe filters and $25 \mu \mathrm{L}$ aliquots were dried and frozen. Samples were then re-dreid with trimethylamine, $1 \mathrm{M} \mathrm{NaAc}$, and methanol. Samples were derivatized with trimethylamine, phenyl isothiocyanate and methanol. Samples were then re-diluted with $100 \mu \mathrm{L}$ of buffer and loaded onto the HPLC. Concentrations of amino acids in the samples were estimated using crystalline amino acid standards that underwent the same derivitization process as feed samples. Feed sample amino acid analysis was run in duplicate on a sample from each period.

\section{Urine and Feces Samples}

The nitrogen content of the feeds, urine and feces samples were determined using an automated carbon/nitrogen analyzer (Elementar $\mathrm{C} / \mathrm{N}$ analyzer, Hanau, Germany). For 
analysis, $500 \mathrm{mg}$ feces, $500 \mathrm{mg}$ feed and $1 \mathrm{~g}$ urine were run in duplicate. Urine was acidified using $10 \%$ phosphoric acid such that the final $\mathrm{pH}$ of the sample was approximately 2. Nitrogen parameters were calculated as described in Table 4.5. Creatinine concentration was determined by enzymatic assay using a commercially available kit (Sigma Aldrich, St. Louis, MO) and analyzed by spectrophotometry in a 96 well plate at $570 \mathrm{~nm}$. 
Table 4.5 Calculation of nitrogen balance parameters

Parameter Calculation

Nitrogen absorbed

Nitrogen retained

Nitrogen absorbed as a percentage of intake

Nitrogen retained as a percentage of intake

Nitrogen retained as a percentage of absorbed
Nitrogen intake - nitrogen excretion in feces

Nitrogen intake - (Nitrogen excreted in urine + nitrogen excreted in feces)

(Nitrogen Absorbed/Nitrogen Intake)*100

(Nitrogen Retained/Nitrogen Intake)*100

(Nitrogen Retained/Nitrogen Absorbed)*100 


\section{Pre- and Post- Feeding Blood Samples}

Pre- and post- feeding blood samples were analyzed for plasma glucose, insulin, urea nitrogen, amino acids, and creatinine concentrations. Plasma glucose concentrations were determined by automated enzymatic assay using a YSI 2700 Select Analyzer (YSI Inc., Life Sciences, Yellow Springs, OH). Plasma insulin concentrations were determined using a Coat-A-Count radioimmunoassay kit (Siemens, Munich, Germany) that has previously been validated for use in horses (Tinworth et al., 2011). Plasma urea nitrogen concentrations were determined using a spectrophotometric assay, as described previously (Urschel et al., 2007). Plasma amino acid concentrations were determined via the HPLC analysis of the phenylisothiocyanate derivatives, as previously described (Urschel et al., 2011). Briefly, samples were deproteinized using 10K spin filters, and 50 $\mu \mathrm{L}$ aliquots were dried and frozen. Samples were then re-dreid with trimethylamine, $1 \mathrm{M}$ NaAc, and methanol. Samples were derivatized with trimethylamine, phenyl isothiocyanate and methanol. Samples were then re-diluted with $100 \mu \mathrm{L}$ of buffer and loaded onto the HPLC.

\section{Muscle Samples}

Muscle samples were analyzed for the abundance and activation (phosphorylation) of proteins associated with the regulation of muscle protein synthesis (Akt, rpS6, AMPK) and degradation (Atrogin-1), by Western Blotting based on previously described methods (Wagner and Urschel, 2012; Mastro et al., 2014). Protein content of the sample homogenate was determined by Bradford assay and samples were diluted in Laemmli buffer to achieve a protein concentration of $2 \mu \mathrm{g} / \mu \mathrm{L}$. Samples were 
loaded into polyacrylamide gels and separated by electrophoresis. All gels were run in duplicate. Protein bands were transferred to polyvinylidene diflouride membranes and stained using fastgreen stain $\left(0.1 \%\right.$ w/v Fast Green FCF, $50 \%$ methanol, $40 \% \mathrm{ddH}_{2} \mathrm{O}$, and $10 \%$ glacial acetic acid). Stained bands were quantified by densitometry using Quantity One computer software (Bio-Rad Laboratories, Hercules, CA). Membranes were then destained and blocked by incubating for ten minutes in $0.5 \%$ fat-free milk solution in the Snap i.d protein detection system (Millipore, Darmstadt, Germany). After 10 minutes, blocking solution was pulled through the membrane under suction and discarded. Membranes were incubated on Snap i.d. in primary antibody for the phosphorylated (active) protein and $0.5 \%$ fat free milk solution as indicated in Table 4.6, and then pulled through the membrane. 
Table 4.6 Primary antibody procedures for Western Blotting

\begin{tabular}{|c|c|c|}
\hline Protein & Dilution & Incubation Time \\
\hline P-Akt $\left(\operatorname{Ser}^{473}\right)$ & $1: 600$ & $\begin{array}{l}1 \mathrm{~h} \text { rocking in Snap i.d. at room } \\
\text { temperature }\end{array}$ \\
\hline Total Akt & $1: 600$ & $\begin{array}{l}1 \mathrm{~h} \text { rocking in Snap i.d. at room } \\
\text { temperature }\end{array}$ \\
\hline $\begin{array}{l}\text { P-rpS6 } \\
\left(\operatorname{Ser}^{235 / 236} \text { and }\right. \\
\left.\text { Ser }^{240 / 244}\right)\end{array}$ & $1: 1,200$ & $\begin{array}{l}1 \mathrm{~h} \text { rocking in Snap i.d. at room } \\
\text { temperature }\end{array}$ \\
\hline Total rpS6 & $1: 6,000$ & $\begin{array}{l}30 \text { minutes rocking in Snap i.d. at } \\
\text { room temperature }\end{array}$ \\
\hline P-AMPK(Thr $\left.{ }^{172}\right)$ & $1: 600$ & $\begin{array}{l}1 \mathrm{~h} \text { rocking in Snap i.d. at room } \\
\text { temperature }\end{array}$ \\
\hline Total AMPK & $1: 600$ & $\begin{array}{l}30 \text { minutes rocking in Snap i.d. at } \\
\text { room temperature }\end{array}$ \\
\hline Atrogin-1 & $1: 600$ & $\begin{array}{l}30 \text { minutes rocking in Snap i.d. at } \\
\text { room temperature }\end{array}$ \\
\hline$\alpha$-Tubulin & $1: 600$ & $\begin{array}{l}30 \text { minutes rocking in Snap i.d. at } \\
\text { room temperature }\end{array}$ \\
\hline
\end{tabular}


Membranes were then washed using Snap i.d., incubated with a goat anti-rabbit secondary antibody conjugated to horseradish peroxidase (Cell Signaling, Danvers, MA) for 20 minutes at room temperature, and washed again in Snap i.d. Membranes were developed with a chemiluminescent kit (ECL Prime Western Blotting Detection Kit, GE Healthcare) and developed by use of a film processor. Membranes were then stripped and re-probed with a second antibody to determine the total amount of the protein of interest. Only total abundance of Atrogin-1 was measured, and it was therefore standardized to $\alpha$ tubulin, which has been previously used as a total protein standardization in equine skeletal muscle samples (Tiley et al., 2008). Protein band densities were measured by densitometry using Quantity One software (Bio-Rad Laboratories, Hercules, CA). Final values are expressed in arbitrary units as a ratio of phosphorylated to total protein, and are corrected for differences in background by averaging the background density and for loading volume using band densities of fastgreen stain bands. The abundances of phosphorylated forms of Akt, rpS6, and AMPK were expressed as a ratio to density of the total protein bands and the abundance of Atrogin- 1 is expressed as a ratio to $\alpha$-tubulin to correct for total protein. The value for the pre-fed CON group was set at 1.0 arbitrary units, and values therefore reflect changes in abundances relative to the pre-fed CON group horses.

\section{Stable Isotope Infusion}

Breath samples from $\left[{ }^{13} \mathrm{C}\right]$ bicarbonate and $\left[{ }^{13} \mathrm{C}\right]$ phenylalanine infusion were analyzed on the day they were collected. Breath samples were analyzed for the ratio of ${ }^{13} \mathrm{CO}_{2}$ to ${ }^{12} \mathrm{CO}_{2}$ using an isotope ratio infrared spectrometer (IRIS-3; Wagner Analysen Technik Vetriebs GmbH, Bremen, Germany). 
Plasma samples were analyzed by Metabolic Solutions Inc. (Nashua, NH) for $\left[{ }^{13} \mathrm{C}\right]$ phenylalanine enrichment, as previously described (Wagner et al., 2013). The average enrichment of isotope at a steady state was calculated in breath samples taken during $\left[{ }^{13} \mathrm{C}\right]$ bicarbonate infusion and blood and breath samples taken during $\left[{ }^{13} \mathrm{C}\right]$ phenylalanine infusion (Table 4.6). $\mathrm{CO}_{2}$ production was calculated using breath samples taken during bicarbonate infusion at the plateau of ${ }^{13} \mathrm{CO}_{2}:{ }^{12} \mathrm{CO}_{2}$ (Table 4.7). Phenylalanine entering the free amino acid pool through intake was calculated based on the phenylalanine content of the feed ingredients and was corrected assuming $40 \%$ phenylalanine digestibility for hay cubes (Gibbs et al., 1988) and 70\% phenylalanine digestibility for concentrates (Farley et al., 1995)

Additionally, extraction by the small intestinal and liver cells prior to entry into general circulation was assumed to be $26.5 \%$ (Tanner, 2014). Whole-body phenylalanine flux (Hsu et al., 2006) and phenylalanine oxidation(Urschel et al., 2012) were calculated as previously described (Table 4.7). Values from the above described parameters were used to estimate phenylalanine release from protein breakdown and non-oxidative phenylalanine disposal (Table 4.7). Although phenylalanine can be converted to tyrosine, that conversion is not accounted for in these equations because it should be equal between treatments since both phenylalanine and tyrosine intakes were equal between treatments. Therefore, differences in non-oxidative phenylalanine disposal between treatments represent differences in whole-body protein synthesis between treatments. 
Table 4.7 Calculation of phenylalanine kinetics parameters ${ }^{1}$

\begin{tabular}{|c|c|}
\hline Parameter & Equation \\
\hline Phenylalanine Intake & $\begin{array}{l}=(0.4 * \text { Phenylalanine in cubes })+(0.7 * \text { Phenylalanine in } \\
\text { concentrate })-(0.265 *(0.4 * \text { Phenylalanine in } \\
\text { cubes })+(0.7 * \text { Phenylalanine in concentrate }))\end{array}$ \\
\hline Isotope Enrichment $^{2}$ & $=\left[R_{s}-R_{b} /\left(1+R_{s}\right)-R_{b}\right] \times 100$ \\
\hline $\mathrm{CO}_{2}$ Production $^{3}$ & $=\mathrm{i} \times[(\mathrm{Ei} / \mathrm{Eb})-1] \times[0.0224 \mathrm{~mL} / \mu \mathrm{mol} \mathrm{CO} 2]$ \\
\hline Phenylalanine $\operatorname{Flux}(Q)^{4}$ & $\begin{array}{l}=\mathrm{i} \times[(\mathrm{Ei} / \mathrm{Ep})-1] \\
=\mathrm{I}+\mathrm{N}+\mathrm{B} \\
=\mathrm{Z}+\mathrm{E}+\mathrm{M}\end{array}$ \\
\hline $\begin{array}{l}\text { Rate of Phenylalanine } \\
\text { Entry into the Free } \\
\text { Amino Acid Pool }\end{array}$ & $=\mathrm{I}+\mathrm{B}$ \\
\hline $\begin{array}{l}\text { Phenylalanine } \\
\text { Oxidation }(E)^{5}\end{array}$ & $=\mathrm{F}^{13} \mathrm{CO}_{2}(1 / \mathrm{Ep}-1 / \mathrm{Ei}) \times 100$ \\
\hline $\begin{array}{l}\text { Phenylalanine Release } \\
\text { from Protein Breakdown }\end{array}$ & $=\mathrm{Q}-\mathrm{I}$ \\
\hline $\begin{array}{l}\text { Rate of Phenylalanine } \\
\text { Exit from Free Amino } \\
\text { Acid Pool }\end{array}$ & $=\mathrm{E}+\mathrm{Z}$ \\
\hline $\begin{array}{l}\text { Non-Oxidative } \\
\text { Phenylalanine Disposal }\end{array}$ & $\begin{array}{l}=\mathrm{Q}-\mathrm{E} \\
=\text { estimate of whole-body protein synthesis }\end{array}$ \\
\hline \multicolumn{2}{|c|}{$\begin{array}{l}{ }^{1} \text { Phenylalanine flux and phenylalanine oxidation were calculated as previously described (Urschel et al., } \\
2012) \text {. } \\
{ }^{2} \mathrm{R}_{\mathrm{s}}=(\mathrm{m}+1):(\mathrm{m}) \text { in enriched sample; } \mathrm{R}_{\mathrm{b}}=(\mathrm{m}+1):(\mathrm{m}) \text { in sample at natural abundance; } \mathrm{m}=\text { molecular ion. } \\
(\text { Wilson et al., } 2000) \\
{ }^{3} \mathrm{i}=\text { rate of isotope infusion }(\mathrm{mg} / \mathrm{kg} \mathrm{BW} / \mathrm{h}) ; \mathrm{E}_{\mathrm{i}}=\text { enrichment of isotope solution; } \mathrm{E}_{\mathrm{b}}=\text { plateau breath } \\
\text { enrichment. (Urschel et al., 2009) } \\
{ }^{4} \mathrm{Q}=\text { flux; } \mathrm{i}=\text { rate of isotope infusion; } \mathrm{E}_{\mathrm{i}}=\text { enrichment of isotope solution; } \mathrm{E}_{\mathrm{p}}=\text { plateau plasma enrichment } \\
\text { (Hsu et al., 2006). } \mathrm{I}=\text { intake; } \mathrm{N}=\mathrm{de} \text { novo synthesis; } \mathrm{B}=\text { Phenylalanine release from protein breakdown; } \mathrm{Z}= \\
\text { protein synthesis; } \mathrm{E}=\text { oxidation; } \mathrm{M}=\text { conversion to other metabolites. } \mathrm{Q}=\mathrm{Rate} \text { of Phe entry into the free } \\
\text { amino acid pool = Rate of Phe exit from the free amino acid pool. } \\
{ }^{5} \mathrm{~F}^{13} \mathrm{CO}_{2}=\text { rate of }{ }^{13} \mathrm{CO}_{2} \text { released by oxidation of isotopic Phe oxidation }(\mu \mathrm{mol} / \mathrm{kg} \mathrm{BW} / \mathrm{h})(\mathrm{Hsu} \text { et al., } 2006) \\
{ }^{6} \mathrm{Horses} \text { do not synthesize phenylalanine de novo, therefore, } \mathrm{N}=0 \text {. }\end{array}$} \\
\hline
\end{tabular}




\section{Statistical Analysis}

Data were analyzed using the mixed procedure of SAS (Version 9.4) with a model appropriate for a replicated Latin square design. Plasma glucose, insulin, urea, amino acid concentrations, nitrogen balance, urinary creatinine, Western blot data, body weight and body condition were analyzed using repeated measures analysis with treatment, period, time, treatment by time interaction and period by time interaction as the fixed effects, horse nested in period as the subject and time as the repeated variable. The variance/covariance matrix used was first order auto regressive. Phenylalanine kinetics and plasma creatinine data were analyzed using a one-way ANOVA, with treatment and period as the fixed effects and horse as a random effect. When model p-values were significant, means were separated using the Tukey-adjusted pdiff option. Statistical significance was considered at $\mathrm{P}<0.05$ and trends were considered at $0.05<\mathrm{P}<0.10$. 


\section{Chapter 5. Results}

\section{Body Weight and Body Condition Score}

There was no significant effect of period $(\mathrm{P}=0.26)$ or treatment $(\mathrm{P}=0.21)$ on body condition score. There was a significant effect of treatment on body weight, where the estimated gain in body weight was higher for the LYS/THR/MET treatment than for the LYS/THR treatment (-11.0 kg BW; P=0.043; Figure 5.1A). It is interesting to note that horses appear to have lost weight while on the LYS/THR treatment, but gained weight while on the CON and LYS/THR/MET treatments. There was also a significant effect of period on change in body weight, where horses had losses in body weight in periods 2 and 5, but gained weight in all of the other periods, leading to lower weight gains in periods 2 and $5(\mathrm{P}<0.1$; Figure 5.1B). 
Figure 5.1 Changes in weight $(\mathrm{kg})$ over the $15 \mathrm{~d}$ experimental period in aged horses receiving concentrates with no amino acid supplementation (CON), lysine and threonine supplementation (LYS/THR) or lysine, threonine and methionine supplementation (LYS/THR/MET) ${ }^{1}$

A: By treatment

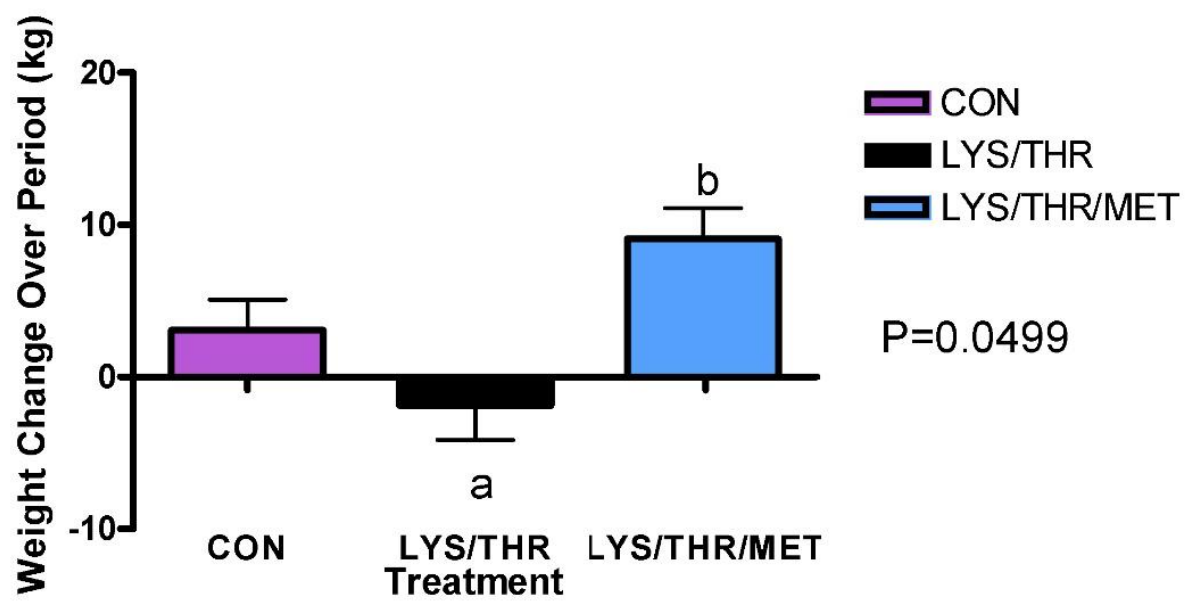

B: By period

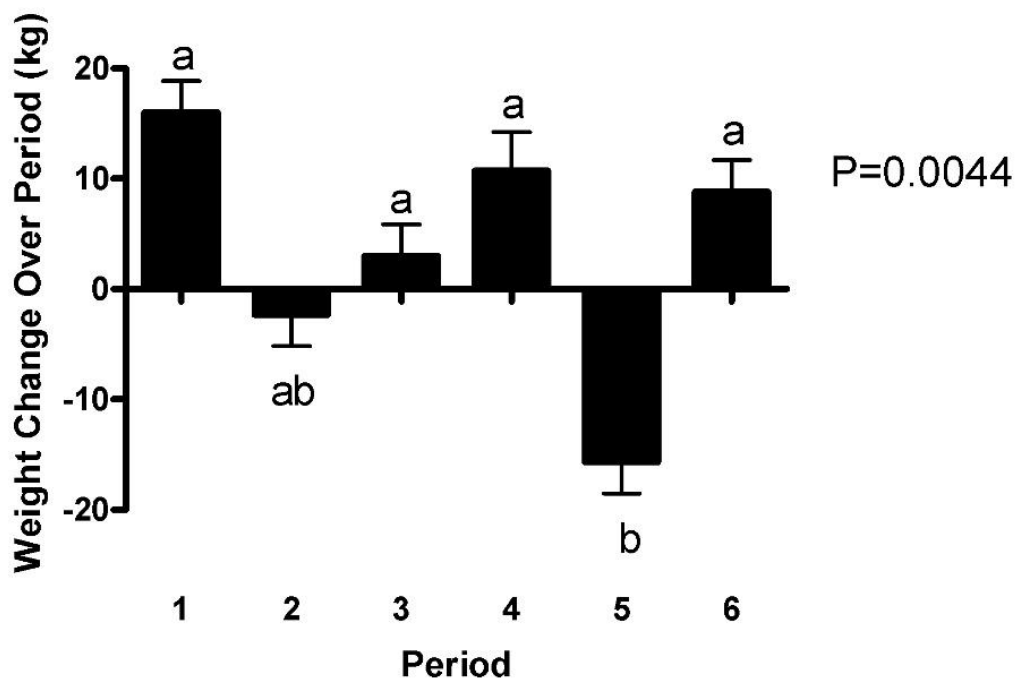




\section{Plasma Glucose and Insulin Concentrations}

In comparison to the CON treatment, LYS/THR was supplemented with 34 $\mathrm{mg} / \mathrm{kg} / \mathrm{d}$ of lysine and $26 \mathrm{mg} / \mathrm{kg} / \mathrm{d}$ of threonine and LYS/THR/MET provided an additional $32 \mathrm{mg} / \mathrm{kg} / \mathrm{d}$ of lysine, $28 \mathrm{mg} / \mathrm{kg} / \mathrm{d}$ of threonine and $10 \mathrm{mg} / \mathrm{kg} / \mathrm{d}$ of methionine (Table 4.4). Feeding increased plasma glucose and insulin concentrations over time $(\mathrm{P}<0.05)$, with concentrations peaking at approximately 60 and 120 minutes respectively (Figure 5.1). There was no effect of treatment (Glucose, $\mathrm{P}=0.57$; Insulin, $\mathrm{P}=0.22$ ), period (Glucose, $\mathrm{P}=0.20$; Insulin, $\mathrm{P}=0.16$ ) or the treatment by time interaction (Glucose, $\mathrm{P}=0.21$; Insulin, $\mathrm{P}=0.39$ ) on plasma glucose or insulin concentrations. There was a significant interaction of period and time $(\mathrm{P}=0.024)$ for glucose concentration, but not for insulin concentration $(\mathrm{P}=0.21)$. 
Figure 5.2 Pre-feeding $(t=-30,0 \mathrm{~min})$ and post-feeding $(t=30-240 \mathrm{~min})$ plasma glucose and insulin concentrations in aged horses receiving concentrates with no amino acid supplementation (CON), lysine and threonine supplementation (LYS/THR) or lysine, threonine and methionine supplementation (LYS/THR/MET) ${ }^{1}$

\section{A: Plasma glucose concentrations}

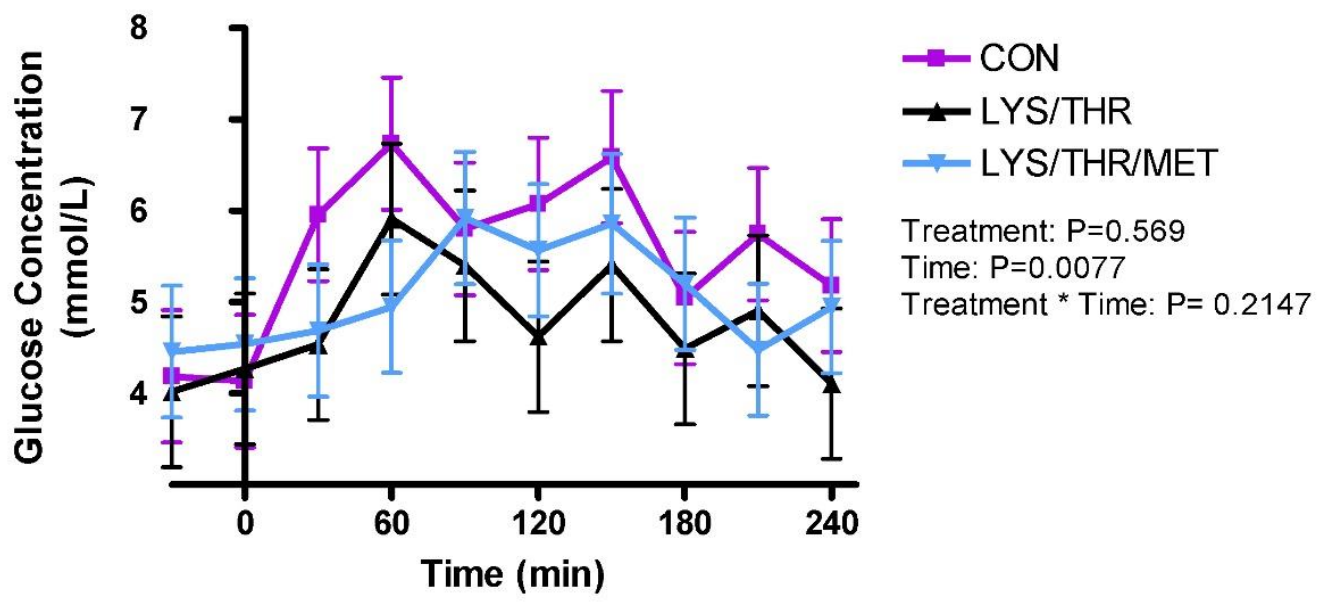

B: Plasma Insulin Concentrations

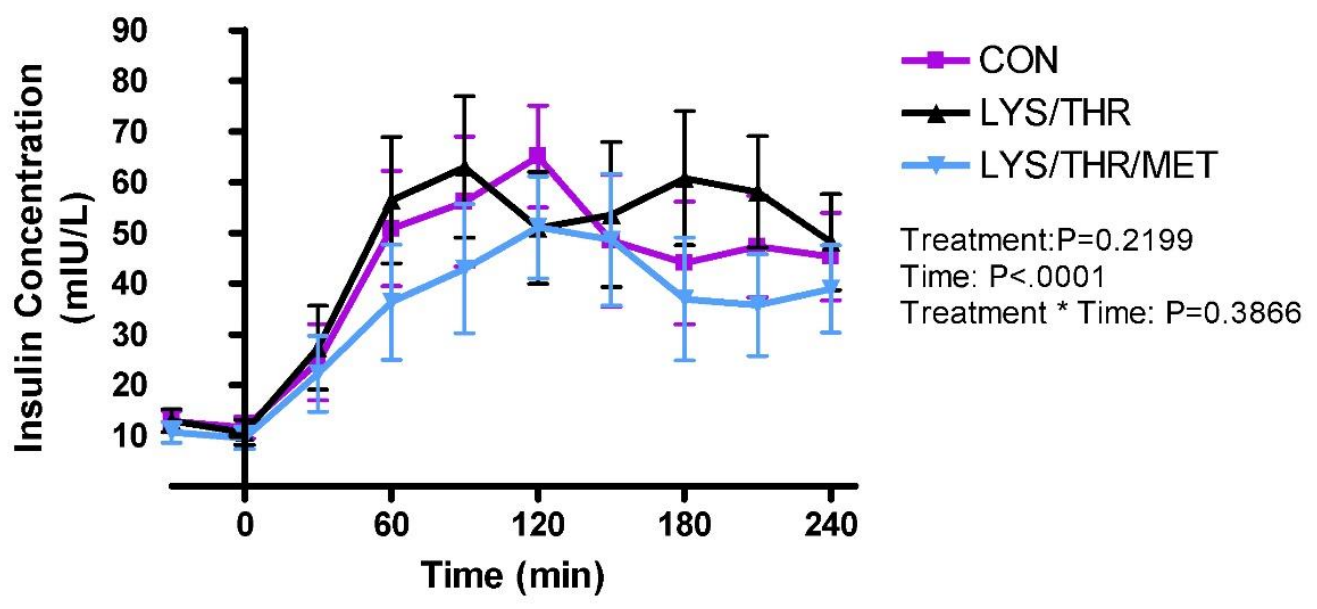

Values are least squares means \pm standard error.

${ }^{1} \mathrm{CON}$ and LYS/THR/MET, $\mathrm{n}=5$; LYS/THR, $\mathrm{n}=5$. For the LYS/THR treatment one horse's data was omitted due to a systemic infection. 


\section{Plasma Urea Nitrogen Concentrations}

PUN concentrations in response to feeding were measured as an indicator of differences in catabolism of dietary amino acids between treatments. Samples were taken before and after a meal on d 10 of collection. PUN concentrations were not affected by time or treatment by time interaction $(\mathrm{P}>0.05$; Figure $5.3 \mathrm{~A})$. PUN concentrations were affected by treatment, with concentrations being higher for LYS/THR and LYS/THR/MET treatments compared to $\mathrm{CON}(\mathrm{P}=0.0058$; Figure 5.3 B). Additionally, PUN concentrations were significantly affected by period $(\mathrm{P}<0.001$; Figure $5.3 \mathrm{C})$, but not by the interaction of period and time $(\mathrm{P}=0.51)$. 
Figure 5.3 Pre-feeding ( $t=-30,0 \mathrm{~min})$ and post-feeding $(\mathrm{t}=30-240 \mathrm{~min})$ PUN concentrations in aged horses receiving concentrates with no amino acid supplementation (CON), lysine and threonine supplementation (LYS/THR) or lysine, threonine and methionine supplementation (LYS/THR/MET)

A: PUN concentrations over time after feeding ${ }^{1}$

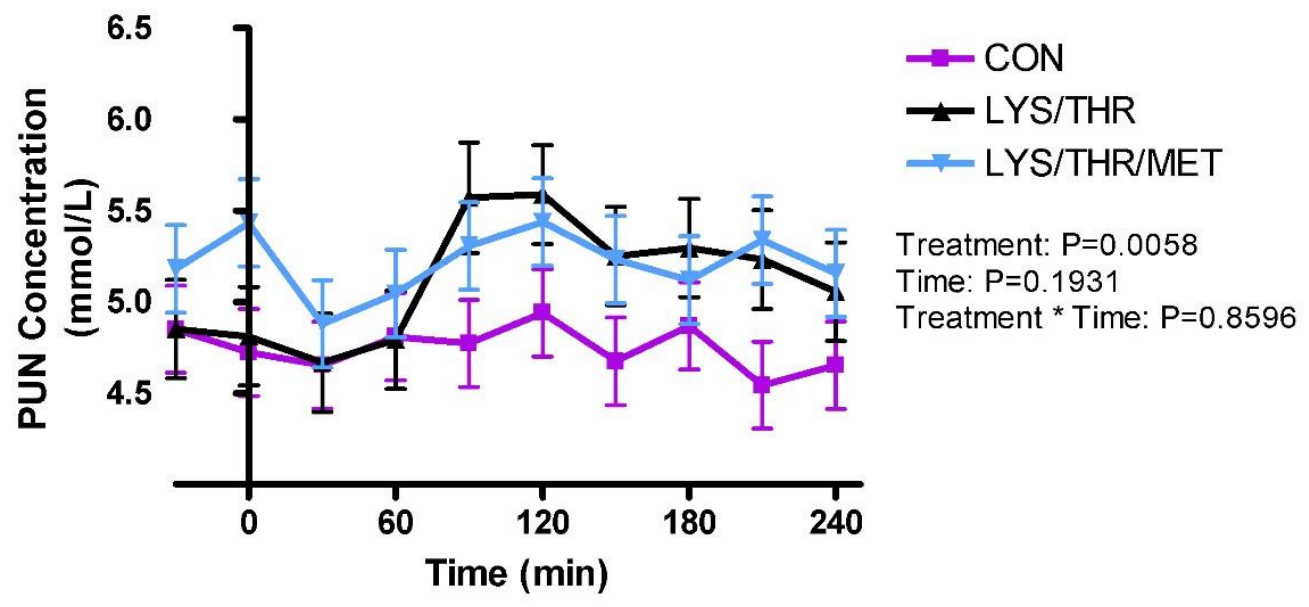

B: PUN concentrations by treatment ${ }^{1}$

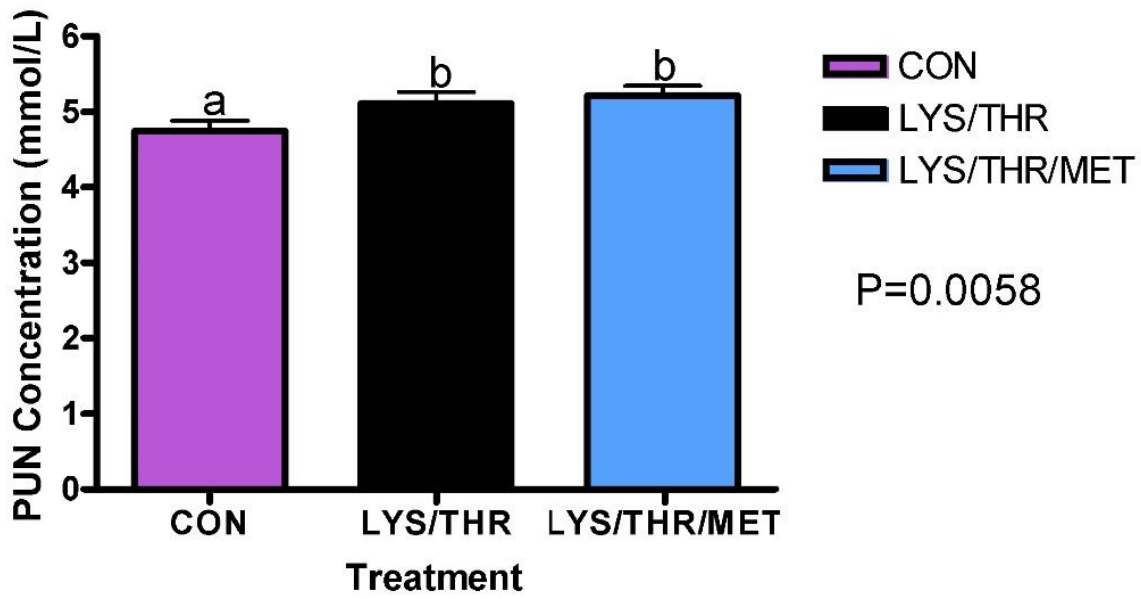


Figure 5.3 Continued

C: PUN concentrations by period ${ }^{2}$

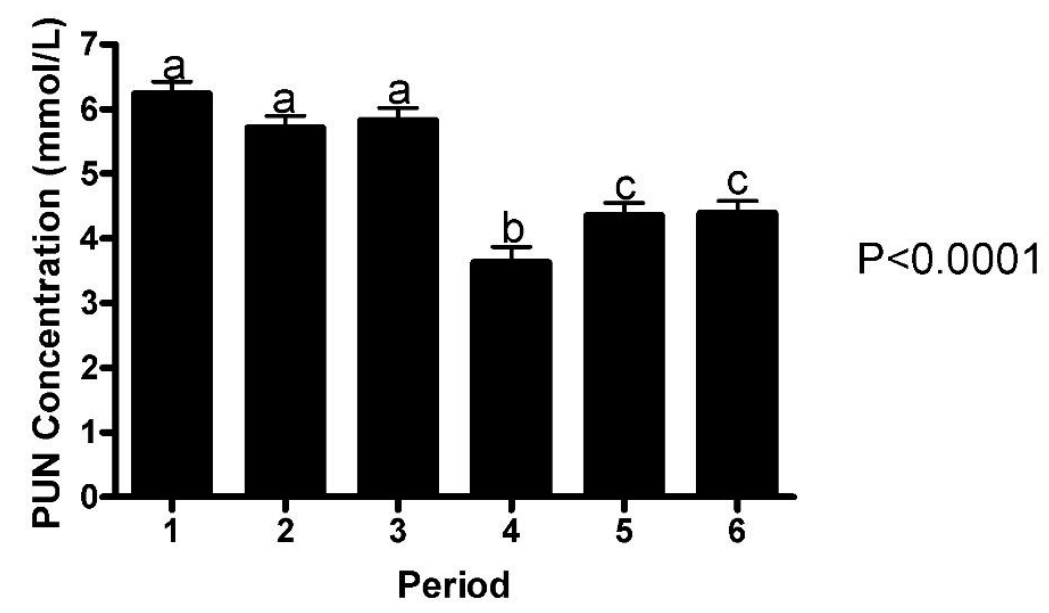

Values are least squares means \pm standard error.

${ }^{1} \mathrm{CON}$ and LYS/THR/MET, n=5; LYS/THR, n=5. For the LYS/THR treatment one horse's data was omitted due to a systemic infection.

${ }^{2}$ Period $1,2,3,5$ and $6, n=3$; Period 4, $n=2$. For period 4, one horse's data was omitted due to a systemic infection. 


\section{Plasma Creatinine Concentrations}

Plasma creatinine concentrations were measured as an indicator of differences in muscle mass between treatments. Samples taken directly before the morning meal on $d$ 10 were analyzed. Creatinine concentrations were not affected by treatment $(\mathrm{P}=0.29$; Figure 5.4 A), but tended to be affected by collection period, $(\mathrm{P}=0.066$; Figure 5.4 B), where period 5 was higher than the other periods. 
Figure 5.4 Plasma creatinine concentrations in aged horses receiving concentrates with no amino acid supplementation (CON), lysine and threonine supplementation (LYS/THR) or lysine, threonine and methionine supplementation (LYS/THR/MET) ${ }^{1}$

\section{A: By treatment ${ }^{2}$}

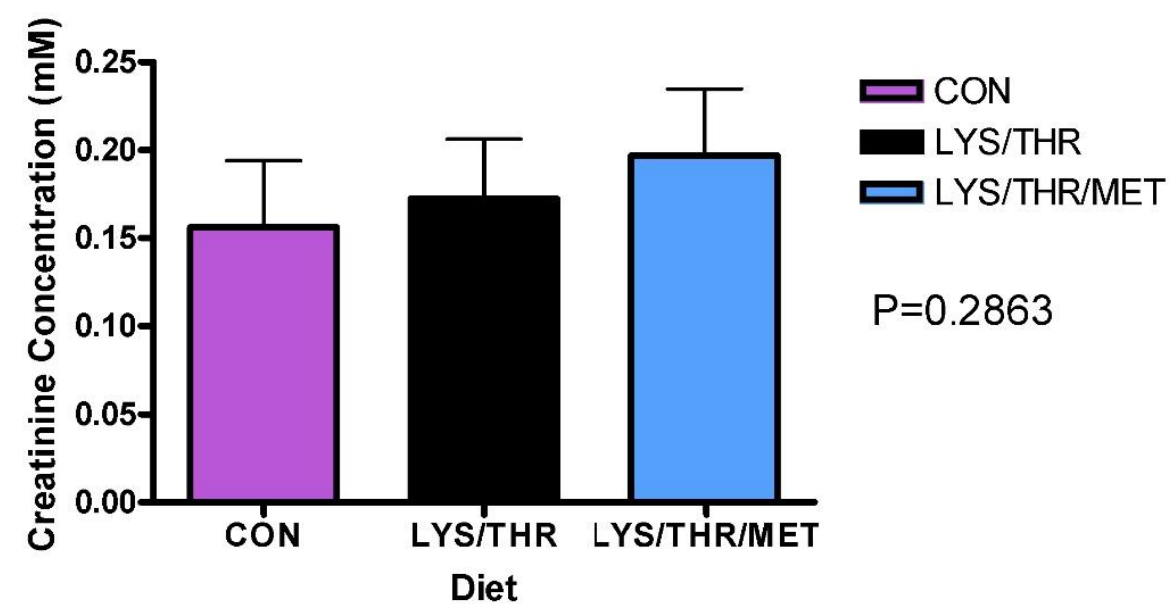

B: By period ${ }^{3}$

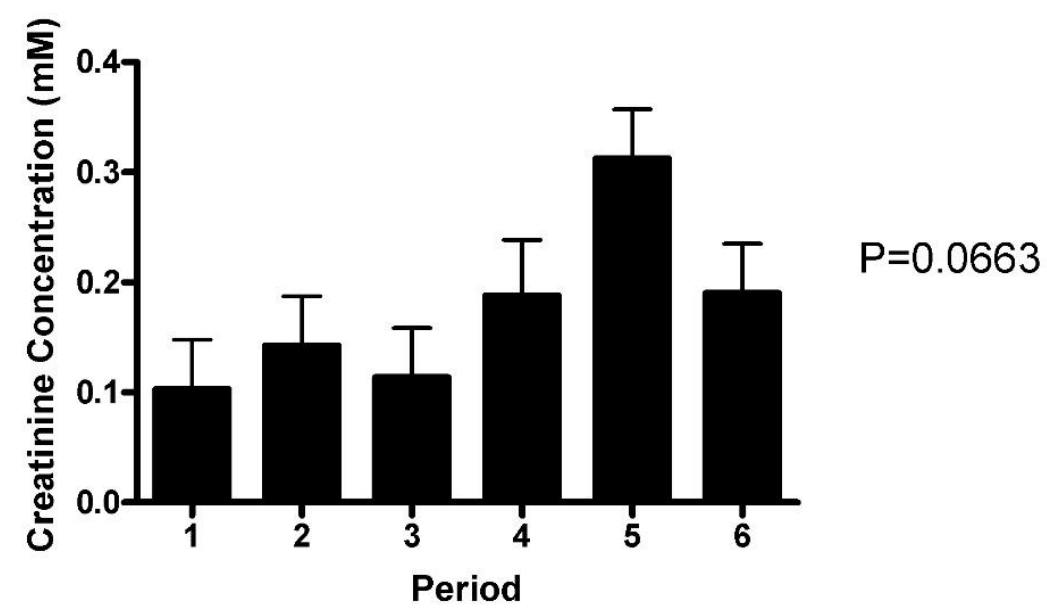

Values are least squares means \pm standard error.

${ }^{1}$ Creatinine concentration in plasma taken directly before morning meal on $\mathrm{d} 10$.

${ }^{2} \mathrm{CON}$ and LYS/THR/MET, $\mathrm{n}=6$; LYS/THR, n=5. For the LYS/THR treatment one horse's data was omitted due to a systemic infection.

${ }^{3}$ Period 1, 2, 3, 5 and $6 n=3$; Period 4, n=2. For period 4, one horse's data was omitted due to a systemic infection. 


\section{Plasma Amino Acid Concentrations}

After consuming the morning meal, the concentrations of most plasma amino acids increased (Table 5.1). Plasma lysine and threonine concentrations were higher approximately 60 minutes after consuming a meal $(\mathrm{P}<0.0001)$ for the horses receiving LYS/THR and LYS/THR/MET compared to CON. Additionally, plasma methionine concentrations were $(\mathrm{P}=0.012)$ higher in horses following consumption of LYS/THR as well as LYS/THR/MET $(\mathrm{P}<0.0001)$ compared to CON (Table 5.1). There was a significant treatment by time interaction for lysine, threonine, and methionine, where plasma concentrations peaked earlier and more sharply when the amino acids were supplemented. The concentrations of all measured amino acids except glutamate, glycine and tryptophan were affected by time $(\mathrm{P}<0.005$; Table 5.1$)$. The concentrations of four amino acids other than the supplemented amino acids were affected by treatment or treatment by time interaction, including glutamate, leucine, phenylalanine and serine. Additionally, alanine concentration tended to be affected by treatment and glycine concentration tended to be affected by treatment by time interaction. Glutamate concentration was higher for CON than for LYS/THR (22.7 mmol/L; P=0.038) and tended to be higher for CON than for LYS/THR/MET (16.7 mmol/L; P=0.094). Leucine concentration tended to be higher for CON than for LYS/THR/MET (11.3 mmol/L; $\mathrm{P}=0.064$ ). Phenylalanine concentration tended to be higher for CON than for LYS/THR (3.4 mmol/L; P=0.069) and was higher for CON than for LYS/THR/MET (5.5 mmol/L; $\mathrm{P}=0.001)$. Serine concentration was higher for LYS/THR than for LYS/THR/MET (39.8 $\mathrm{mmol} / \mathrm{L} ; \mathrm{P}=0.025)$. Alanine concentration tended to be higher for LYS/THR and for 
LYS/THR/MET ( $35.7 \mathrm{mmol} / \mathrm{L} ; \mathrm{P}=0.060)$. Glycine concentration tended to be affected by the treatment by time interaction $(\mathrm{P}=0.052$; Table 5.1$)$. 
Table 5.1 Pre-feeding $(t=-30,0)$ and post-feeding $(t=30-240)$ plasma amino acid concentrations $(\mu \mathrm{mol} / \mathrm{L})$ in aged horses receiving concentrates with no amino acid supplementation (CON), lysine and threonine supplementation (LYS/THR) or lysine, threonine and methionine supplementation (LYS/THR/MET)

\begin{tabular}{|c|c|c|c|c|c|c|c|}
\hline Amino Acid & $\begin{array}{l}\text { Time } \\
(\min )\end{array}$ & $\mathrm{CON}$ & LYS/THR & $\begin{array}{l}\text { LYS/THR/ } \\
\text { MET }\end{array}$ & & & \\
\hline \multirow[t]{10}{*}{ Lysine } & -30 & $142 \pm 22$ & $151 \pm 22$ & $155 \pm 22$ & Treat & Time & Treat*Time \\
\hline & 0 & $153 \pm 22$ & $154 \pm 25$ & $146 \pm 22$ & $<0.0001$ & $<0.0001$ & 0.0091 \\
\hline & 30 & $161 \pm 22$ & $239 \pm 25$ & $191 \pm 23$ & & & \\
\hline & 60 & $205 \pm 22$ & $370 \pm 26$ & $324 \pm 22$ & Period & Period*Time & \\
\hline & 90 & $213 \pm 22$ & $372 \pm 25$ & $330 \pm 22$ & 0.3819 & 0.5263 & \\
\hline & 120 & $200 \pm 22$ & $355 \pm 25$ & $354 \pm 22$ & & & \\
\hline & 150 & $193 \pm 22$ & $345 \pm 25$ & $334 \pm 22$ & & & \\
\hline & 180 & $185 \pm 22$ & $314 \pm 25$ & $292 \pm 22$ & & & \\
\hline & 210 & $194 \pm 22$ & $321 \pm 25$ & $299 \pm 22$ & & & \\
\hline & 240 & $192 \pm 22$ & $317 \pm 25$ & $308 \pm 22$ & & & \\
\hline \multirow[t]{10}{*}{ Threonine } & -30 & $192 \pm 31$ & $286 \pm 33$ & $294 \pm 31$ & Treat & Time & Treat*Time \\
\hline & 0 & $185 \pm 31$ & $264 \pm 33$ & $279 \pm 31$ & $<0.0001$ & $<0.0001$ & 0.0112 \\
\hline & 30 & $189 \pm 32$ & $352 \pm 33$ & $304 \pm 32$ & & & \\
\hline & 60 & $226 \pm 31$ & $439 \pm 34$ & $408 \pm 31$ & Period & Period*Time & \\
\hline & 90 & $229 \pm 31$ & $451 \pm 33$ & $442 \pm 31$ & 0.2985 & 0.6206 & \\
\hline & 120 & $218 \pm 31$ & $463 \pm 33$ & $462 \pm 31$ & & & \\
\hline & 150 & $219 \pm 31$ & $462 \pm 33$ & $452 \pm 31$ & & & \\
\hline & 180 & $205 \pm 31$ & $426 \pm 33$ & $430 \pm 31$ & & & \\
\hline & 210 & $205 \pm 31$ & $453 \pm 33$ & $436 \pm 31$ & & & \\
\hline & 240 & $211 \pm 31$ & $452 \pm 33$ & $447 \pm 31$ & & & \\
\hline \multirow[t]{9}{*}{ Methionine } & -30 & $50 \pm 6$ & $53 \pm 6$ & $61 \pm 6$ & Treat & Time & Treat*Time \\
\hline & 0 & $49 \pm 6$ & $56 \pm 6$ & $57 \pm 6$ & $<0.0001$ & $<0.0001$ & 0.0056 \\
\hline & 30 & $50 \pm 6$ & $67 \pm 6$ & $68 \pm 6$ & & & \\
\hline & 60 & $58 \pm 6$ & $77 \pm 7$ & $95 \pm 6$ & Period & Period*Time & \\
\hline & 90 & $59 \pm 6$ & $79 \pm 6$ & $94 \pm 6$ & 0.4266 & 0.7153 & \\
\hline & 120 & $58 \pm 6$ & $78 \pm 6$ & $107 \pm 6$ & & & \\
\hline & 150 & $56 \pm 6$ & $81 \pm 6$ & $105 \pm 6$ & & & \\
\hline & 180 & $53 \pm 6$ & $74 \pm 6$ & $94 \pm 6$ & & & \\
\hline & 210 & $55 \pm 6$ & $78 \pm 6$ & $95 \pm 6$ & & & \\
\hline
\end{tabular}


Table 5.1 Continued

\begin{tabular}{|c|c|c|c|c|c|c|c|}
\hline & 240 & $53 \pm 6$ & $76 \pm 6$ & $101 \pm 6$ & & & \\
\hline \multirow[t]{10}{*}{ Alanine } & -30 & $284 \pm 26$ & $294 \pm 28$ & $269 \pm 26$ & Treat & Time & Treat*Time \\
\hline & 0 & $277 \pm 26$ & $288 \pm 28$ & $261 \pm 26$ & 0.0707 & $<0.0001$ & 0.7352 \\
\hline & 30 & $325 \pm 26$ & $313 \pm 28$ & $254 \pm 27$ & & & \\
\hline & 60 & $351 \pm 26$ & $348 \pm 29$ & $332 \pm 26$ & Period & Period*Time & \\
\hline & 90 & $364 \pm 26$ & $374 \pm 28$ & $352 \pm 26$ & 0.5159 & 0.0230 & \\
\hline & 120 & $360 \pm 26$ & $398 \pm 28$ & $358 \pm 26$ & & & \\
\hline & 150 & $350 \pm 26$ & $397 \pm 28$ & $354 \pm 26$ & & & \\
\hline & 180 & $342 \pm 26$ & $379 \pm 28$ & $334 \pm 26$ & & & \\
\hline & 210 & $339 \pm 26$ & $400 \pm 28$ & $348 \pm 26$ & & & \\
\hline & 240 & $345 \pm 26$ & $395 \pm 28$ & $368 \pm 26$ & & & \\
\hline \multirow[t]{10}{*}{ Arginine } & -30 & $99 \pm 11$ & $93 \pm 12$ & $91 \pm 11$ & Treat & Time & Treat*Time \\
\hline & 0 & $100 \pm 11$ & $93 \pm 12$ & $87 \pm 11$ & 0.3513 & $<0.0001$ & 0.9849 \\
\hline & 30 & $109 \pm 11$ & $109 \pm 12$ & $94 \pm 11$ & & & \\
\hline & 60 & $151 \pm 11$ & $136 \pm 12$ & $130 \pm 11$ & Period & Period $*$ Time & \\
\hline & 90 & $148 \pm 11$ & $144 \pm 12$ & $136 \pm 11$ & 0.0549 & 0.0339 & \\
\hline & 120 & $149 \pm 11$ & $151 \pm 12$ & $146 \pm 11$ & & & \\
\hline & 150 & $142 \pm 11$ & $144 \pm 12$ & $139 \pm 11$ & & & \\
\hline & 180 & $133 \pm 11$ & $137 \pm 12$ & $128 \pm 11$ & & & \\
\hline & 210 & $143 \pm 11$ & $145 \pm 12$ & $130 \pm 11$ & & & \\
\hline & 240 & $140 \pm 11$ & $138 \pm 12$ & $139 \pm 11$ & & & \\
\hline \multirow[t]{10}{*}{ Aspartate } & -30 & $34 \pm 6$ & $23 \pm 7$ & $26 \pm 6$ & Treat & Time & Treat*Time \\
\hline & 0 & $33 \pm 6$ & $19 \pm 7$ & $24 \pm 6$ & 0.1423 & $<0.0001$ & 0.9754 \\
\hline & 30 & $39 \pm 6$ & $28 \pm 7$ & $29 \pm 6$ & & & \\
\hline & 60 & $52 \pm 6$ & $35 \pm 7$ & $39 \pm 6$ & Period & Period*Time & \\
\hline & 90 & $52 \pm 6$ & $38 \pm 7$ & $40 \pm 6$ & 0.1796 & 0.0710 & \\
\hline & 120 & $53 \pm 6$ & $39 \pm 7$ & $44 \pm 6$ & & & \\
\hline & 150 & $50 \pm 6$ & $39 \pm 7$ & $43 \pm 6$ & & & \\
\hline & 180 & $49 \pm 6$ & $33 \pm 7$ & $38 \pm 6$ & & & \\
\hline & 210 & $49 \pm 6$ & $39 \pm 7$ & $39 \pm 6$ & & & \\
\hline & 240 & $48 \pm 6$ & $36 \pm 7$ & $40 \pm 6$ & & & \\
\hline \multirow[t]{2}{*}{ Asparagine } & -30 & $73 \pm 12$ & $65 \pm 13$ & $68 \pm 12$ & Treat & Time & Treat*Time \\
\hline & 0 & $54 \pm 12$ & $67 \pm 13$ & $61 \pm 12$ & 0.1752 & $<0.0001$ & 0.8027 \\
\hline
\end{tabular}


Table 5.1 Continued

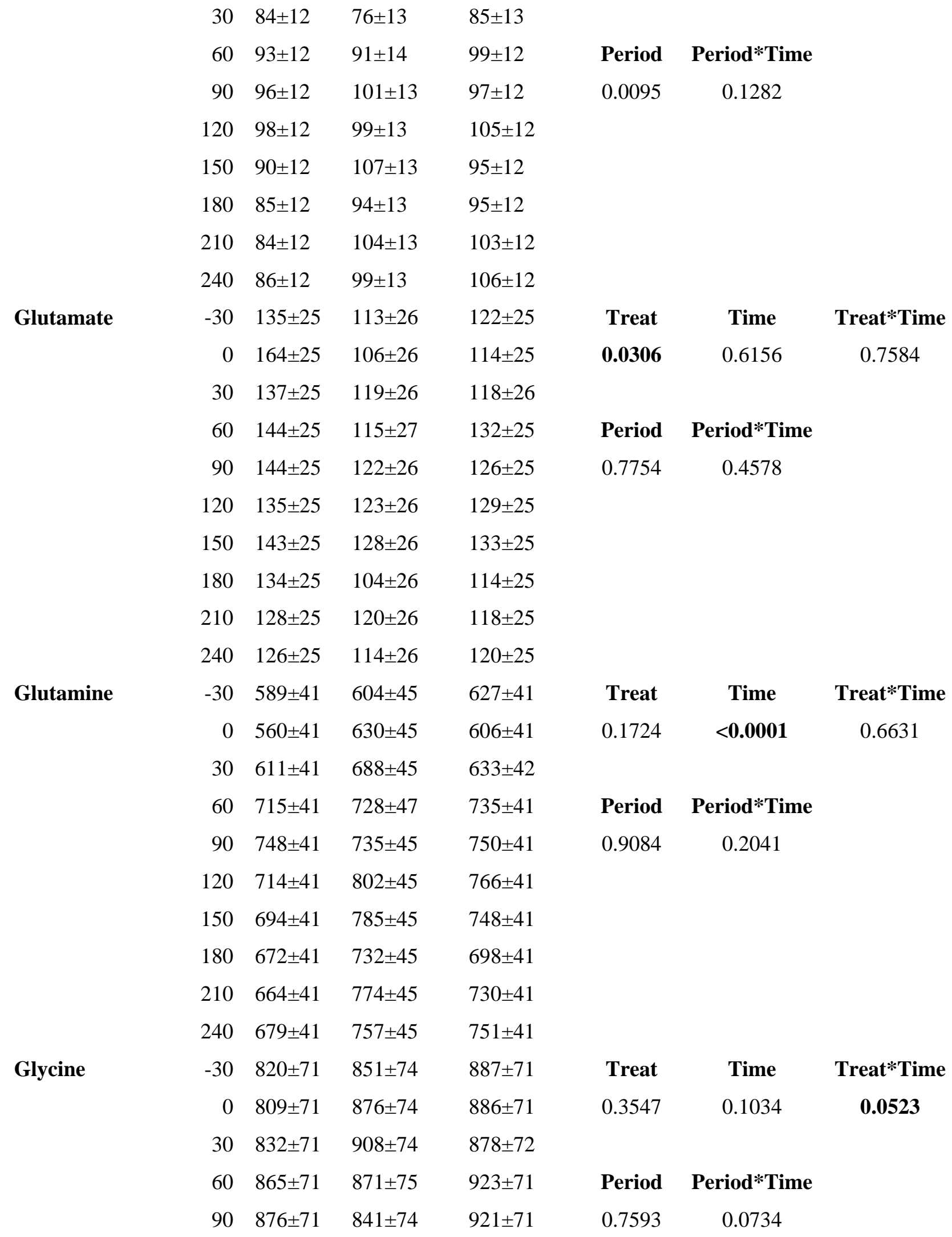


Table 5.1 Continued

\begin{tabular}{|c|c|c|c|c|c|c|c|}
\hline & 120 & $826 \pm 71$ & $903 \pm 74$ & $884 \pm 71$ & & & \\
\hline & 150 & $830 \pm 71$ & $874 \pm 74$ & $865 \pm 71$ & & & \\
\hline & 180 & $816 \pm 71$ & $815 \pm 74$ & $816 \pm 71$ & & & \\
\hline & 210 & $798 \pm 71$ & $855 \pm 74$ & $844 \pm 71$ & & & \\
\hline & 240 & $804 \pm 71$ & $831 \pm 74$ & $872 \pm 71$ & & & \\
\hline \multirow[t]{10}{*}{ Histidine } & -30 & $84 \pm 5$ & $82 \pm 5$ & $84 \pm 5$ & Treat & Time & Treat*Time \\
\hline & 0 & $81 \pm 5$ & $75 \pm 5$ & $81 \pm 5$ & 0.7902 & $<0.0001$ & 0.875 \\
\hline & 30 & $81 \pm 5$ & $83 \pm 5$ & $83 \pm 5$ & & & \\
\hline & 60 & $96 \pm 5$ & $92 \pm 6$ & $93 \pm 5$ & Period & Period*Time & \\
\hline & 90 & $99 \pm 5$ & $91 \pm 5$ & $98 \pm 5$ & 0.1172 & 0.3868 & \\
\hline & 120 & $96 \pm 5$ & $102 \pm 5$ & $101 \pm 5$ & & & \\
\hline & 150 & $98 \pm 5$ & $97 \pm 5$ & $98 \pm 5$ & & & \\
\hline & 180 & $91 \pm 5$ & $89 \pm 5$ & $93 \pm 5$ & & & \\
\hline & 210 & $90 \pm 5$ & $95 \pm 5$ & $95 \pm 5$ & & & \\
\hline & 240 & $93 \pm 5$ & $95 \pm 5$ & $98 \pm 5$ & & & \\
\hline \multirow[t]{10}{*}{ Isoleucine } & -30 & $92 \pm 6$ & $89 \pm 7$ & $95 \pm 6$ & Treat & Time & Treat*Time \\
\hline & 0 & $93 \pm 6$ & $89 \pm 7$ & $91 \pm 6$ & 0.6208 & $<0.0001$ & 0.9588 \\
\hline & 30 & $97 \pm 6$ & $95 \pm 7$ & $88 \pm 7$ & & & \\
\hline & 60 & $115 \pm 6$ & $106 \pm 7$ & $106 \pm 6$ & Period & Period*Time & \\
\hline & 90 & $114 \pm 6$ & $107 \pm 7$ & $108 \pm 6$ & 0.1372 & 0.0087 & \\
\hline & 120 & $111 \pm 6$ & $107 \pm 7$ & $110 \pm 6$ & & & \\
\hline & 150 & $105 \pm 6$ & $106 \pm 7$ & $103 \pm 6$ & & & \\
\hline & 180 & $98 \pm 6$ & $98 \pm 7$ & $93 \pm 6$ & & & \\
\hline & 210 & $100 \pm 6$ & $100 \pm 7$ & $96 \pm 6$ & & & \\
\hline & 240 & $100 \pm 6$ & $98 \pm 7$ & $104 \pm 6$ & & & \\
\hline \multirow[t]{8}{*}{ Leucine } & -30 & $176 \pm 9$ & $165 \pm 10$ & $175 \pm 9$ & Treat & Time & Treat*Time \\
\hline & 0 & $178 \pm 9$ & $165 \pm 10$ & $167 \pm 9$ & 0.0473 & $<0.0001$ & 0.9760 \\
\hline & 30 & $183 \pm 9$ & $175 \pm 10$ & $163 \pm 10$ & & & \\
\hline & 60 & $213 \pm 9$ & $189 \pm 11$ & $195 \pm 9$ & Period & Period*Time & \\
\hline & 90 & $214 \pm 9$ & $193 \pm 10$ & $195 \pm 9$ & 0.0051 & 0.0008 & \\
\hline & 120 & $203 \pm 9$ & $194 \pm 10$ & $198 \pm 9$ & & & \\
\hline & 150 & $194 \pm 9$ & $190 \pm 10$ & $183 \pm 9$ & & & \\
\hline & 180 & $180 \pm 9$ & $175 \pm 10$ & $163 \pm 9$ & & & \\
\hline
\end{tabular}


Table 5.1 Continued

\begin{tabular}{|c|c|c|c|c|c|c|c|}
\hline & 210 & $182 \pm 9$ & $176 \pm 10$ & $171 \pm 9$ & & & \\
\hline \multirow[t]{10}{*}{ Phenylalanine } & -30 & $75 \pm 3$ & $72 \pm 3$ & $73 \pm 3$ & Treat & Time & Treat*Time \\
\hline & 0 & $77 \pm 3$ & $72 \pm 3$ & $69 \pm 3$ & 0.0013 & $<0.0001$ & 0.8790 \\
\hline & 30 & $77 \pm 3$ & $77 \pm 3$ & $70 \pm 3$ & & & \\
\hline & 60 & $87 \pm 3$ & $80 \pm 4$ & $80 \pm 3$ & Period & Period*Time & \\
\hline & 90 & $87 \pm 3$ & $78 \pm 3$ & $79 \pm 3$ & 0.2283 & 0.0007 & \\
\hline & 120 & $85 \pm 3$ & $82 \pm 3$ & $81 \pm 3$ & & & \\
\hline & 150 & $81 \pm 3$ & $80 \pm 3$ & $76 \pm 3$ & & & \\
\hline & 180 & $78 \pm 3$ & $76 \pm 3$ & $70 \pm 3$ & & & \\
\hline & 210 & $79 \pm 3$ & $78 \pm 3$ & $74 \pm 3$ & & & \\
\hline & 240 & $78 \pm 3$ & $76 \pm 3$ & $77 \pm 3$ & & & \\
\hline \multirow[t]{10}{*}{ Proline } & -30 & $95 \pm 12$ & $93 \pm 14$ & $96 \pm 12$ & Treat & Time & Treat*Time \\
\hline & 0 & $98 \pm 12$ & $90 \pm 14$ & $92 \pm 12$ & 0.6404 & $<0.0001$ & 0.7393 \\
\hline & 30 & $108 \pm 12$ & $109 \pm 14$ & $96 \pm 13$ & & & \\
\hline & 60 & $148 \pm 12$ & $135 \pm 14$ & $130 \pm 12$ & Period & Period*Time & \\
\hline & 90 & $152 \pm 12$ & $136 \pm 14$ & $139 \pm 12$ & 0.2038 & 0.0120 & \\
\hline & 120 & $152 \pm 12$ & $142 \pm 14$ & $151 \pm 12$ & & & \\
\hline & 150 & $147 \pm 12$ & $147 \pm 14$ & $142 \pm 12$ & & & \\
\hline & 180 & $145 \pm 12$ & $140 \pm 14$ & $136 \pm 12$ & & & \\
\hline & 210 & $157 \pm 12$ & $152 \pm 14$ & $144 \pm 12$ & & & \\
\hline & 240 & $151 \pm 12$ & $145 \pm 14$ & $159 \pm 12$ & & & \\
\hline \multirow[t]{10}{*}{ Serine } & -30 & $380 \pm 33$ & $386 \pm 34$ & $375 \pm 33$ & Treat & Time & Treat*Time \\
\hline & 0 & $390 \pm 33$ & $392 \pm 34$ & $367 \pm 33$ & 0.028 & $<.0001$ & 0.4080 \\
\hline & 30 & $388 \pm 33$ & $432 \pm 34$ & $352 \pm 34$ & & & \\
\hline & 60 & $460 \pm 33$ & $458 \pm 35$ & $423 \pm 33$ & Period & Period*Time & \\
\hline & 90 & $468 \pm 33$ & $456 \pm 34$ & $447 \pm 33$ & 0.4154 & 0.0054 & \\
\hline & 120 & $449 \pm 33$ & $490 \pm 34$ & $446 \pm 33$ & & & \\
\hline & 150 & $444 \pm 33$ & $476 \pm 34$ & $432 \pm 33$ & & & \\
\hline & 180 & $433 \pm 33$ & $452 \pm 34$ & $396 \pm 33$ & & & \\
\hline & 210 & $444 \pm 33$ & $471 \pm 34$ & $411 \pm 33$ & & & \\
\hline & 240 & $450 \pm 33$ & $467 \pm 34$ & $433 \pm 33$ & & & \\
\hline \multirow[t]{2}{*}{ Tryptophan } & -30 & $11 \pm 2$ & $8 \pm 2$ & $7 \pm 2$ & Treat & Time & Treat*Time \\
\hline & 0 & $8 \pm 2$ & $7 \pm 2$ & $6 \pm 2$ & 0.2677 & 0.4424 & 0.6513 \\
\hline
\end{tabular}


Table 5.1 Continued

\begin{tabular}{|c|c|c|c|c|c|c|c|}
\hline & 30 & $7 \pm 2$ & $6 \pm 2$ & $9 \pm 2$ & & & \\
\hline & 60 & $9 \pm 2$ & $7 \pm 3$ & $7 \pm 2$ & Period & Period*Time & \\
\hline & 90 & $10 \pm 2$ & $8 \pm 2$ & $12 \pm 2$ & 0.6520 & 0.3525 & \\
\hline & 120 & $10 \pm 2$ & $9 \pm 2$ & $9 \pm 2$ & & & \\
\hline & 150 & $12 \pm 2$ & $6 \pm 2$ & $7 \pm 2$ & & & \\
\hline & 180 & $7 \pm 2$ & $6 \pm 2$ & $6 \pm 2$ & & & \\
\hline & 210 & $8 \pm 2$ & $7 \pm 2$ & $6 \pm 2$ & & & \\
\hline & 240 & $7 \pm 2$ & $11 \pm 2$ & $7 \pm 2$ & & & \\
\hline Tyrosine & -30 & $119 \pm 9$ & $121 \pm 9$ & $132 \pm 9$ & Treat & Time & Treat*Time \\
\hline & 0 & $120 \pm 9$ & $123 \pm 9$ & $132 \pm 9$ & 0.1087 & $<0.0001$ & 0.1357 \\
\hline & 30 & $130 \pm 9$ & $136 \pm 9$ & $129 \pm 9$ & & & \\
\hline & 60 & $152 \pm 9$ & $147 \pm 10$ & $152 \pm 9$ & Period & Period*Time & \\
\hline & 90 & $154 \pm 9$ & $144 \pm 9$ & $150 \pm 9$ & 0.0170 & 0.0049 & \\
\hline & 120 & $141 \pm 9$ & $153 \pm 9$ & $158 \pm 9$ & & & \\
\hline & 150 & $142 \pm 9$ & $160 \pm 9$ & $153 \pm 9$ & & & \\
\hline & 180 & $133 \pm 9$ & $146 \pm 9$ & $144 \pm 9$ & & & \\
\hline & 210 & $146 \pm 9$ & $149 \pm 9$ & $151 \pm 9$ & & & \\
\hline & 240 & $141 \pm 9$ & $148 \pm 9$ & $156 \pm 9$ & & & \\
\hline Valine & -30 & $353 \pm 21$ & $309 \pm 25$ & $323 \pm 21$ & Treat & Time & Treat*Time \\
\hline & 0 & $346 \pm 21$ & $317 \pm 25$ & $311 \pm 21$ & 0.1753 & 0.0004 & 0.8161 \\
\hline & 30 & $358 \pm 21$ & $333 \pm 25$ & $303 \pm 22$ & & & \\
\hline & 60 & $403 \pm 21$ & $346 \pm 26$ & $345 \pm 21$ & Period & Period*Time & \\
\hline & 90 & $408 \pm 21$ & $346 \pm 25$ & $351 \pm 21$ & 0.3619 & 0.0833 & \\
\hline & 120 & $395 \pm 21$ & $363 \pm 25$ & $355 \pm 21$ & & & \\
\hline & 150 & $387 \pm 21$ & $358 \pm 25$ & $345 \pm 21$ & & & \\
\hline & 180 & $370 \pm 21$ & $333 \pm 25$ & $316 \pm 21$ & & & \\
\hline & 210 & $373 \pm 21$ & $347 \pm 25$ & $332 \pm 21$ & & & \\
\hline & 240 & $375 \pm 21$ & $336 \pm 25$ & $347 \pm 21$ & & & \\
\hline
\end{tabular}

Values are least squares means \pm standard error.

${ }^{1} \mathrm{CON}$ and LYS/THR/MET, $\mathrm{n}=6$; LYS/THR, $\mathrm{n}=5$. For the LYS/THR treatment one horse's data was omitted due to a systemic infection. 


\section{Nitrogen Retention}

Nitrogen intakes and urinary and fecal nitrogen excretions were not significantly different between treatments $(\mathrm{P}>0.05$; Table 5.2), and there was therefore no significant

difference in nitrogen absorption, nitrogen retention, nitrogen absorbed as a percentage of intake, nitrogen retained as a percentage of intake, or nitrogen retained as a percentage of absorbed between treatments ( $\mathrm{P}>0.05$; Table 5.2). 
Table 5.2 Nitrogen consumption, urinary excretion, fecal excretion and nitrogen retention in aged horses receiving concentrates with no amino acid supplementation (CON), lysine and threonine supplementation (LYS/THR) or lysine, threonine and methionine supplementation (LYS/THR/MET) over a three day collection period by treatment ${ }^{1}$

\begin{tabular}{lllll}
\hline & CON & LYS/THR & $\begin{array}{l}\text { LYS/THR/ } \\
\text { MET }\end{array}$ & $\begin{array}{l}\text { P-values } \\
\text { (Treatment) }\end{array}$ \\
\hline $\begin{array}{l}\text { Nitrogen Intake (g/kg } \\
\text { BW) }\end{array}$ & $0.38 \pm 0.005$ & $0.39 \pm 0.005$ & $0.38 \pm 0.005$ & 0.2660 \\
$\begin{array}{l}\text { Nitrogen Excreted in } \\
\text { Urine (g/kg BW) }\end{array}$ & $0.21 \pm 0.03$ & $0.22 \pm 0.03$ & $0.22 \pm 0.03$ & 0.8399 \\
$\begin{array}{l}\text { Nitrogen Excreted in } \\
\text { Feces (g/kg BW) }\end{array}$ & $0.21 \pm 0.009$ & $0.22 \pm 0.010$ & $0.21 \pm 0.009$ & 0.5328 \\
$\begin{array}{l}\text { Nitrogen Absorbed } \\
\text { (g/kg BW) }\end{array}$ & $0.17 \pm 0.008$ & $0.17 \pm 0.009$ & $0.18 \pm 0.008$ & 0.6946 \\
$\begin{array}{l}\text { Nitrogen Retained } \\
\text { (g/kg BW) }\end{array}$ & $-0.04 \pm 0.02$ & $-0.06 \pm 0.03$ & $-0.05 \pm 0.03$ & 0.8562 \\
$\begin{array}{l}\text { Nitrogen Absorbed as a } \\
\text { Percentage of Intake }(\%)\end{array}$ & $45.3 \pm 1.9$ & $43.2 \pm 2.3$ & $45.6 \pm 2.0$ & 0.6763 \\
$\begin{array}{l}\text { Nitrogen Retained as a } \\
\text { Percentage of Intake }(\%)\end{array}$ & $-10.6 \pm 5.9$ & $-15.2 \pm 6.8$ & $-12.4 \pm 6.1$ & 0.8441 \\
$\begin{array}{l}\mathbf{N}(\%) \\
\text { Percentage of } \\
\text { Absorbed }(\%)\end{array}$ & $-26.8 \pm 12.5$ & $-38.9 \pm 14.6$ & $-27.9 \pm 13.2$ & 0.7499 \\
\hline
\end{tabular}

Values are least squares means \pm standard error.

${ }^{1}$ (CON and LYS/THR/MET, $n=6$; LYS/THR, n=5). For the LYS/THR treatment one horse's data was omitted due to a systemic infection.

${ }^{2}$ Nitrogen absorbed was calculated by taking the difference between nitrogen intake and fecal nitrogen excretion.

${ }^{3}$ Nitrogen retained was calculated by taking the difference between nitrogen intake and the sum of fecal and urinary nitrogen excretion.

${ }^{4}$ Nitrogen absorbed as a percentage of intake $=($ Nitrogen Absorbed/Nitrogen Intake $) * 100$.

${ }^{5}$ Nitrogen retained as a percentage of intake $=($ Nitrogen Retained/Nitrogen Intake $) * 100$.

${ }^{6}$ Nitrogen retained as a percentage of absorbed $=($ Nitrogen Retained/Nitrogen Absorbed $) * 100$. 
Nitrogen intake was significantly lower for periods 2, 4 and 6 than for periods 1 and 3 (Figure 5.5A; $\mathrm{P}<0.05$ ), and nitrogen intake was significantly lower for period 5 than all other periods (Figure 5.5A; $\mathrm{P}<0.05$ ). Nitrogen absorbed was significantly lower for periods 4, 5 and 6 than for periods 1, 2 and 3 (Figure 5.5A; $\mathrm{P}<0.05)$. Urinary nitrogen, fecal nitrogen, nitrogen retention, nitrogen absorbed as a percentage of intake, nitrogen retained as a percentage of intake, and nitrogen retained as a percentage of absorbed were not significantly different between periods $(\mathrm{P}>0.05$; Table $5.3)$.

Nitrogen intake, absorption, and urinary and fecal excretions of nitrogen were not significantly different between days of collection $(\mathrm{P}>0.05)$. However, nitrogen absorption tended to be lower on $\mathrm{d} 10$ than on $\mathrm{d} 11$ (Figure $5.5 \mathrm{~B} ;-0.018 \mathrm{~g} \mathrm{~N} / \mathrm{kg} \mathrm{BW} / \mathrm{d} ; \mathrm{P}=0.085$ ). There was no significant difference in nitrogen retention, nitrogen absorbed as a percentage of intake, nitrogen retained as a percentage of intake, or nitrogen retained as a percentage of absorbed between days of collection (Table 5.3; P>0.05). 
Table 5.3 Nitrogen consumption, urinary excretion, fecal excretion and nitrogen retention in aged horses receiving concentrates with no amino acid supplementation (CON), lysine and threonine supplementation (LYS/THR) or lysine, threonine and methionine supplementation (LYS/THR/MET) by day of collection

\begin{tabular}{|c|c|c|c|c|}
\hline & d 10 & d 11 & d 12 & $\begin{array}{l}\text { P-values } \\
\text { (Time) }\end{array}$ \\
\hline $\begin{array}{l}\text { Nitrogen Intake(g/kg } \\
\text { BW) }\end{array}$ & $0.37 \pm 0.005$ & $0.38 \pm 0.005$ & $0.39 \pm 0.005$ & 0.0958 \\
\hline $\begin{array}{l}\text { Nitrogen Excreted in } \\
\text { Urine }(\mathrm{g} / \mathrm{kg} \mathrm{BW})\end{array}$ & $0.21 \pm 0.027$ & $0.23 \pm 0.026$ & $0.22 \pm 0.026$ & 0.7015 \\
\hline $\begin{array}{l}\text { Nitrogen Excreted in } \\
\text { Feces }(\mathrm{g} / \mathrm{kg} \mathrm{BW})\end{array}$ & $0.21 \pm 0.008$ & $0.21 \pm 0.008$ & $0.21 \pm 0.008$ & 0.7129 \\
\hline $\begin{array}{l}\text { Nitrogen Absorbed } \\
(\mathrm{g} / \mathrm{kg} \mathrm{BW})\end{array}$ & $0.16 \pm 0.007$ & $0.18 \pm 0.007$ & $0.18 \pm 0.007$ & 0.0827 \\
\hline $\begin{array}{l}\text { Nitrogen Retained }{ }^{2} \\
(\mathrm{~g} / \mathrm{kg} \mathrm{BW})\end{array}$ & $-0.05 \pm 0.026$ & $-0.05 \pm 0.025$ & $-0.04 \pm 0.025$ & 0.8141 \\
\hline $\begin{array}{l}\text { Nitrogen Absorbed as a } \\
\text { Percentage of Intake }(\%)\end{array}$ & $42.2 \pm 1.9$ & $46.1 \pm 1.9$ & $45.7 \pm 1.9$ & 0.2047 \\
\hline $\begin{array}{l}\text { Nitrogen Retained as a } \\
\text { Percentage of Intake }(\%)\end{array}$ & $-13.7 \pm 6.3$ & $-13.9 \pm 6.1$ & $-10.7 \pm 6.1$ & 0.8960 \\
\hline $\begin{array}{l}\text { Nitrogen Retained as a } \\
\text { Percentage of } \\
\text { Absorbed }^{6}(\%)\end{array}$ & $-35.1 \pm 14.3$ & $-31.2 \pm 13.8$ & $-27.4 \pm 13.8$ & 0.9142 \\
\hline
\end{tabular}

Values are least squares means \pm standard error.

${ }^{1}$ Periods $1,2,3,5$ and $6, n=3$; Period 4, $n=2$. For period 4, one horse's data was omitted due to a systemic infection.

${ }^{2}$ Nitrogen retained was calculated by taking the difference between nitrogen intake and the sum of fecal and urinary nitrogen excretion.

${ }^{3}$ Nitrogen absorbed was calculated by taking the difference between nitrogen intake and fecal nitrogen excretion.

${ }^{4}$ Nitrogen absorbed as a percentage of intake $=($ Nitrogen Absorbed/Nitrogen Intake $) * 100$.

${ }^{5}$ Nitrogen retained as a percentage of intake $=($ Nitrogen Retained/Nitrogen Intake $) * 100$.

${ }^{6} \mathrm{Nitrogen}$ retained as a percentage of absorbed $=($ Nitrogen Retained/Nitrogen Absorbed $) * 100$. 
Figure 5.5 Nitrogen intake and absorption in aged horses receiving concentrates with no amino acid supplementation (CON), lysine and threonine supplementation (LYS/THR) or lysine, threonine and methionine supplementation (LYS/THR/MET) A: By period ${ }^{1}$

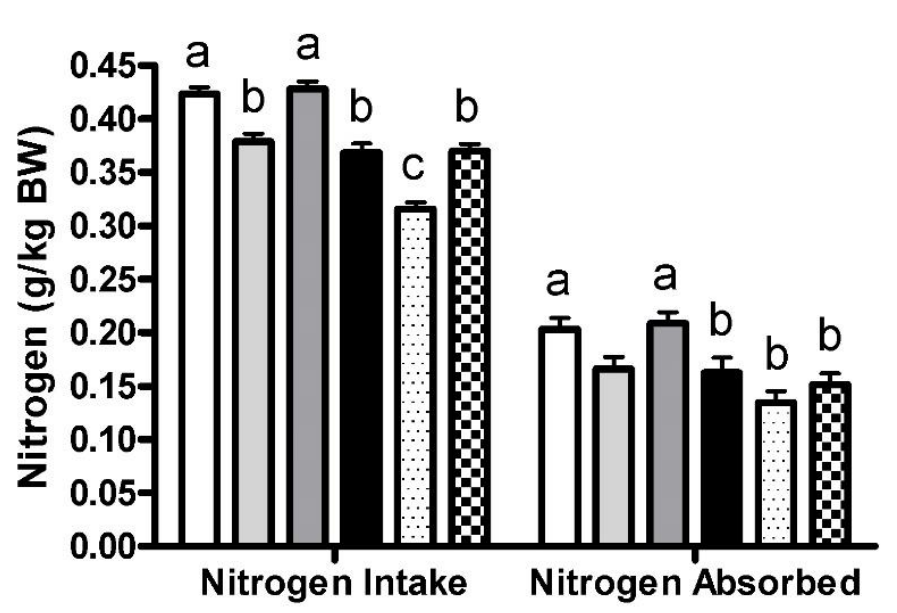

Period
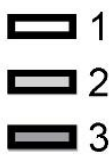

4

5

묘 6

Nitrogen Intake: $P=0.0002$

Nitrogen Absorbed: $P=0.0142$

B: By day of collection

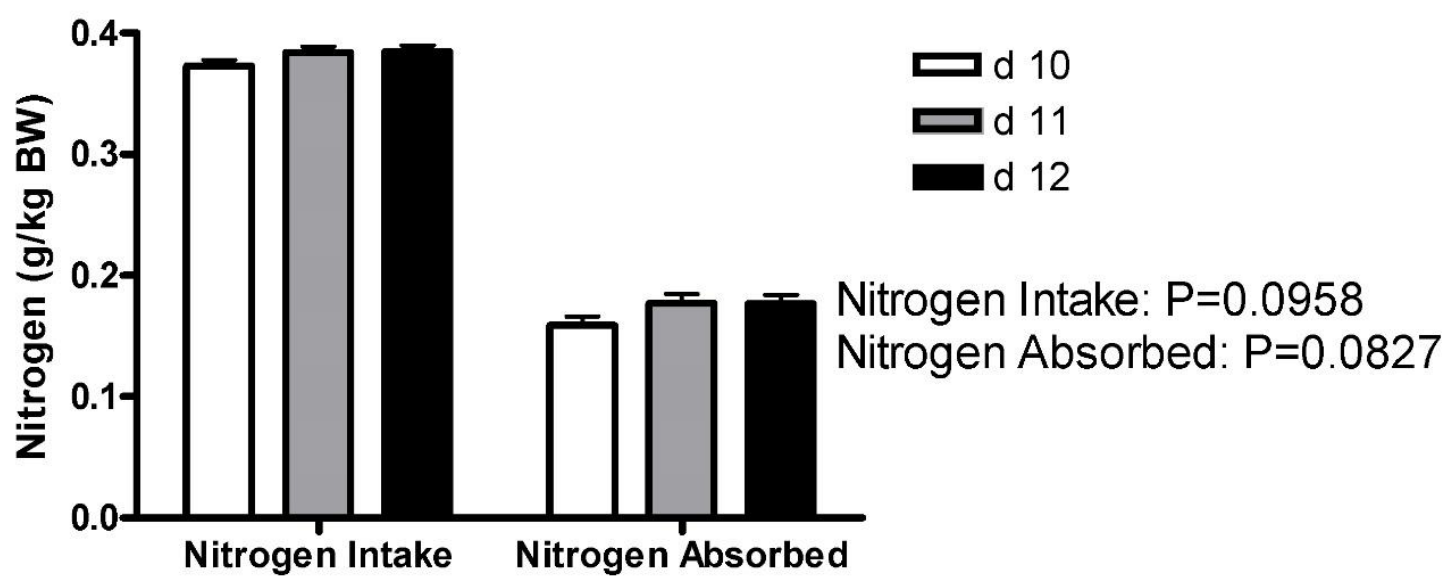

Values are least squares means \pm standard error

${ }^{1}$ Period $1,2,3,5$ and $6, n=3$, period $4, n=2$. For period 4, one horse's data was omitted due to a systemic infection. 


\section{Urinary Creatinine Output}

Urinary creatinine output did not differ significantly (Figure 5.6 A; P=0.58) between treatments. There was a significant effect of period on urinary creatinine output. Urinary creatinine output was significantly higher in period 1, 2, 4 and 5 than in period 3 and 6 (Figure $5.6 \mathrm{~B} ; \mathrm{P}<0.05$ ). Additionally, there was a significant effect of day of collection on urinary creatinine output. Urinary creatinine output tended to be higher on d 10 of collection than on $\mathrm{d} 11$ (Figure $5.5 \mathrm{C} ; 12.2 \mathrm{mmol} / \mathrm{d} ; \mathrm{P}=0.058$ ) and was significantly higher on d 10 of collection than on d 12 (Figure $5.5 \mathrm{C} ; 21.8 \mathrm{mmol}$ creatinine/d; $\mathrm{P}=$ $0.0003)$. 
Figure 5.6 Daily creatinine output in aged horses receiving concentrates with no amino acid supplementation (CON), lysine and threonine supplementation (LYS/THR) or lysine, threonine and methionine supplementation (LYS/THR/MET)

A: By treatment ${ }^{1}$

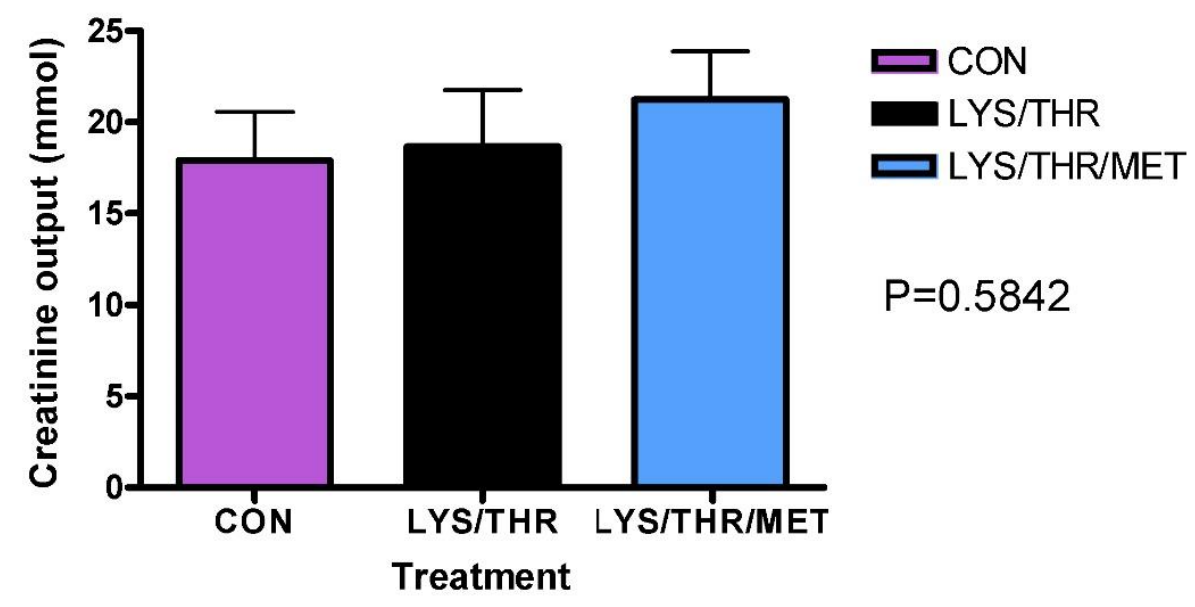

B: By period ${ }^{2}$

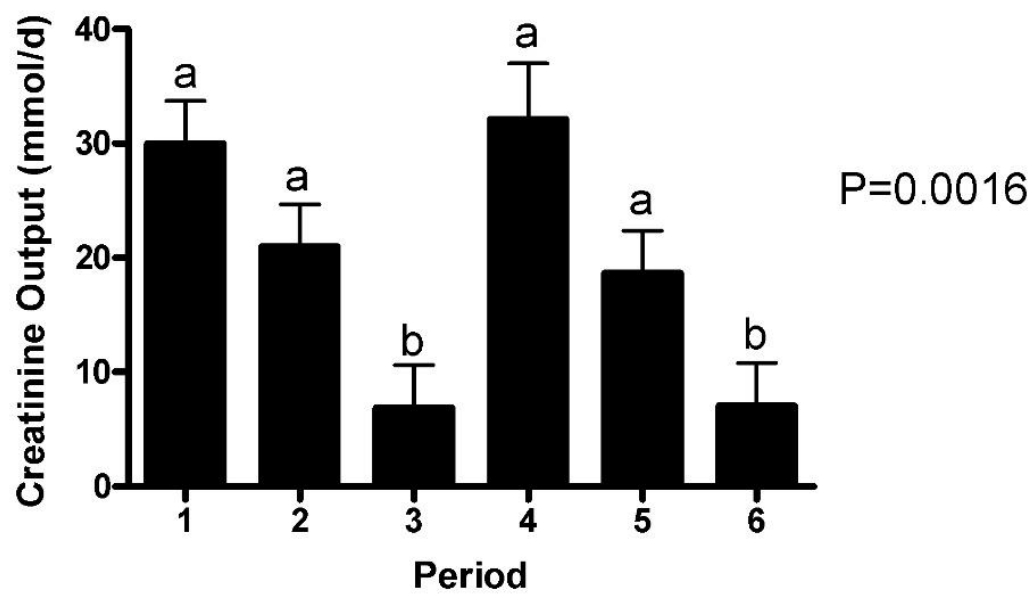


Figure 5.6 Continued

\section{C: By day of collection ${ }^{3}$}

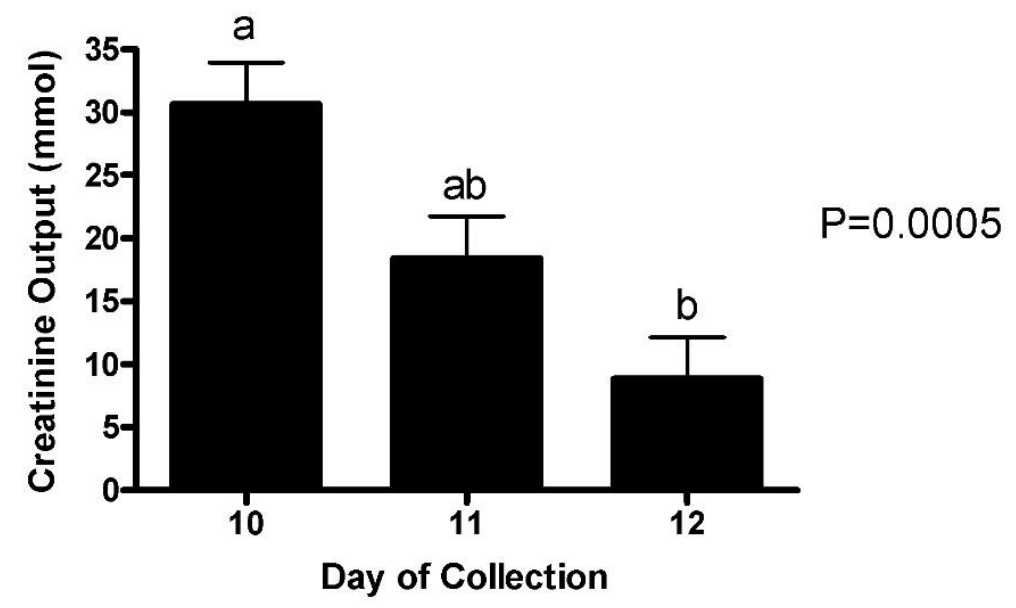

${ }^{1} \mathrm{CON}$ and LYS/THR/MET, $\mathrm{n}=6$; LYS/THR, $\mathrm{n}=5$. For the LYS/THR treatment one horse's data was omitted due to a systemic infection.

${ }^{2}$ Period 1, 2, 3, 5 and 6, $\mathrm{n}=3$; Period 4, $\mathrm{n}=2$. For the period 4, one horse's data was omitted due to a systemic infection.

${ }^{3}$ Creatinine output for each collection day within a period 


\section{Phenylalanine Kinetics}

There was no significant effect of treatment on $\mathrm{CO}_{2}$ production, phenylalanine flux, phenylalanine intake, phenylalanine oxidation, non-oxidative phenylalanine disposal or phenylalanine release from protein breakdown $(\mathrm{P}>0.05$; Table 5.4). However, it is noted that for all three treatments, phenylalanine release from protein breakdown is consistently higher than non-oxidative phenylalanine disposal. 
Table 5.4 Whole-body phenylalanine kinetics in aged horses receiving concentrates with no amino acid supplementation (CON), lysine and threonine supplementation (LYS/THR) or lysine, threonine and methionine supplementation (LYS/THR/MET) ${ }^{1}$

\begin{tabular}{|c|c|c|c|c|c|}
\hline & $\mathrm{CON}$ & LYS/THR & $\begin{array}{l}\text { LYS/THR } \\
\text { /MET }\end{array}$ & $\begin{array}{l}\text { p-value } \\
\text { (Treatment) }\end{array}$ & $\begin{array}{l}\text { p-value } \\
\text { (Period) }\end{array}$ \\
\hline $\begin{array}{l}\mathrm{CO}_{2} \\
\text { Production } \\
(\mu \mathrm{mol} / \mathrm{kg} \\
\mathrm{BW} / \mathrm{h})\end{array}$ & $15993 \pm 366$ & $15004 \pm 452$ & $15415 \pm 366$ & 0.2769 & 0.5769 \\
\hline $\begin{array}{l}\text { Phenylalanine } \\
\text { Flux } \\
(\mu \mathrm{mol} / \mathrm{kg} / \mathrm{h})\end{array}$ & $59 \pm 2.98$ & $61 \pm 3.57$ & $61 \pm 2.98$ & 0.8447 & 0.2685 \\
\hline $\begin{array}{l}\text { Phenylalanine } \\
\text { Intake } \\
(\mu \mathrm{mol} / \mathrm{kg} / \mathrm{h})\end{array}$ & $9.9 \pm 0.11$ & $9.7 \pm 0.13$ & $9.7 \pm 0.11$ & 0.2774 & $<0.0001$ \\
\hline $\begin{array}{l}\text { Phenylalanine } \\
\text { Released from } \\
\text { Protein } \\
\text { Breakdown } \\
(\mu \mathrm{mol} / \mathrm{kg} / \mathrm{h})\end{array}$ & $49 \pm 2.99$ & $51 \pm 3.59$ & $52 \pm 2.99$ & 0.8144 & 0.2785 \\
\hline $\begin{array}{l}\text { Phenylalanine } \\
\text { Oxidation } \\
(\mu \mathrm{mol} / \mathrm{kg} / \mathrm{h})\end{array}$ & $19 \pm 1.12$ & $19 \pm 1.19$ & $18 \pm 1.12$ & 0.1898 & 0.6489 \\
\hline $\begin{array}{l}\text { Non-oxidative } \\
\text { Phenylalanine } \\
\text { Disposal } \\
(\mu \mathrm{mol} / \mathrm{kg} / \mathrm{h})\end{array}$ & $40 \pm 2.32$ & $42 \pm 2.66$ & $44 \pm 2.32$ & 0.6154 & 0.1604 \\
\hline
\end{tabular}

Values are least squares means \pm standard error.

${ }^{1} \mathrm{CON}$ and LYS/THR/MET, n = 6; LYS/THR, n=5. For the LYS/THR treatment one horse's data was omitted due to a systemic infection. 


\section{Muscle Protein Synthesis and Degradation Signaling Akt and rpS6}

Akt and rpS6 proteins are associated with stimulation of protein synthesis signaling. rpS6 activation (amount of phosphorylated corrected for total) was significantly higher $(\mathrm{P}<0.0001$; Figure 5.8) after meal feeding, but there was no significant effect of meal feeding on Akt activation ( $\mathrm{P}=0.11$; Figure 5.7). Additionally, there was no significant effect $(\mathrm{P}>0.05$; Figure $5.7 \& 5.8)$ of treatment, treatment by time interaction, period or period by time interaction on the activation of Akt or rpS6. 
Figure 5.7 Before the morning meal (Pre) and after the morning meal (Post) activation of Akt (arbitrary units) in aged horses receiving concentrates with no amino acid supplementation (CON), lysine and threonine supplementation (LYS/THR) or lysine, threonine and methionine supplementation (LYS/THR/MET) $\mathbf{A}^{1}$

\section{CON LYS/THR LYS/THR/MET}

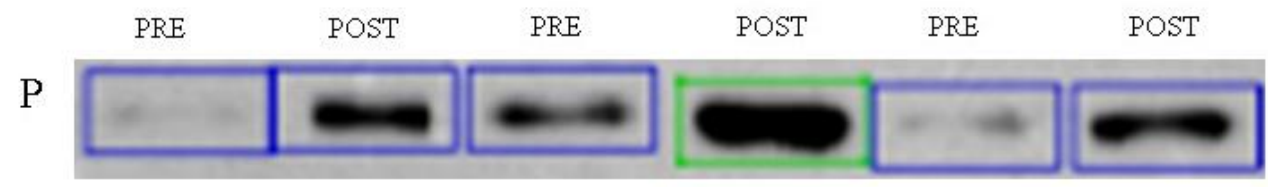

$\mathrm{T}$

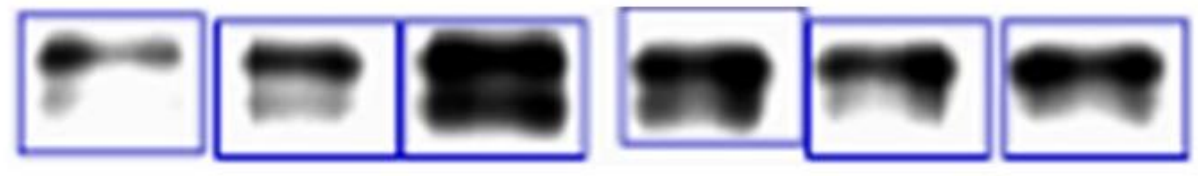

$\mathbf{B}^{2}$

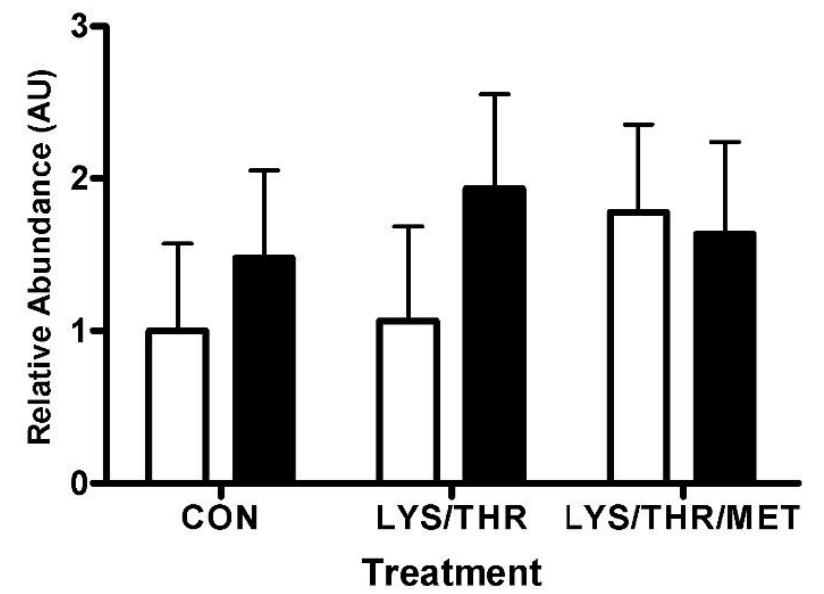

pre-feeding

Treatment: $P=0.5660$

Time: $P=0.1131$

Treatment * Time: $P=0.2741$

CON, $n=6 ;$ LYS/THR and LYS/THR/MET post, $n=5$. For the LYS/THR treatment one horse's data was omitted due to a systemic infection.

For the LYS/THR/MET treatment post time point $\mathrm{n}=5$. One horse's data was omitted due to injury and inability to collect sample.

${ }^{1}$ Representative western blots of phosphorylated $(\mathrm{P})$ and total $(\mathrm{T})$ forms of Akt

${ }^{2}$ Least squares mean \pm pooled standard error expression of phosphorylated form of Akt in gluteal muscle samples taken in the pre-feeding state (white bars) and the post-feeding state (black bars). Expression of the phosphorylated form of Akt was expressed relative to total expression, and the values for pre-feeding CON horses were expressed as an arbitrary value of 1.0. 
Figure 5.8 Before the morning meal (Pre) and after the morning meal (Post) activation of rpS6 (arbitrary units) in aged horses receiving concentrates with no amino acid supplementation (CON), lysine and threonine supplementation (LYS/THR) or lysine, threonine and methionine supplementation (LYS/THR/MET) $\mathbf{A}^{\mathbf{1}}$

\section{CON LYS/THR LYS/THR/MET}

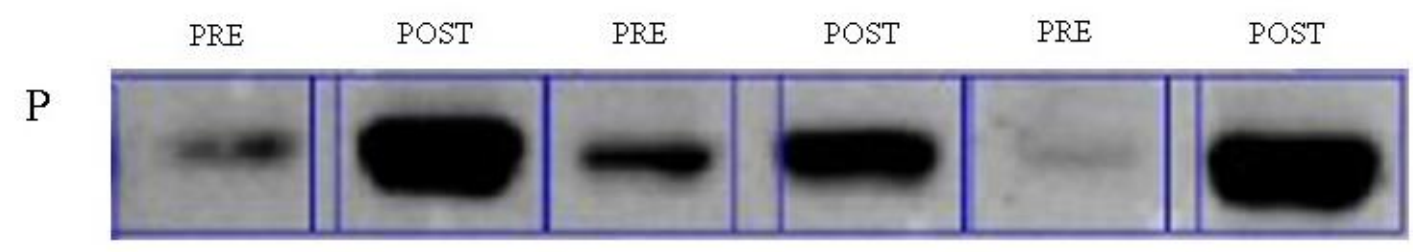

$\mathrm{T}$

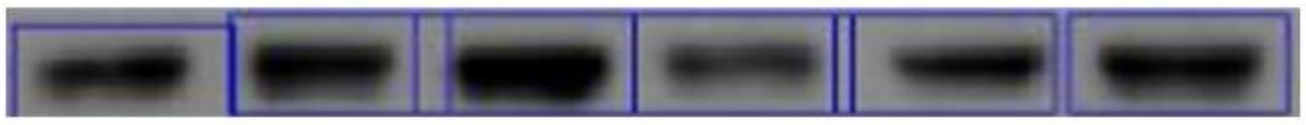

$\mathbf{B}^{2}$

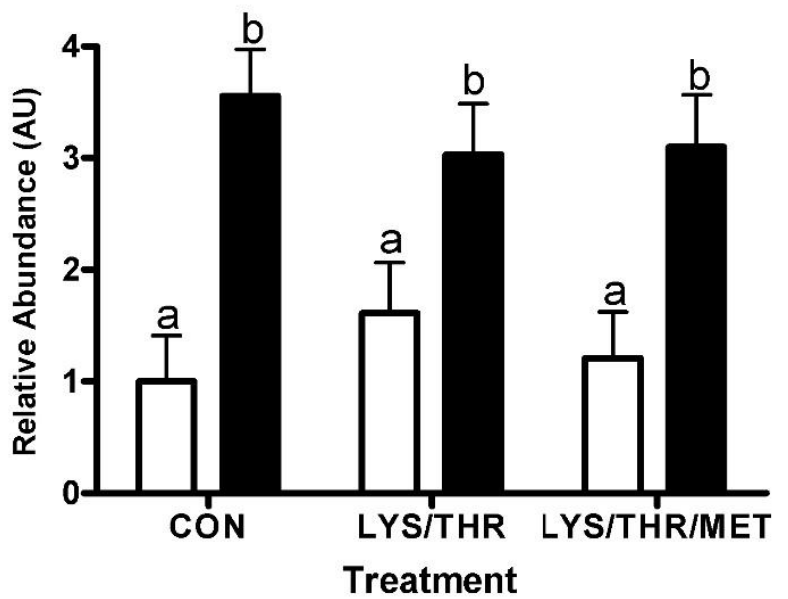

$\square$ pre-feeding

post-feeding

Treatment: $P=0.8754$

Time: $P<0.0001$

Treat * Time: $\mathrm{P}=0.2981$

CON, n=6; LYS/THR and LYS/THR/MET post, $n=5$. For the LYS/THR treatment one horse's data was omitted due to a systemic infection.

For the LYS/THR/MET treatment post time point $\mathrm{n}=5$. One horse's data was omitted due to injury and inability to collect sample.

${ }^{1}$ Representative western blots of phosphorylated (P) and total (T) forms of rpS6

${ }^{2}$ Least squares mean \pm pooled standard error expression of phosphorylated form of rpS6 in gluteal muscle samples taken in the pre-feeding state (white bars) and the post-feeding state (black bars). Expression of the phosphorylated form of rpS6 was expressed relative to total expression, and the values for pre-feeding CON horses were expressed as an arbitrary value of 1.0. 


\section{Atrogin-1}

Atrogin-1 is a protein associated with muscle protein degradation. There was no significant effect of treatment or time on Atrogin-1 activation ( $\mathrm{P}>0.05$; Figure 5.9), however, there was a significant $(\mathrm{P}=0.035$; Figure 5.9) treatment by time interaction, where post-feeding CON activation tended to be lower than pre-feeding CON activation $(\mathrm{P}=0.068)$. There was no significant effect of period $(\mathrm{P}=0.50)$ or period by time interaction $(\mathrm{P}=0.20)$ on Atrogin-1 abundance. 
Figure 5.9 Before the morning meal (Pre) and after the morning meal (Post) relative abundances of Atrogin-1 (arbitrary units) in aged horses receiving concentrates with no amino acid supplementation $(\mathrm{CON})$, lysine and threonine supplementation (LYS/THR) or lysine, threonine and methionine supplementation (LYS/THR/MET) $\mathbf{A}^{1}$

\section{CON LYS/THR LYS/THR/MET}

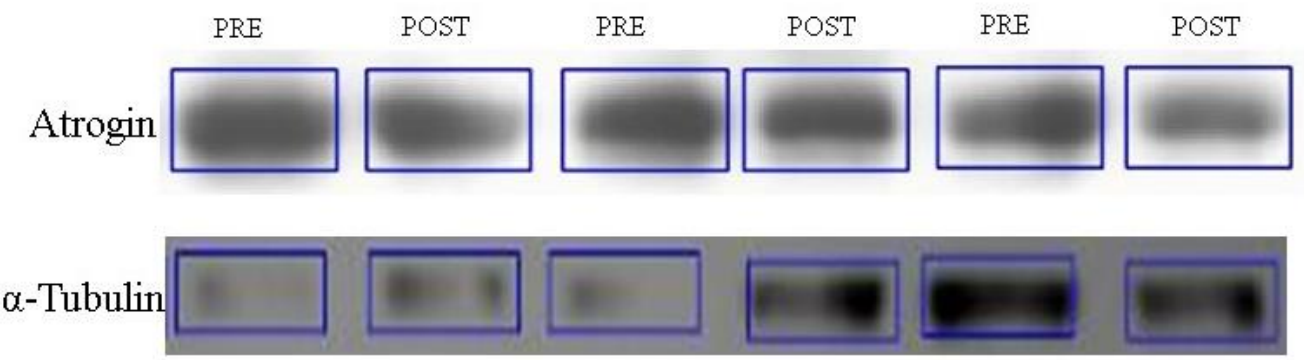

$\mathbf{B}^{2}$

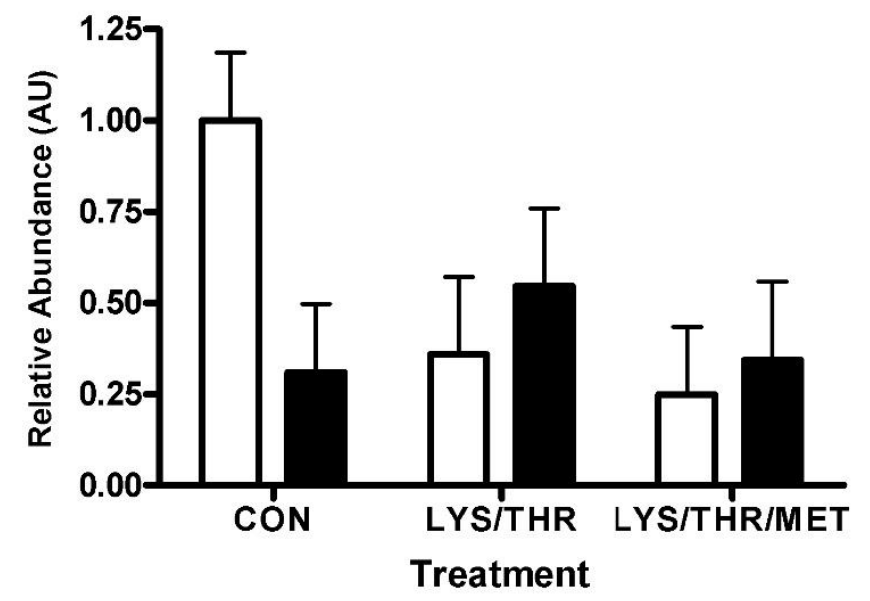

pre-feeding

Treatment: $P=0.3280$

Time: $P=0.3176$

Treatment * Time: $\mathrm{P}=0.0347$

CON, n=6; LYS/THR and LYS/THR/MET post, $\mathrm{n}=5$. For the LYS/THR treatment one horse's data was omitted due to a systemic infection.

For the LYS/THR/MET treatment post time point $\mathrm{n}=5$. One horse's data was omitted due to injury and inability to collect sample.

${ }^{1}$ Representative western blots of Atrogin- 1 and $\alpha$-Tubulin

${ }^{2}$ Least squares mean \pm pooled standard error expression of Atrogin- 1 in gluteal muscle samples taken in the pre-feeding state (white bars) and the post-feeding state (black bars). Expression of Atrogin-1 was expressed relative to $\alpha$-Tubulin, a control for total protein expression, and the values for pre-feeding CON horses were expressed as an arbitrary value of 1.0. 


\begin{abstract}
AMPK
AMPK is a protein associated with inhibition of protein synthesis signaling There was no significant effect of treatment or time (P>0.05; Figure 5.10) on AMPK activation. However, there was a significant effect of period $(\mathrm{P}=0.040$; Figure 5.10) on AMPK activation, where AMPK activation appears to increase, although not significantly $(\mathrm{P}>0.05)$, from collection period one to six. Additionally, there tended to be a significant treatment by time interaction $(\mathrm{P}=0.069)$, where the $\mathrm{CON}$ treatment and LYS/THR/MET treatment had slightly, but not significantly, higher post-feeding values of AMPK activation, but the LYS/THR treatment had slightly, but not significantly, higher $(\mathrm{P}>0.05)$ pre-feeding values of AMPK activation. Finally, there tended to be a significant period by time interaction $(\mathrm{P}=0.066)$ on $\mathrm{AMPK}$ activation, where period one and two had similar pre- and post-fed levels of AMPK activation, period three and four had slightly, but not significantly, lower $(\mathrm{P}>0.05)$ pre-feeding levels of AMPK activation, and period five and six had slightly, but not significantly, higher $(\mathrm{P}>0.05)$ pre- feeding values compared to post-feeding AMPK activation.
\end{abstract}


Figure 5.10 Before the morning meal (Pre) and after the morning meal (Post) relative abundances of AMPK (arbitrary units) in aged horses receiving concentrates with no amino acid supplementation (CON), lysine and threonine supplementation (LYS/THR) or lysine, threonine and methionine supplementation (LYS/THR/MET)

$\mathbf{A}^{1}$

CON
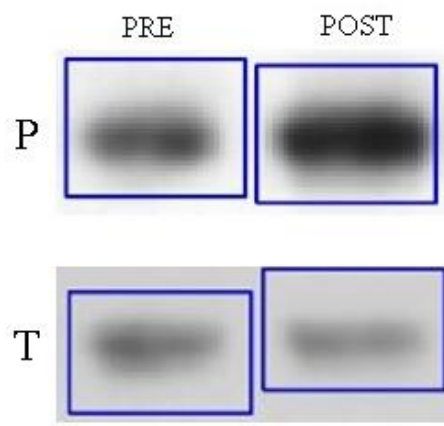

\section{LYS/THR LYS/THR/MET}
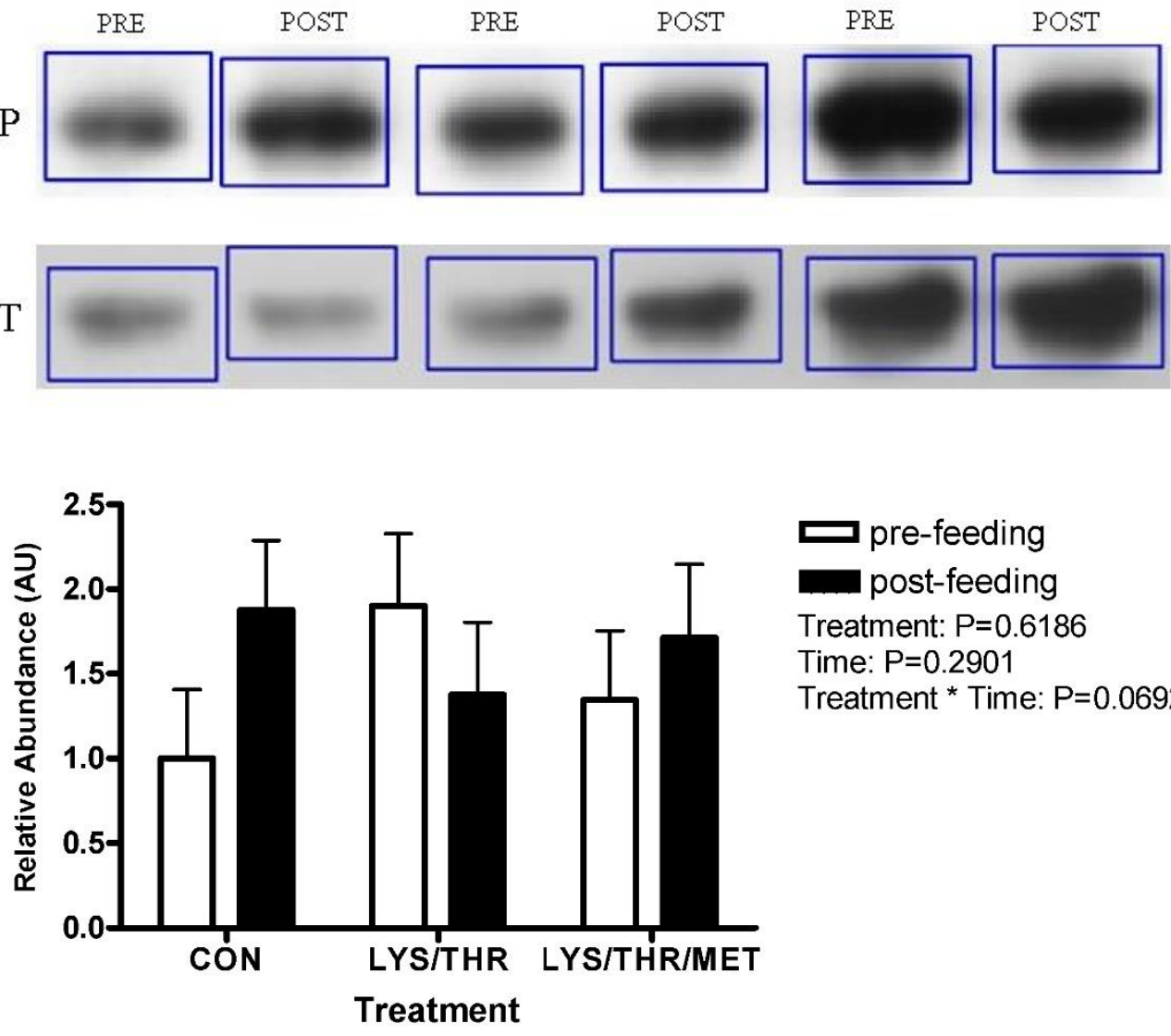

pre-feeding

post-feeding

Treatment: $P=0.6186$

Time: $P=0.2901$

Treatment * Time: $P=0.0692$ 


\section{Figure 5.10 Continued}

\section{C: AMPK by Period}

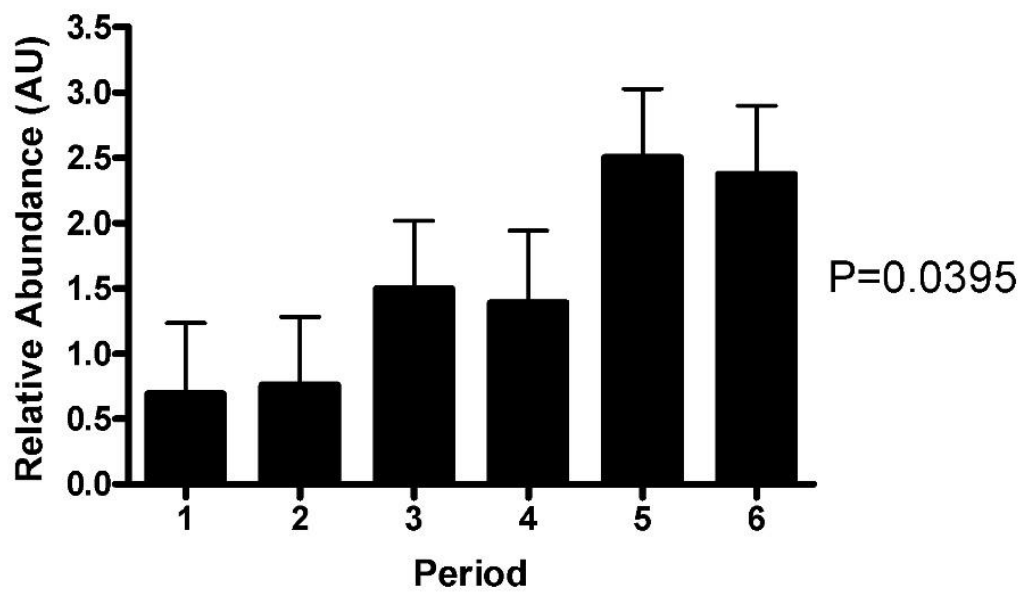

CON, n=6; LYS/THR and LYS/THR/MET post, n=5. For the LYS/THR treatment one horse's data was omitted due to a systemic infection.

For the LYS/THR/MET treatment post time point $\mathrm{n}=5$. One horse's data was omitted due to injury and inability to collect sample.

${ }^{1}$ Representative western blots of phosphorylated (P) and total (T) forms of AMPK

${ }^{2}$ Least squares mean \pm pooled standard error expression of phosphorylated form of AMPK in gluteal muscle samples taken in the pre-feeding state (white bars) and the post-feeding state (black bars).

Expression of the phosphorylated form of AMPK was expressed relative to total expression, and the values for pre-feeding CON horses were expressed as an arbitrary value of 1.0.

${ }^{3}$ Period $1,2,3,5$ and $6, n=3$; Period $4, n=2$. For the period $4 n=2$. One horse's data was omitted due to a systemic infection 


\section{Chapter 6. Discussion}

\section{Crude Protein Intake}

Although the treatments in this study were designed to meet or slightly exceed recommended nutrient intakes for mature horses at maintenance, an unexpectedly high crude protein and digestible energy content of the hay cubes led to a higher crude protein and digestible energy intake than was expected. There was approximately a 5.5 Mcal digestible energy, and a $670 \mathrm{~g}$ excess crude protein intake (for a $500 \mathrm{~kg}$ horse) per day. Because of this, it is likely that the horses on the $\mathrm{CON}$ treatment were already consuming more amino acids than they required, and it is not likely that further supplementation with amino acids above the CON intakes would have shown improvements in whole-body or muscle protein metabolism.

\section{Body Weight}

The significant effect of treatment on body weight suggests that horses receiving the LYS/THR/MET treatment gained more weight over the course of the period than horses receiving the LYS/THR treatment. However, there was also a significant effect of period on body weight, where horses seemed to gain an appreciable amount of weight over their first experimental period (periods 1 and 4), and then lose weight during their second experimental period (periods 2 and 5). Since horses were kept on pasture prior to being enrolled in our experiment, there was a large difference in diet composition between their previous diets and the adaptation and experimental treatments. Thus, it seems that horses may have been experiencing changes in body weight in response to 
changes in diet during the first experimental period. This would suggest that the 2 weeks of adaptation to housing and diets prior to the beginning of experimental procedures was not a sufficient amount of time for the horses to adapt. Additionally, differences in weight gain between treatments are likely due to natural variation in adaptation and weight gain, rather than a true effect of treatment.

\section{Plasma Glucose, Insulin, Urea Nitrogen and Creatinine Concentrations}

Peak glucose concentrations occurred at approximately 60 minutes after feeding and peak insulin concentrations occurred at approximately 120 minutes after feeding, suggesting that horses were in a fed state approximately 60 minutes after consuming a meal. Similar plasma glucose and insulin concentrations in response to meal feeding suggest a similar glycemic and insulinemic responses between treatments. Horses had the expected post-prandial glycemic and insulinemic responses, and glucose and insulin concentrations were within normal ranges, and similar to previously reported data (Ralston et al., 1988; Stull and Rodiek, 1988).

No significant difference in PUN concentrations over time suggests that circulating PUN concentrations were not influenced by feeding a meal. There was a significant effect of period, where PUN concentrations were significantly higher for periods 1-3 than for 4-6. This difference is likely due to the fact that periods 1-3 used geldings, and periods 4-6 used mares. PUN concentrations have been shown to be significantly affected by sex in other species such as pigs, where PUN concentrations were higher for barrows than for gilts at 149 days of age, although the same patterns of 
PUN concentrations and sex were not observed at 107 and 128 days of age (Klindt et al., 2006).

\section{PUN concentrations $(\mathrm{CON}=4.75 ; \mathrm{LYS} / \mathrm{THR}=5.11 ; \mathrm{LYS} / \mathrm{THR} / \mathrm{MET}=5.21$}

$\mathrm{mmol} / \mathrm{L} ; \mathrm{P}<0.0001)$ were similar to values previously reported in aged horses, where concentrations were higher for horses not supplemented with amino acids $(7.44 \pm 0.31$ $\mathrm{mmol} / \mathrm{L})$ than horses supplemented with lysine and threonine $(5.59 \pm 0.31$ mmol/L)(Graham-Thiers and Kronfeld, 2005). Additionally, the concentrations were slightly higher than concentrations observed in foals and yearlings that were either fed a basal diet that was $14 \%$ crude protein $(\mathrm{PUN}=3.12 \pm 0.06 \mathrm{mmol} / \mathrm{L})$ or fed a lower protein $(\mathrm{CP}=8.5 \%)$ diet supplemented with lysine and threonine (PUN=3.13 $\pm 0.06 \mathrm{mmol} / \mathrm{L})$, in a study that also showed no effect of supplementation on PUN concentrations (Staniar et al., 2001). It is worth noting that both in the present study and in the study of weanlings and yearlings (Staniar et al., 2001), where there was no significant effect of supplementation on PUN concentrations, animals were not regularly exercised, whereas in the previous study that did observe treatment related differences in PUN concentrations (Graham-Thiers and Kronfeld, 2005), horses were in an exercise program. It is likely that in the sedentary horses in the present study, amino acid requirements were met by the basal diet, as the crude protein intake for the CON treatment was higher than what is currently recommended (NRC, 2007). In the previous study the crude protein intakes were likely closer to the actual requirement, because of a combination of lower crude protein intake and exercise. Therefore, it is reasonable to have observed differences in PUN concentrations between treatments in the previous study. 
Significant effects of treatment on PUN concentrations suggest that there are differences in dietary amino acid use between treatments. PUN concentrations in horses receiving amino acid supplementation, LYS/THR and LYS/THR/MET, relative to CON suggest a greater catabolism of absorbed dietary amino acids. This could indicate that the supplemented amino acids were not contributing to additional protein synthesis, but were instead being catabolized. This similar degree of catabolism of supplemented dietary amino acids suggests that neither lysine, threonine, nor methionine were limiting amino acids in the CON diet. Diets were formulated to be isonitrogenous, and nitrogen intakes were therefore similar across all treatments, despite the supplementation of amino acids. However, the additional amino acids in the $\mathrm{CON}$ diet were protein-bound, as the CON diet was kept isonitrogenous by altering the contributions of wheat middlings and soybean hulls (Table 4.3). Therefore, if digestion of the protein-containing fractions was not complete in the small intestine, the additional amino acids in the CON treatment may not have been available for absorption as in the supplemented treatments, resulting in less absorption of amino acids, and therefore less catabolism as evidenced by PUN concentrations. However, it is worth noting that nitrogen absorption as calculated from the difference between intake and fecal excretion did not show significant differences between treatments (Table 5.2). However, it is also important to note that the reported values for nitrogen absorption are only an estimate based on intake and excretion, not a direct measurement of absorption, and therefore may not have been sensitive enough to identify small differences in nitrogen excretion as may have been caused by fecal excretion of the relatively small amounts of supplemented free amino acids. 
There were no significant effects of treatment on plasma creatinine concentrations, which suggests that there were not significant differences in muscle mass between treatments. The observed plasma creatinine concentrations were similar to those published in previous studies of aged horses (Graham-Thiers and Kronfeld, 2005). While some studies have shown increases in plasma creatinine concentrations in response to supplementation of specific amino acids (Graham-Thiers and Kronfeld, 2005; da Costa Cordeiro Manso et al., 2015), the same improvement in plasma creatinine concentration was not observed in this study. This result could be due to the fact that 15 days of adaptation to a diet without the influence of exercise might not be a sufficient amount of time to induce significant changes in muscle mass, as other studies have used between 30 days (da Costa Cordeiro Manso et al., 2015) and 14 weeks (Graham-Thiers and Kronfeld, 2005) of adaptation to diet before re-assessing creatinine levels. However, when taken together with lack of significant differences in whole-body phenylalanine kinetics and nitrogen balance, the data suggests that the supplementation of lysine and threonine, or lysine, threonine and methionine did not positively alter amino acid metabolism and protein synthesis, and it is therefore unlikely that there would have been significant changes in muscle mass if given a longer adaptation time. Additionally, in previous studies showing significant improvements in plasma creatinine concentrations, horses were in a regular exercise program, in addition to receiving amino acid supplementation (Graham-Thiers and Kronfeld, 2005; da Costa Cordeiro Manso et al., 2015). Therefore, improvements in muscle mass as indicated by plasma creatinine concentrations may have been due to a combination of amino acid supplementation and exercise, rather than amino acid supplementation alone. 
It is interesting to note that there tended to be an effect of period, and that period 5 had higher plasma creatinine concentrations compared to other periods. However, there was not a significant difference of any other variable measured for period five, including urinary creatinine output, which was not significantly different from periods one, two, or four. Therefore, the cause of the high plasma creatinine concentration in period five is unknown.

\section{Plasma Amino Acid Concentrations}

In the present study, all measured plasma amino acid concentrations except glutamate, glycine and tryptophan were significantly affected by time, and increased after feeding a meal. This confirms that dietary amino acids were being absorbed during the time of blood sampling. These results are similar to a previous study examining the effects of threonine supplementation on plasma metabolite concentrations in growing and mature horses, where all amino acid concentrations except glutamate, tryptophan and aspartate were higher 90 minutes after feeding a meal compared to the pre-feeding baseline (Mastellar et al., 2016b). These results are in contrast to a previous study examining the effects of pituitary pars intermedia dysfunction on whole-body phenylalanine kinetics and skeletal muscle protein signaling in aged horses, where there was no observed increase in plasma amino acid concentrations 90 minutes after feeding a meal, despite increases in plasma glucose and insulin concentrations, suggesting that horses were in a postprandial state (Mastro et al., 2014). The differences observed between studies likely result from the fact that the aforementioned previous studies only analyzed samples taken directly before feeding, and 90 minutes after consuming a meal, 
whereas the present study examined samples every 30 minutes from 30 minutes before feeding a meal to 240 minutes after feeding a meal. Because of the small window of time in which samples in the previous studies were taken, small differences in rates of digestion and absorption or metabolism of amino acids could account for the differences seen. However, it should be noted that in the present study, the plasma amino acid concentrations of the 90 minute samples were significantly higher than plasma amino acid concentrations of both the -30 min and the 0 min baseline samples $(\mathrm{P}<0.05$; Table 5.1) for all of the amino acids that showed a significant effect of time on plasma amino acid concentration. Additionally, horses in the present study were consuming approximately twice the recommended protein intake, which could have led to larger post-feeding changes in plasma amino acid concentrations than were observed in the previous studies.

As expected, plasma lysine and threonine concentrations were significantly higher in horses receiving LYS/THR and LYS/THR/MET than when horses received the CON treatment. Lysine and threonine concentrations peaked at approximately 60 minutes, similar to glucose and insulin concentrations. Plasma concentrations of methionine peaked between 90 and 120 minutes, and as expected, the supplementation of methionine resulted in significantly higher plasma methionine concentrations. However, it is interesting to note that supplementation of lysine and threonine also resulted in higher plasma methionine concentrations when compared to CON. Elevated methionine concentrations in response to threonine supplementation have been previously documented in horses, and have been suggested to result from negative feedback of threonine degradation (Mastellar et al., 2016b). Since threonine degradation (Dale, 1978) 
and methionine degradation (Finkelstein, 1990) can both lead to the production of $\alpha$ ketobutyrate, it is possible that increases in threonine degradation of the supplemented threonine produced $\alpha$-ketobutyrate, which fed back to inhibit the degradation of methionine, and resulted in increased plasma methionine concentrations. Conversely, there was a small amount of DL - Methionine added to the LYS/THR concentrate to maintain similar methionine levels between treatments as the ratios of soybean hulls and wheat middlings were altered (Table 4.3). Since the DL - Methionine added was in the form of crystalline amino acid, it is possible that it was absorbed more readily than the methionine in the CON treatment, leading to increased methionine concentrations compared to the CON treatment. Furthermore, it is interesting that methionine concentrations peaked approximately 30 minutes later than lysine and threonine concentrations, suggesting either a delay in digestion or absorption of methionine.

In addition to significant differences in plasma concentrations of the supplemented amino acids, there was a significant effect of treatment on the plasma concentrations of glutamate, leucine, phenylalanine and serine. Glutamate was significantly higher for CON than for LYS/THR (22.7 mmol/L; P=0.0379) and tended to be higher for CON than for LYS/THR/MET (16.7 mmol/L; P=0.094). Differences in plasma glutamate concentrations likely resulted from differences in metabolism of other amino acids. Glutamate is a common acceptor of ammonia in nitrogen sparing reactions, and is the preferred nitrogen donor in many transamination reactions (Mourtzakis and Graham, 2002). Therefore, the higher glutamate concentrations for CON suggest that more amino acids were being transaminated to glutamate as a result of excess dietary amino acid intake, to spare nitrogen that would be lost during amino acid catabolism and 
excretion. This increase in nitrogen sparing could be responsible for the decreased plasma urea concentrations observed in CON as compared to LYS/THR and LYS/THR/MET. Conversely, higher plasma glutamate concentrations could be owing to the fact that glutamate/glutamine concentrations were slightly higher for the $\mathrm{CON}$ concentrate (1.58\%) than for the LYS/THR (1.43\%) and LYS/THR/MET (1.35\%) concentrates (Table 4.2). However, it is unlikely that these small differences in intake could have accounted for the differences in plasma glutamate observed.

Serine concentrations were significantly higher for LYS/THR than for LYS/THR/MET, and glycine concentrations tended to be affected by the treatment*time interaction, where glycine concentrations peaked earlier and more sharply for LYS/THR and LYS/THR/MET than for CON. Differences between treatments likely arise because threonine, glycine and serine metabolism are closely linked. In order to enter the citric acid cycle, hydrocarbons from threonine and glycine are converted to serine. Therefore, increases in glycine, serine and PUN concentrations for LYS/THR and LYS/THR/MET suggest that the supplemented threonine was being catabolized. Increasing dietary threonine intake has been shown to increase concentrations of serine and glycine in swine (Edmonds and Baker, 1987), and to increase glycine concentrations in horses (Mastellar et al., 2016b).

\section{Nitrogen Metabolism and Urinary Creatinine Output}

The lack of significant differences in nitrogen balance between treatments further supports the conclusion that there were no significant improvements in whole body nitrogen metabolism when potentially limiting amino acids were supplemented in the diet 
of aged horses. Furthermore, the consistently slightly negative nitrogen balance suggests a net loss of nitrogen, and therefore of body protein. Negative nitrogen balance could be indicative of a net loss of skeletal muscle protein, and therefore muscle mass, which could be indicative of muscle wasting, as is the case for aged animals experiencing sarcopenia. In humans, increased proportions of non-muscle protein in the body, namely visceral tissue, which is known to have a relatively high protein turnover rate, have been linked to higher protein intakes required to maintain nitrogen balance, and authors suggest that higher protein intakes may minimize sarcopenia (Morais et al., 2006).

Alternatively, a negative nitrogen balance could be an indicator of the stress of confinement and collection procedures, as negative nitrogen balance has been observed in response to emotional anxiety in humans (Scrimsha, et al., 1966). The observed tendency toward decrease in nitrogen intake and absorption on d 10 were possibly due to the acute stress of confinement and collection procedures. However, these fluctuations in intake and absorption did not result in significant differences in any of the nitrogen retention parameters, suggesting either that on d 10 the animals had a slightly, but not significantly, lower urinary nitrogen output, or that the differences in intake and absorption were statistically, but not physiologically significant.

Similar to plasma creatinine concentrations, there were no significant differences in urinary creatinine output between treatments, further supporting the conclusion that there was not a significant difference in muscle mass between treatments after 10 days of supplementation with lysine and threonine or lysine, threonine and methionine. However, there was a significant effect of period on urinary creatinine output, where the first two collection periods for each set of horses had significantly higher creatinine outputs than 
the last period for each set of horses, and there was a significant effect of day of collection, where the last day of collection showed lower urinary creatinine output than the first two days of collection. In essence, it appears that urinary creatinine output decreased consistently both within and between collection periods as time progressed for both groups of horses. The most likely cause of this change is a decrease in stress as animals adapted to stress related to wearing collection harnesses. It has been well documented in humans that feelings of restlessness, apprehension or anger exhibit increased urinary creatinine output (Schottstaedt et al., 1956; Price, 1971). Although horses were exposed to collection harnesses before beginning experimental procedures, changes in daily routine such as restriction to the stall during total urine and feces collection and the collection of urine and feces every $4 \mathrm{~h}$ for $72 \mathrm{~h}$ may have caused emotional distress, and therefore increased urinary creatinine output. Increased urinary creatinine output during stress has been attributed to increased glomerular filtration during times of emotional diuresis in some instances (Miles et al., 1952). However, there was no evidence of emotional diuresis in the present study, as urine output was not significantly different between days of collection $(\mathrm{P}=0.7261)$ or collection period $(\mathrm{P}=0.7307)$.

\section{Phenylalanine Kinetics}

Non-oxidative phenylalanine disposal (use for protein synthesis) was consistently lower than rates of phenylalanine release from protein breakdown, which is in agreement with the consistently negative nitrogen balance data. Together, the data indicate that regardless of supplementation with lysine and threonine or lysine, threonine and 
methionine, the aged horses in the present study were degrading protein at a greater rate than they were accreting it, which suggest a net loss of body protein. Although the horses in the present study were aged, it is important to note that they were not clinically diagnosed with sarcopenia. However, the imbalances in nitrogen retention and phenylalanine kinetics data suggest that there was an imbalance in protein synthesis and degradation similar to that which is observed during sarcopenia. Additionally, if the protein being degraded was primarily skeletal muscle, this imbalance could have been contributing to the loss of muscle mass and function characteristic of sarcopenia. Conversely, the loss of body protein could have been owing to high endogenous losses of protein, or breakdown and loss of protein from tissues other than muscle. Taking together the lack of significant differences in creatinine, phenylalanine kinetics and nitrogen balance, the data suggests that there was no change in whole-body protein synthesis or skeletal muscle accretion with supplementation of lysine and threonine or lysine, threonine and methionine, but that horses had a net loss of body protein regardless of diet.

Phenylalanine flux (approximately $60 \pm 3 \mu \mathrm{mol} / \mathrm{kg} / \mathrm{h}$; Table 5.4) in the present study was similar to values observed in mature horses (approximately $60 \pm 3 \mu \mathrm{mol} / \mathrm{kg} / \mathrm{h}$ ) observed in a previous study (Mok, 2015). However, phenylalanine released from protein breakdown (approximately $35 \mu \mathrm{mol} / \mathrm{kg} / \mathrm{h}$ ) in the previous study (Mok, 2015) was considerably lower that what was observed in the aged horses in the present study (approximately $50 \pm 3 \mu \mathrm{mol} / \mathrm{kg} / \mathrm{h}$; Table 5.4). Furthermore, rates of non-oxidative phenylalanine disposal (approximately $45 \mu \mathrm{mol} / \mathrm{kg} / \mathrm{h}$ ) in the previous study (Mok, 2015) was similar to those observed in the present study (approximately $40 \pm 3 \mu \mathrm{mol} / \mathrm{kg} / \mathrm{h}$; Table 
5.4). Together, these data suggest that the aged horses in the current study were experiencing higher rates of protein degradation and lower rates of protein synthesis than the previously observed mature horses.

In comparing the balance between non-oxidative phenylalanine disposal and phenylalanine released from protein breakdown to previous literature in horses of different ages, there are a number of interesting differences. In the present study, phenylalanine released from protein breakdown was higher than non-oxidative phenylalanine disposal, which suggests that rates of protein breakdown were higher than rates of protein synthesis. These results are in contrast to previous studies, where growing horses (Tanner et al., 2014; Mastellar et al., 2016b) and mature horses (Urschel et al., 2012; Mastellar et al., 2016b) exhibit higher rates of non-oxidative disposal than phenylalanine released from protein breakdown. For the growing horses observed in previous studies (Tanner et al., 2014; Mastellar et al., 2016b), a higher flux coupled with higher non-oxidative phenylalanine disposal compared to the previous data observed in mature and aged horses (Urschel et al., 2012; Wagner et al., 2013; Mastellar et al., 2016b) suggests that there were higher rates of both protein turnover and accretion in growing horses, which is characteristic of muscle deposition. For the mature horses previously studied (Urschel et al., 2012; Wagner et al., 2013; Mastellar et al., 2016b), lower rates of flux and non-oxidative disposal compared to the growing horses (Tanner et al., 2014; Mastellar et al., 2016b) suggests that mature horses were in a steadier protein metabolic state, rather than accreting muscle. Similar to the present study, a previous study in aged horses (Wagner et al., 2013) showed higher rates of phenylalanine released from protein breakdown compared with rates of non-oxidative phenylalanine disposal, 
suggesting that the aged horses in the present study, as well as the previous study, may have been experiencing tissue protein loss.

\section{Muscle Protein Synthesis and Degradation Signaling}

Akt is an upstream effector, and rpS6 is a downstream effector of mTOR, and both are proteins which when activated, stimulate protein synthesis signaling in the mTOR pathway. The significant increase in $\mathrm{rpS} 6$ activation in response to meal feeding suggests that consuming a meal lead to increased protein synthesis as signaled by rpS6, but lack of effect of meal feeding on Akt suggests that the increase in activation was brought about by an upstream effector other than Akt. There are a number of upstream effectors other than Akt that could been responsible, including mitogen activated protein kinase kinase kinase kinase-3 (MAP4K3) or human vacuolar protein sorting 34 (hVps34), two proteins that can be activated by presence of amino acids (Drummond et al., 2009). However, these results are in contrast to a previous study of the effect of meal feeding on mTOR protein signaling in horses, which saw significant increases in rpS6 and Akt activation 90 minutes after consuming a meal compared to a post-absorptive state (Wagner and Urschel, 2012). Lack of feed withholding in this study likely accounts for

the differences in our results. Since there was an approximately 18-hour window between the evening and morning meal, animals often took several hours, or even all night to finish their hay cube ration, therefore it is possible that horses had access to small amounts of food up to 2 hours before the beginning of pre-feeding biopsy procedures. Additionally, in the previous study (Wagner and Urschel, 2012), insulin concentrations from samples taken in a post-absorptive state were between 0 and $5 \mathrm{mIU} / \mathrm{L}$, whereas 
insulin concentrations of samples taken before morning feeding in the present study were approximately $10 \mathrm{mIU} / \mathrm{L}$. Since insulin is an upstream stimulator of Akt activity, we expected that increases in plasma insulin concentrations after feeding would have stimulated increased Akt phosphorylation. However, there was likely not a large difference in activation between pre-feeding samples and post-feeding samples in the present study because pre-feeding insulin concentrations in the present study were not as low as those observed in previous studies.

The lack of significant effect of treatment on rpS6 and Akt activation suggest that stimulatory proteins in the mTOR pathway are not significantly affected by supplementation of lysine and threonine or lysine, threonine and methionine. This is in contrast to studies in other species that have examined the effects of other amino acids on rpS6 activation. Whey protein in humans after resistance exercise (Wang et al., 2015), and leucine and histidine in cell cultures of bovine mammary tissue (Gao et al., 2015) have been shown to increase the activation of rpS6 over the control treatments. Therefore, the current study does not support the idea that supplementation of lysine and threonine or lysine, threonine and methionine increases protein synthesis as signaled through Akt or rpS6.

Atrogin- 1 is a protein associated with muscle protein degradation. There was a significant treatment by time interaction on Atrogin-1, where the post-feeding CON activation tended to be lower than pre-feeding CON activation. However, there was no significant difference in pre- feeding and post-feeding activation for the supplemented treatments. Some previous studies have shown an improvement in Atrogin-1 signaling when amounts of limiting amino acid are increased in the diet (Tesseraud et al., 2009; 
Wen et al., 2014). The decreased activation of Atrogin-1 when animals were in a prefeeding state during amino acid supplementation suggests that supplementation with lysine and threonine, as well as lysine, threonine and methionine may have decreased signaling associated with muscle protein degradation while horses were in a postabsorptive state.

AMPK is a protein associated with the inhibition of protein synthesis signaling, and its activation is related to unfavorable cellular energy status. Lack of significant differences in AMPK activation between treatments suggests that lysine and threonine or lysine, threonine and methionine supplementation did not decrease signals that inhibit protein synthesis through AMPK. This is in contrast to research on the effects of other amino acids, such as leucine, which when supplemented has been shown to decrease the activation of AMPK in rats (Ribeiro et al., 2015). We did see a trend toward a treatment by time interaction for AMPK activation. The CON treatment and LYS/THR/MET treatment had slightly, but not significantly, higher post-feeding values of AMPK activation, but the LYS/THR treatment had a slightly, but not significantly, higher prefeeding value of AMPK activation. The differences in pre- versus post-feeding responses may arise from the fact that differences in AMPK activation typically arise from a negative cellular energy balance, and since horses were likely never in a truly fasted state, differences in AMPK activation likely reflect natural variations between horses, rather than true effects of fasting. Additionally, there was a significant effect of period, where AMPK activation appears to increase, although not significantly, from collection period one to six. Since periods one through three and four through six were different groups of horses, that would also suggest that AMPK activation was slightly, but not significantly 
higher for horses in periods four through six. Since AMPK is activated in response to negative cellular energy balance (Viollet et al., 2009), this would suggest that horses were in an increasingly declining cellular energy status as they progressed through periods of collection. However, it is important to note that while there was a significant main effect of period, separation of means showed no significant differences between periods, and the observed differences may therefore also be due to natural variations in AMPK abundance and activation between horses.

Taking all of the signaling data from the present study together, it appears that for the proteins in the pathways measured there was not an increase in stimulatory signaling of protein synthesis, or a decrease in signaling for proteins that inhibit protein synthesis when lysine and threonine or lysine, threonine and methionine were supplemented. There was an improvement in signaling for a protein that stimulates protein breakdown when amino acids were supplemented. The lack of significant effect of treatment on most measures of skeletal muscle signaling was mirrored by no significant improvements in phenylalanine kinetics or nitrogen balance between treatments.

\section{Comparison of the Present Study to Previous Equine Research}

The levels of lysine and threonine supplementation in the present study were selected based on those used by Graham-Thiers and Kronfeld (Graham-Thiers and Kronfeld, 2005), which resulted in improvement of certain measures of muscle mass in aged horses. In the present study, supplementation with lysine and threonine or lysine, threonine and methionine did not improve the balance between muscle protein accretion 
and degradation in old horses. Comparing the current study to the previous study that showed significant improvements in PUN, 3MH, creatinine and subjective muscle mass scores in aged horses (Graham-Thiers and Kronfeld, 2005) with supplementation of lysine and threonine, there are several factors that could account for the different outcomes.

First, the forage used in the current study had a higher crude protein (11.1\%), lysine $(0.43 \%)$, threonine $(0.38 \%)$ and methionine $(0.22 \%)$ content than the forage used in the previous study $($ crude protein $=9 \%$; lysine $=0.23 \%$; threonine $=0.24 \%$; methionine $=$ $0.09 \%$ ). Because forage formed the majority of the diet used in both studies, it is likely that the horses in the present study were consuming a better quality diet with respect to protein before additional supplementation of amino acids, and crude protein intakes for the control treatment for the horses in the previous study were lower (approximately 2.3 $\mathrm{g} / \mathrm{kg} \mathrm{BW} / \mathrm{d}$ ) than in the present study (approximately $2.6 \mathrm{~g} / \mathrm{kg} \mathrm{BW} / \mathrm{d}$ ). Additionally, lysine intakes were considerably lower for control horses in the previous study (approximately $69 \mathrm{mg} / \mathrm{kg} \mathrm{BW} / \mathrm{d}$ ) than in the present study (approximately $100 \mathrm{mg} / \mathrm{kg}$ $\mathrm{BW} / \mathrm{d})$. However, it is interesting to note that the recommended lysine intake as a percentage of crude protein intake (4.3\% CP as lysine; NRC, 2007) was not met by the control diet in the present study (approximately 3.9\% CP intake as lysine) or by the control diet in the previous study (approximately 3.0\% CP intake as lysine). However, data suggests that lysine and threonine may have been limiting protein synthesis in the study conducted in 2005 (Graham-Thiers and Kronfeld, 2005), but that the requirements 
may have been met by the $\mathrm{CON}$ diet in the present study, resulting in lack of significant differences with additional supplementation.

Second, in the previous study, the treatments were not isonitrogenous (GrahamThiers and Kronfeld, 2005), whereas the diets in the current study were isonitrogenous. Therefore, improvements in the measures of protein metabolism in the previous study may have resulted from increased nitrogen intake, rather than a better balance of amino acids.

Additionally, the horses in the previous study (Graham-Thiers and Kronfeld, 2005) were used in a college riding program throughout the study, whereas the horses in the current study were sedentary. Many studies show improvements in markers of protein metabolism in aged individuals that are both exercising and receiving amino acid supplementation (Graham-Thiers and Kronfeld, 2005; Montoro et al., 2015; Phillips, 2015; Trabal et al., 2015). It is possible that in the previous studies, the combination of protein or amino acid supplementation and anabolic effects of exercise combined could be responsible for the significant improvements observed. Conversely, since exercising increases the estimated protein requirement (NRC, 2007), it is possible that the horses in the previous study simply had higher protein requirements than the sedentary horses in the present study, and the control treatment in the previous study was therefore closer to meeting, rather than exceeding the required amount of protein intake. Therefore, while exercise may have necessitated additional amino acids in previous studies, the sedentary horses in the present study may not have required additional amino acids.

Finally, it horses in the previous study were fed experimental treatments for a total of 14 weeks, whereas horses in the present study were only fed each experimental 
treatment for a total of 15 days. It is possible that the length of time needed to see significant improvements in protein metabolism in response to lysine and threonine, or lysine, threonine and methionine metabolism is longer than 15 days.

\section{Limitations and Avenues of Further Research}

There are a number of aspects of the current experiment that could be improved upon, and there are many avenues of research that could be pursued in light of results of the current study.

In the present study, it was postulated that one of the reasons we measured no significant differences, despite the fact that a similar previous study did (Graham-Thiers and Kronfeld, 2005), was that the hay cubes that we used were of a high enough protein quality to exceed horses' protein and amino acid requirements when fed in combination with the CON concentrate. The hay cubes used in the current study were $11.1 \%$ crude protein, which is similar to the average estimate for mature cool-season grass hay provided by the NRC $(10.8 \%)$ and, the lysine concentration of our hay cubes was $0.43 \%$, which is also similar to the estimate for mature cool -season grass $(0.38 \%)$ published in the NRC (NRC, 2007). However, the hay cubes were fed at a rate of $1.8 \%$ of body weight per day, and the concentrates were fed at a rate of $0.5 \%$ of body weight per day, summing to a total daily intake of $2.3 \%$ of body weight per day. It may have been prudent to feed hay at a rate of $1.5 \%$ of body weight per day instead of $1.8 \%$ of body weight per day, because feeding at a lower percentage of body weight would decrease crude protein and lysine intakes, and thus supplementation of individual limiting amino 
acids may improve markers of whole body and muscle protein metabolism. If that is the case, rations could be formulated with hay fed at a slightly lower percentage of body weight, which could be more cost effective, and may also be helpful for horses that do not readily consume feed at higher percentages of body weight.

With respect to nitrogen balance and urinary creatinine output data, there is some evidence to support the idea that there were acute effects of stress on the animals studied as a result of confinement and/or collection procedures. Indicators of acute stress included consistently negative nitrogen balance data, significantly lower nitrogen intake on the first day of collection, and decreasing urinary creatinine output throughout the three-day collection period. In light of these changes, a longer urine and feces collection procedure may have offered the animals a chance to better adapt to collection procedures, and also may have allowed for more accurate measurement of normal fluctuations in nitrogen and creatinine output.

With respect to improvements in the design of this experiment, inclusion of exercise as a factor in the experiment may have shown more significant differences in nitrogen balance and phenylalanine kinetics, as exercise has been shown to improve nitrogen retention (Campbell et al., 1995) and whole body protein metabolism (SheffieldMoore et al., 2004; Short et al., 2004) in humans. Additionally, exercise may cause additional nitrogen losses from sweating, increased muscle turnover, and other factors, resulting in a higher demand for essential amino acids. Furthermore, there is an abundance of data in humans that suggests that leucine supplementation and exercise ameliorate sarcopenia (Bukhari et al., 2015; Trabal et al., 2015; Ispoglou et al., 2016). Therefore, inclusion of a leucine-supplemented diet in addition to including an exercise 
program may show more significant improvements in measures of whole body and muscle protein metabolism in aged horses.

\section{Conclusion}

Despite the fact that horses in the present study were in a negative nitrogen balance and had higher rates of phenylalanine oxidation than non-oxidative phenylalanine disposal, the data from the present study indicated no improvements in nitrogen balance, phenylalanine kinetics, or muscle mass as indicated by circulating creatinine or creatinine output with supplementation of lysine and threonine or lysine, threonine and methionine. Furthermore, it suggests that muscle protein synthesis signaling in the aged horses in the present study was not improved by supplementation of lysine and threonine or lysine, threonine and methionine. This suggests that the net loss of nitrogen as evidenced by negative nitrogen balance and higher rates of phenylalanine oxidation than non-oxidative phenylalanine disposal in the sedentary horses studied was not owing to limitations in lysine and threonine or lysine, threonine and methionine. 


\section{Literature Cited}

Antilley, T. J., G. D. Potter, P. G. Gibbs, B. D. Scott, and L. D. Claborn. 2007.

Evaluating the technique of using nitrogen retention as a response criterion for amino acid studies in the horse. Journal of Equine Veterinary Science 27: 525530.

AOAC International. 2005. AOAC Official Method 994.12 Amino Acids in Feeds AOAC.

APHIS. 2005. 1: Baseline Reference of Equine Health and Management, 2005. National Animal Health Monitoring System, Fort Collins: 1-60.

Ball, R. O., K. L. Urschel, and P. B. Pencharz. 2007. Nutritional consequences of interspecies differences in arginine and lysine metabolism. Journal of Nutrition 137: 1626S-1641S.

Bergen, W. G. 2015. Small-intestinal or colonic microbiota as a potential amino acid source in animals. Amino Acids 47: 251-258.

Boisen, S., T. Hvelplund, and M. R. Weisbjerg. 2000. Ideal amino acid profiles as a basis for feed protein evaluation. Livestock Production Science 64: 239-251.

Bochroder, B., R. Schubert, and D. Bodeker. 1994. Studies on the transport in-vitro of lysine, histidine, arginine and ammonia across the mucosa of the equine colon. Equine Veterinary Journal 26: 131-133.

Breuer, L., L. Kasten, and J. Word. 1970. Protein and amino acid utilization in the young horse. In: Proc. 2nd Equine Nutr. Res. Symp., Ithaca, NY. p 16.

Bukhari, S. S. I, Phillips, B. E., Wilkinson, D. J., Limb, M. C., Rankin, D., Mitchell, W. K., Kobayashi, H., Greenhaff, P. L., Smith, K., and P. J. Atherton. 2015. Intake of low-dose leucine-rich essential amino acids stimulates muscle anabolism equivalently to bolus whey protein in older women at rest and after exercise. American Journal of Physiology-Endocrinology and Metabolism 308: E1056E1065.

Campbell, W. W., M. C. Grim, V. R. Young, L. J. Joseph, and W. J. Evans. 1995. Effects of resistance training and dietary protein-intake on protein-metabolism in older adults. American Journal of Physiology-Endocrinology and Metabolism 268: E1143-E1153.

Campbell, W. W., C. A. Johnson, G. P. McCabe, and N. S. Carnell. 2008. Dietary protein requirements of younger and older adults. American Journal of Clinical Nutrition 88: 1322-1329.

Christensen, R. A., S. V. Radecki, K. Malinowski, C. G. Scanes, and H. D. Hafs. 1996. Chronic effects of equine growth hormone (eGH) on insulin-like growth factor (IGF)-I and IGF binding proteins (IGFBP) in mares. Faseb Journal 10: 44424442.

Coma, J., D. Carrion, and D. R. Zimmerman. 1995. Use of plasma urea nitrogen as a rapid response criterion to determine the lysine requirement of pigs. Journal of Animal Science 73: 472-481.

Combaret, L., D. Dardevet, D. Bechet, D. Taillandier, L. Mosoni, and D. Attaix. 2009. Skeletal muscle proteolysis in aging. Current Opinion in Clinical Nutrition and Metabolic Care 12: 37-41. 
Manso, H.E, C.J. da Silva, B. d. Barbosa, J. L. Vasconcelos, and H. C. Filho. 2015. Effects of Supplementation with Glutamine and Glutamate on the Blood Hematimetric Indices and Biomarkers of Equines. Acta Scientiae Veterinariae 43.

Dale, R. A. 1978. Catabolism of threonine in mammals by coupling of L-threonine 3dehydrogenase with 2-amino-3-oxybutyrate-CoA ligase. Biochimica Et Biophysica Acta 544: 496-503.

Drenan, R. M., X. Liu, P. G. Bertram, and X. S. Zheng. 2004. FKBP12-rapamycinassociated protein or mammalian target of rapamycin (FRAP/mTOR) localization in the endoplasmic reticulum and the Golgi apparatus. Journal of Biological Chemistry 279: 772-778.

Drummond, M. J., H. C. Dreyer, B. Pennings, C. S. Fry, S. Dhanani, E. L. Dillon, M. Sheffield-Moore, E. Volpi, and B. B Rasmussen. 2008. Skeletal muscle protein anabolic response to resistance exercise and essential amino acids is delayed with aging. Journal of Applied Physiology 104: 1452-1461.

Drummond, M. J., H. C. Dreyer, C. S. Fry, E. L. Glynn, and B. B. Rasmussen. 2009. Nutritional and contractile regulation of human skeletal muscle protein synthesis and mTORC1 signaling. Journal of Applied Physiology 106: 1374-1384.

Edmonds, M. S., and D. H. Baker. 1987. Amino-acid excess for young-pigs - effects of excess methionine, tryptophan, threonine or leucine. Journal of Animal Science 64: 1664-1671.

Elango, R., R. O. Ball, and P. B. Pencharz. 2008. Indicator amino acid oxidation: concept and application. The Journal of Nutrition 138: 243-246.

Ellis, A. C., M. Patterson, T. Dudenbostel, D. Calhoun, and B. Gower. 2016. Effects of 6month supplementation with beta-hydroxy-beta-methylbutyrate, glutamine and arginine on vascular endothelial function of older adults. European Journal of Clinical Nutrition 70: 269-273.

Farley, E. B., G. D. Potter, P. G. Gibbs, J. Schumacher, and M. MurrayGerzik. 1995. Digestion of soybean meal protein in the equine small and large intestine at various levels of intake. Journal of Equine Veterinary Science 15: 391-397.

Finkelstein, J. D. 1990. Methionine metabolism in mammals. Journal of Nutritional Biochemistry 1: 228-237.

Freeman, D., G. Potter, G. Schelling, and J. Kreider. 1986. Nitrogen metabolism in the mature physically conditioned horse. 1. Response to conditioning. Equine Practice 8: 6-10.

Freeman, D. W., G. D. Potter, G. T. Schelling, and J. L. Kreider. 1988. Nitrogenmetabolism in mature horses at varying levels of work. Journal of Animal Science 66: 407-412.

Gallagher, D., S. B. Heymsfield, and Z. M. Wang. 1999. The role of protein and amino acids in sustaining and enhancing performance. Skeletal muscle markers 255-277.

Gao, H. N., H. Hu, N. Zheng, and J. Q. Wang. 2015. Leucine and histidine independently regulate milk protein synthesis in bovine mammary epithelial cells via mTOR signaling pathway. Journal of Zhejiang University-Science B 16: 560-572.

Gibbs, P. G., G. D. Potter, G. T. Schelling, J. L. Kreider, and C. L. Boyd. 1988. Digestion of hay protein in different segments of the equine digestive-tract. Journal of Animal Science 66: 400-406. 
Glade, M., and N. Luba. 1990. Benefits to foals of feeding soybean meal to lactating broodmares. Journal of Equine Veterinary Science 10: 422-428.

Graham-Thiers, P. M., and L. K. Bowen. 2011. Effect of protein source on nitrogen balance and plasma amino acids in exercising horses. Journal of Animal Science 89: 729-735.

Graham-Thiers, P. M., and D. S. Kronfeld. 2005. Amino acid supplementation improves muscle mass in aged and young horses. Journal of Animal Science 83: 2783-2788.

Graham, P. M., E. Ott, J. Brendemuhl, and S. TenBroeck. 1994. The effect of supplemental lysine and threonine on growth and development of yearling horses. Journal of Animal Science 72: 380-386.

Hall, M. N. 2008. mTOR - What Does It Do? Transplantation Proceedings 40: S5-S8.

Harper, O. F., and Vanderno.Gw. 1974. Protein requirements of mature maintenance horses. Journal of Animal Science 39: 183-183.

Hay, N., and N. Sonenberg. 2004. Upstream and downstream of mTOR. Genes \& Development. 18: 1926-1945.

Heymsfield, S. B., C. Arteaga, C. McManus, J. Smith, and S. Moffitt. 1983a. Measurment of muscle mass in humans - validity of the 24-hour urinary creatinine method. American Journal of Clinical Nutrition 37: 478-494.

Heymsfield, S. B., C. Arteaga, C. McManus, J. Smith, and S. Moffitt. 1983b. Measurement of muscle mass in humans: validity of the 24-hour urinary creatinine method. The American Journal of Clinical Nutrition 37: 478-494.

Hintz, H., H. Schryver, and J. Lowe. 1971. Comparison of a blend of milk products and linseed meal as protein supplements for young growing horses. Journal of Animal Science 33: 1274-1277.

Hintz, H. F., and H. F. Schryver. 1972. Nitrogen utilization in ponies. Journal of Animal Science 34: 592-\&.

Hsu, J. W. C., L. A. Goonewardene, M. Rafii, R. O. Ball, and P. B. Pencharz. 2006. Aromatic amino acid requirements in healthy men measured by indicator amino acid oxidation. American Journal of Clinical Nutrition 83: 82-88.

Ishibashi, T. 1985. Lysine requirement of laying hens. Japanese Journal of Zootechnical Science 56: 827-834.

Ispoglou, T., H. White, T. Preston, S. McElhone, J. McKenna, and K. Hind. 2016. Double-blind, placebo-controlled pilot trial of L-Leucine-enriched amino-acid mixtures on body composition and physical performance in men and women aged 65-75 years. European Journal of Clinical Nutrition 70: 182-188.

Johnson, P., C. Harris, and S. Perry. 1967. 3-Methylhistidine in actin and other muscle proteins. Biochemical Journal 105: 361-370.

Kalhan, S. C., L. Gruca, S. Marczewski, C. Bennett, and C. Kummitha. 2016. Whole body creatine and protein kinetics in healthy men and women: effects of creatine and amino acid supplementation. Amino Acids 48: 677-687.

Kim, Y., R. H. Williams, S. E. Schutzler, C. J. Lasley, D. L. Bodenner, R. R. Wolfe, and R. H. Coker. 2014. Acute lysine supplementation does not improve hepatic or peripheral insulin sensitivity in older, overweight individuals. Nutrition \& Metabolism 11. 
Klindt, J., R. Thallman, and T. Wise. 2006. Effects of sire line, sire, and sex on plasma urea nitrogen, body weight, and backfat thickness in offspring of Duroc and Landrace boars. Journal of Animal Science 84: 1323-1330.

Koopman, R., and L. J. C. van Loon. 2009. Aging, exercise, and muscle protein metabolism. Journal of Applied Physiology 106: 2040-2048.

Laplante, M., and D. M. Sabatini. 2009. mTOR signaling at a glance. Journal of Cell Science 122: 3589-3594.

Luiking, Y. C., N. E. P. Deutz, R. G. Memelink, S. Verlaan, and R. R. Wolfe. 2014. Postprandial muscle protein synthesis is higher after a high whey protein, leucineenriched supplement than after a dairy-like product in healthy older people: a randomized controlled trial. Nutrition Journal 13.

Malesky, S., J. Turner, C. Loest, L. Chen, and J. Browne-Silva. 2013. Nitrogen Retention and Plasma Amino Acid Responses in Mature Geldings Fed Three Dietary Concentrations of Lysine. Journal of Equine Veterinary Science 33: 733-738.

Marcell, T. J. 2003. Review article: sarcopenia: causes, consequences, and preventions. The Journals of Gerontology Series A: Biological Sciences and Medical Sciences 58: M911-M916.

Martin, R. G., N. P. McMeniman, B. W. Norton, and K. F. Dowsett. 1996. Utilization of endogenous and dietary urea in the large intestine of the mature horse. British Journal of Nutrition 76: 373-386.

Mastellar, S., T. Barnes, K. Cybulak, and K. Urschel. 2016a. Splanchnic extraction of phenylalanine in mature mares was not affected by threonine supplementation. The Veterinary Journal 207: 190-192.

Mastellar, S., A. Moffet, P. Harris, and K. Urschel. 2016b. Effects of threonine supplementation on whole-body protein synthesis and plasma metabolites in growing and mature horses. The Veterinary Journal 207: 147-153.

Mastro, L. M., A. A. Adams, and K. L. Urschel. 2014. Whole-body phenylalanine kinetics and skeletal muscle protein signaling in horses with pituitary pars intermedia dysfunction. American Journal of Veterinary Research 75: 658-667.

Matthews, D. 1975. Intestinal absorption of peptides. Physiological Reviews 55: 537608.

McGivney, B. A., S. S. Eivers, D. E. MacHugh, J. N. MacLeod, G. M. O'Gorman, S. De Park, L. M. Katz, and E. W. Hill. 2009. Transcriptional adaptations following exercise in Thoroughbred horse skeletal muscle highlights molecular mechanisms that lead to muscle hypertrophy. BMC Genomics 10: 18.

McMeniman, N. P., R. Elliott, S. Groenendyk, and K. F. Dowsett. 1987. Synthesis and absorption of cysteine form the hindgut of the horse. Equine Veterinary Journal 19: 192-194.

Meyer, H. 1983. Protein metabolism and protein requirement in horses. Colloques de l'INRA (France).

Meyer, H., S. Von Stein, and M. Schmidt. 1985. Investigations to determine endogenous faecal and renal N losses in horses. Proceedings 9th ENSP, USA: 68-72.

Miles, B. E., H. E. Dewardener, and R. R. McSwiney. 1952. Renal function during emotional diuresis. American Journal of Medicine 12: 659-666. 
Mitchell, J. R., Jr., D. E. Becker, A. H. Jensen, B. G. Harmon, and H. W. Norton. 1968. Determination of amino acid needs of the young pig by nitrogen balance and plasma-free amino acids. Journal of Animal Science 27: 1327-1331.

Moehn, S., R. F. Bertolo, P. B. Pencharz, and R. O. Ball. 2005. Development of the indicator amino acid oxidation technique to determine the availability of amino acids from dietary protein in pigs. The Journal of Nutrition 135: 2866-2870.

Mok, C. 2015. Using the Indicator Amino Acid Oxidation Technique to Study Threonine Requirements in Horses Fed Different Feed Compositions. University of Kentucky Theses and Dissertations-Animal and Food Sciences. Paper 53.

Montoro, M. V. P., J. A. P. Montilla, E. L. Aguilera, and M. A. Checa. 2015. Sarcopenia intervention, with progressive resistance training and protein nutritional supplements. Nutricion Hospitalaria 31: 1481-1490.

Morais, J. A., S. Chevalier, and R. Gougeon. 2006. Protein turnover and requirements in the healthy and frail elderly. Journal of Nutrition Health \& Aging 10: 272-283.

Mourtzakis, M., and T. E. Graham. 2002. Glutamate ingestion and its effects at rest and during exercise in humans. Journal of Applied Physiology 93: 1251-1259.

NRC. 2007. Nutrient requirements of horses. 6th rev. ed. Washington, D.C. : National Academies Press, Washington, D.C.

NRC. 2012. Nutrient requirements of swine. 11th rev. ed. Washington, D.C. : National Academies Press, Washington, D.C.

Ohta, Y., T. Yoshida, and T. Ishibashi. 2007. Estimation of dietary lysine requirement using plasma amino acid concentrations in mature thoroughbreds. Animal Science Journal 78: 41-46.

Olsman, A. F. S., W. L. Jansen, M. M. S. van Oldruitenborgh-Oosterbaan, and A. C. Beynen. 2003. Assessment of the minimum protein requirement of adult ponies. Journal of Animal Physiology and Animal Nutrition 87: 205-212.

World Health Organization, and Joint FAO. 2007. Protein and amino acid requirements in human nutrition: Report of a joint FA.

Pham, P. T. T., S. J. Heydrick, H. L. Fox, S. R. Kimball, L. S. Jefferson, and C. J. Lynch. 2000. Assessment of cell-signaling pathways in the regulation of mammalian target of rapamycin (mTOR) by amino acids in rat adipocytes. Journal of Cellular Biochemistry 79: 427-441.

Phillips, S. M. 2015. Nutritional Supplements in Support of Resistance Exercise to Counter Age-Related Sarcopenia. Advances in Nutrition 6: 452-460.

Potter, G., and J. Huchton. 1975. Growth of yearling horses fed different sources of protein with supplemental lysine. In: Proc. 4th Eq. Nutr. Physiol. Symp. p 19.

Price, J. 1971. Method of assessing short term creatinine excretion in acute schizophrenics. Journal of Nervous and Mental Disease 153: 280-\&.

Rafii, M., K. Chapman, J. Owens, R. Elango, W. W. Campbell, R. O. Ball, P. B. Pencharz, and G. Courtney-Martin. 2015. Dietary Protein Requirement of Female Adults > 65 Years Determined by the Indicator Amino Acid Oxidation Technique Is Higher Than Current Recommendations. Journal of Nutrition 145: 18-24.

Ralston, S. L., K. Malinowski, R. Christensen, and L. Breuer. 2001. Digestion in aged horses - Revisited. Journal of Equine Veterinary Science 21: 310-311. 
Ralston, S. L., E. L. Squires, and C. F. Nockels. 1988. Differences in diagnostic test results and hematologic data between aged and young horses. American Journal of Veterinary Research 49: 1387-1392.

Ralston, S. L., E. L. Squires, and C. F. Nockels. 1989. Digestion in the aged horse. Journal of Equine Veterinary Science 9: 203-205.

Reitnour, C. M., and R. L. Salsbury. 1972. Digestion and utilization of cecally infused protein by equine. Journal of Animal Science 35: 1190-1193.

Reitnour, C. M., and R. L. Salsbury. 1976. Utilization of proein by equine species. American Journal of Veterinary Research 37: 1065-1067.

Ribeiro, C. B., Christofoletti, D. C., Pezolato, V. A., Durigan, R. D. M., Prestes, J., Tibana, R. A., Pereira, E. C. L., Neto, I. V. D., Durigan, J. L. Q. and C. A. da Silva. 2015. Leucine minimizes denervation-induced skeletal muscle atrophy of rats through akt/mtor signaling pathways. Frontiers in Physiology 6.

Richardson, C. R., and E. E. Hatfield. 1978. Limiting amino-acids in growing cattle. Journal of Animal Science 46: 740-745.

Russell, J. B. 2002. Rumen microbiology and its role in ruminant nutrition. Cornell University.

Santilli, V., A. Bernetti, M. Mangone, and M. Paoloni. 2014. Clinical definition of sarcopenia. Clinical cases in mineral and bone metabolism : The official journal of the Italian Society of Osteoporosis, Mineral Metabolism, and Skeletal Diseases 11: 177-180.

Schottstaedt, W. W., W. J. Grace, and H. G. Wolff. 1956. Life situations, behavior, attitudes, emotions, and renal excretion of fluid and electrolytes.5. Variations in excretion of endogenous creatinine. Journal of Psychosomatic Research 1: 292298.

Scrimsha, N.S, Habicht, J. P., Piche, M. L., Cholakos, B., and Arroyave, G.. 1966. Protein metabolism of young men during university examinations. American Journal of Clinical Nutrition 18: 321-\&.

Shavlakadze, T., Z. Soffe, T. Anwari, G. Cozens, and M. D. Grounds. 2013. Short-Term Feed Deprivation Rapidly Induces the Protein Degradation Pathway in Skeletal Muscles of Young Mice. Journal of Nutrition 143: 403-409.

Sheffield-Moore, M., C.W. Yeckel, E. Volpi, S.E. Wolf, B. Morio, D.L. Chinkes, D. Paddon-Jones and R.R. Wolfe. 2004. Postexercise protein metabolism in older and younger men following moderate-intensity aerobic exercise. American Journal of Physiology-Endocrinology and Metabolism 287: E513-E522.

Short, K. R., J. L. Vittone, M. L. Bigelow, D. N. Proctor, and K. S. Nair. 2004. Age and aerobic exercise training effects on whole body and muscle protein metabolism. American Journal of Physiology-Endocrinology and Metabolism 286: E92-E101.

Slade, L. M., D. W. Robinson, and K. E. Casey. 1970. Nitrogen metabolism in nonruminant herbivores .1. Influence of nonprotein nitrogen and protein quality on nitrogen retention of adult mares. Journal of Animal Science 30: 753-\&.

Staniar, W. D. S. Kronfeld, J. A. Wilson, L. A. Lawrence, W. L. Cooper, and P. A. Harris. 2001. Growth of thoroughbreds fed a low-protein supplement fortified with lysine and threonine. Journal of Animal Science 79: 2143-2151.

Stull, C. L., and A. V. Rodiek. 1988. Responses of blood-glucose, insulin and cortisol concentrations to common equine diets. Journal of Nutrition 118: 206-213. 
Suryawan, A., and T. A. Davis. 2014. Regulation of protein degradation pathways by amino acids and insulin in skeletal muscle of neonatal pigs. Journal of Animal Science and Biotechnology 5.

Tanner, S. L. 2014. Evaluating dietary amino acid adequacy in horses using isotopic techniques. University of Kentucky Theses and Dissertations-Animal and Food Sciences. Paper 38.

Tanner, S. L., A. L. Wagner, R. N. Digianantonio, P. A. Harris, J. T. Sylvester, and K. L. Urschel. 2014. Dietary crude protein intake influences rates of whole-body protein synthesis in weanling horses. Veterinary Journal 202: 236-243.

Tesseraud, S., I. Bouvarel, A. Collin, E. Audouin, S. Crochet, I. Seiliez, and C. Leterrier. 2009. Daily Variations in Dietary Lysine Content Alter the Expression of Genes Related to Proteolysis in Chicken Pectoralis major Muscle. Journal of Nutrition 139: 38-43.

Tiley, H. A., R. J. Geor, and L. J. McCutcheon. 2008. Effects of dexamethasone administration on insulin resistance and components of insulin signaling and glucose metabolism in equine skeletal muscle. American Journal of Veterinary Research 69: 51-58.

Tinworth, K. D., P.C. Wynn, R. C. Boston, P. A. Harris, M. N. Sillence, M. Thevis, A. Thomas, and G. K. Noble. 2011. Evaluation of commercially available assays for the measurement of equine insulin. Domest. Anim. Endocrinol. 41: 81-90.

Trabal, J., M. Forga, P. Leyes, F. Torres, J. Rubio, E. Prieto, and A. Farran-Codina. 2015. Effects of free leucine supplementation and resistance training on muscle strength and functional status in older adults: a randomized controlled trial. Clinical Interventions in Aging 10: 713-723.

Urschel, K., T. Smith, R. Drake, P. Harris, and R. Geor. 2009. Using [13 C] Sodium bicarbonate to measure carbon dioxide production in horses at rest. Journal of Equine Veterinary Science 29: 375-376.

Urschel, K. L., J. Escobar, L. J. McCutcheon, and R. J. Geor. 2011. Effect of feeding a high-protein diet following an 18-hour period of feed withholding on mammalian target of rapamycin-dependent signaling in skeletal muscle of mature horses. American Journal of Veterinary Research 72: 248-255.

Urschel, K. L., J. Escobar, L. J. McCutcheon, and R. J. Geor. 2014. Insulin infusion stimulates whole-body protein synthesis and activates the upstream and downstream effectors of mechanistic target of rapamycin signaling in the gluteus medius muscle of mature horses. Domest. Anim. Endocrinol. 47: 92-100.

Urschel, K. L., R. J. Geor, M. D. Hanigan, and P. A. Harris. 2012. Amino Acid Supplementation Does Not Alter Whole-Body Phenylalanine Kinetics in Arabian Geldings. Journal of Nutrition 142: 461-469.

Urschel, K. L., and L. M. Lawrence. 2013. 6 - Amino acids and protein. In: R. J. G. A. H. Coenen (ed.) Equine Applied and Clinical Nutrition. p 113-135. W.B. Saunders.

Urschel, K. L., M. Rafii, P. B. Pencharz, and R. O. Ball. 2007. A multitracer stable isotope quantification of the effects of arginine intake on whole body arginine metabolism in neonatal piglets. American Journal of Physiology-Endocrinology and Metabolism 293: E811-E818.

Viollet, B., Y. Athea, R. Mounier, B. Guigas, E. Zarrinpashneh, S. Horman, L. Lantier, S. Hebrard, J. Devin-Leclerc, and C. Beauloye. 2009. AMPK: Lessons from 
transgenic and knockout animals. Frontiers in Bioscience (Landmark edition) 14: 19.

Wagner, A. L., and K. L. Urschel. 2012. Developmental regulation of the activation of translation initiation factors of skeletal muscle in response to feeding in horses. American Journal of Veterinary Research 73: 1241-1251.

Wagner, A. L., K. L. Urschel, A. Betancourt, A. A. Adams, and D. W. Horohov. 2013. Effects of advanced age on whole-body protein synthesis and skeletal muscle mechanistic target of rapamycin signaling in horses. American Journal of Veterinary Research 74: 1433-1442.

Wang, W. Y., R. H. Choi, G. J. Solares, H. M. Tseng, Z. P. Ding, K. Kim, and J. L. Ivy. 2015. L-Alanylglutamine inhibits signaling proteins that activate protein degradation, but does not affect proteins that activate protein synthesis after an acute resistance exercise. Amino Acids 47: 1389-1398.

Wen, C., P. Wu, Y. P. Chen, T. Wang, and Y. M. Zhou. 2014. Methionine improves the performance and breast muscle growth of broilers with lower hatching weight by altering the expression of genes associated with the insulin-like growth factor-I signalling pathway. British Journal of Nutrition 111: 201-206.

Wilson, D. C., M. Rafii, R. O. Ball, and P. B. Pencharz. 2000. Threonine requirement of young men determined by indicator amino acid oxidation with use of L- 1-C-13 phenylalanine. American Journal of Clinical Nutrition 71: 757-764.

Wineland, N. 1998. Part 1: baseline reference of 1998 equine health and management. National Animal Health Monitoring System: 42-46.

Winsco, K. N., J. A. Coverdale, T. A. Wickersham, and J. L. Shelton. 2011. Influence of dietary methionine concentration on growth and nitrogen balance in weanling Quarter Horses. Journal of Animal Science 89: 2132-2138.

Woodward, A., S. J. Holcombe, J. P. Steibel, W. B. Staniar, C. Colvin, and N. L. Trottier. 2010. Cationic and neutral amino acid transporter transcript abundances are differentially expressed in the equine intestinal tract. Journal of Animal Science 88: 1028-1033.

Yamamoto, J., S. Kamata, A. Miura, T. Nagata, R. Kainuma, and I. Ishii. 2015. Differential adaptive responses to 1-or 2-day fasting in various mouse tissues revealed by quantitative PCR analysis. Febs Open Bio 5: 357-368.

Young, V., and H. Munro. 1978. Ntau-methylhistidine (3-methylhistidine) and muscle protein turnover: an overview. In: Federation proceedings. p 2291-2300.

Zacharewicz, E., P. Della Gatta, J. Reynolds, A. Garnham, T. Crowley, A. P. Russell, and S. Lamon. 2014. Identification of MicroRNAs Linked to Regulators of Muscle Protein Synthesis and Regeneration in Young and Old Skeletal Muscle. Plos One 9. 


\section{Curriculum Vitae}

\section{Christine Latham}

\section{Education}

University of Kentucky-Animal and Food Science Department - Lexington, KY

M.S. in Animal and Food Science

Projected Graduation Date: May 2016

GPA: 3.895

Thesis: Effects of dietary amino acid supplementation on measures of whole-body and muscle protein metabolism in aged horses

Graduate Advisor: Dr. Kristine Urschel

University of Florida-Animal Science Department- Gainesville, Florida

B.S. in Animal Science, Cum Laude

Major: Animal Science (Specialization in the Equine Industry)

Minor: Management and Sales in Agribusiness

Graduation Date: May 2014

GPA in Major: 3.81

Overall GPA: 3.26

GRE: 160 Quantitative, 163 Verbal, 4.5 Writing

\section{Professional Competencies}

Total Urine and Feces Collection using the Equisan "Nappy."

Muscle Biopsy Procedures using the Bergstrom muscle biopsy technique.

Indicator Amino Acid Oxidation Method involving skills such as catheterization, constant IV infusion of isotopic sodium bicarbonate, sampling of blood from the jugular vein, and sampling breath using a modified breath mask.

HPLC Analysis of amino acids and various other metabolites.

Western Blotting Techniques to determine relative abundances of various proteins in protein synthesis and degradation pathways.

Various Other Analytical Lab Procedures such as enzymatic colorimetric measurement of plasma urea nitrogen and creatinine, measurement of glucose using a YSI glucose analyzer, measurement of insulin using radioimmunoassay kits, and measurement of total nitrogen of urine and feces using the Elementar nitrogen analyzer. 
Abstracts

Latham, C. M., T. Brewster-Barnes, K. L. Urschel, and A. L. Wagner. 46 Postprandial changes in plasma urea nitrogen concentrations in response to amino acid supplementation in horses. Journal of Equine Veterinary Science 35: 403-404.

Skurupey, L. A., C. M. Latham, P. A. Harris, and L. K. Warren. 96 Effects of dietary calcium level and source on environmentally relevant phosphorus excretion in horses. Journal of Equine Veterinary Science 35: 424-425.

\section{Conference Presentations}

Equine Science Society Meeting 2015

Graduate Student Competition (Nutrition): Postprandial changes in plasma urea nitrogen concentrations in response to amino acid supplementation in horses

\section{Professional Experience}

University of Kentucky- Dr. Kristine Urschel- Employer

Position: Graduate Research Assistant: 5/2014- Present

University of Florida- Dr. Lori Warren- Employer/ Leigh Ann Skurupey- Supervisor

Position:_Undergraduate Research Assistant: 11/2013-2/2014

\section{Awards}

University of Kentucky Animal and Food Science Graduate Association Poster Symposium

First place Master's Degree Student Poster, Fall 2014

University of Florida Dean's List (Full time semester GPA of 3.7 or higher)

Fall 2012, Spring 2013, and Fall 2013

\section{Professional Activities}

Teaching Assistant

Animal Nutrition and Feeding: August 2015-Present

Primary Instructors: Dr. Tayo Adedokun and Dr. Eric Vanzant)

Animal Physiology: August 2015-Present

Primary Instructor: Dr. Kristine Urschel

University of Kentucky Animal and Food Science Graduate Association

Member: August 2014- Present

Social Chair: November 2014- November 2015 